SUPPORTING INFORMATION

\title{
Design, Synthesis and Evaluation of Irciniastatin Analogues: Simplification of the Tetrahydropyran Core and the C(11) Substituents
}

Qi Liu, Chihui An, Karen TenDyke, Hongsheng Cheng, Young Yongchun Shen, Adam T. Hoye, Amos B. Smith III*

Department of Chemistry, Laboratory for Research on the Structure of Matter, and Monell Chemical Senses Center, University of Pennsylvania

Philadelphia, Pennsylvania 19104

smithab@sas.upenn.edu

CD spectrum of intermediates.

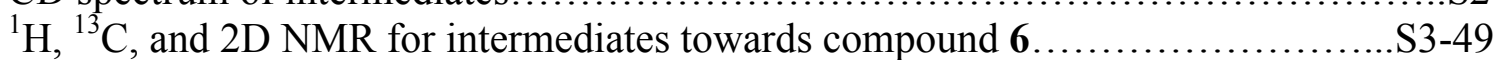

${ }^{1} \mathrm{H}$ and ${ }^{13} \mathrm{C}$ NMR for intermediates towards compound 8-11 .................... $550-65$ 

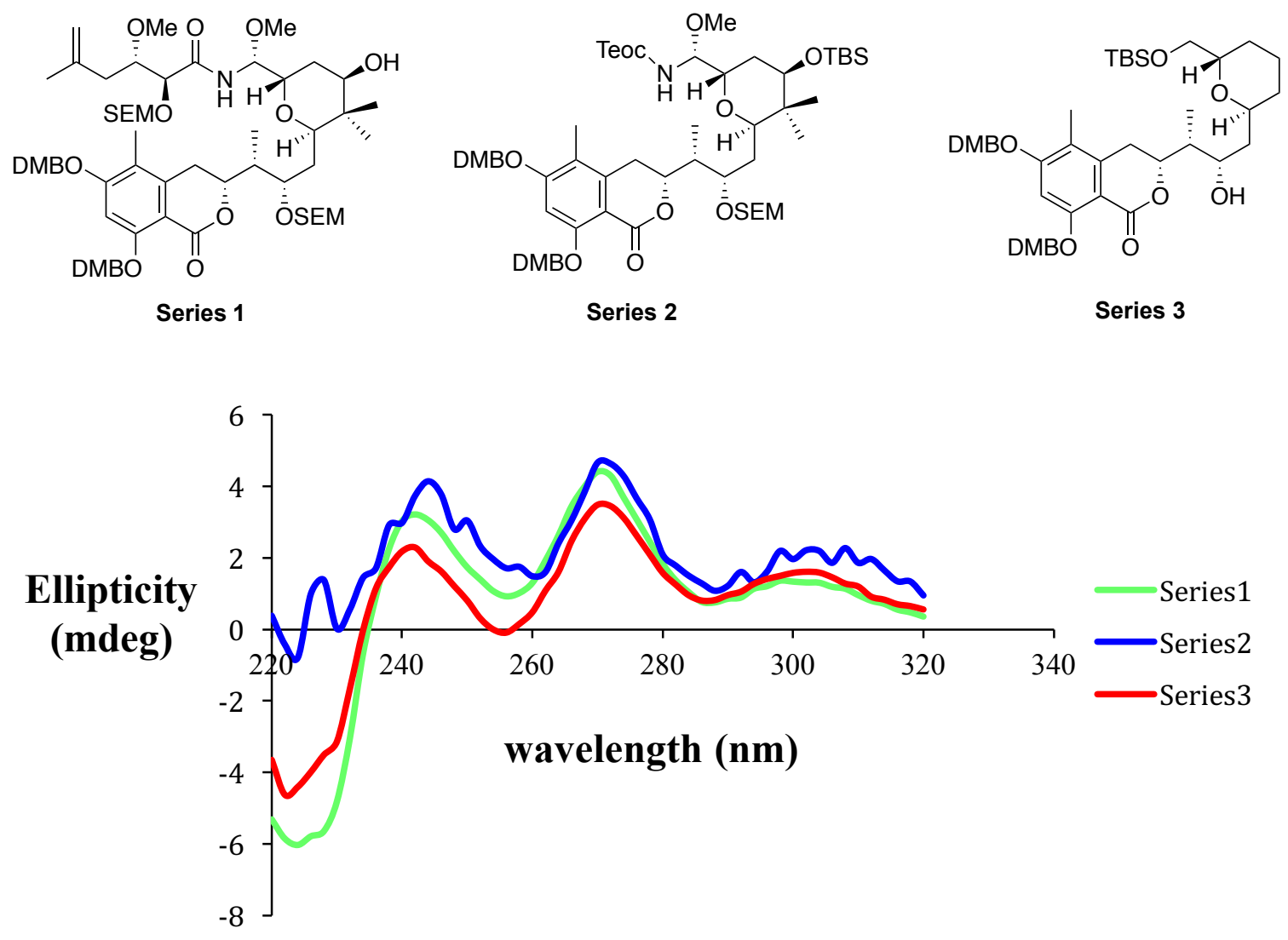

Figure 1 CD Spectrum of Intermediates en Route to (+)-C(8)-desmethoxy-C(11)-deoxyC(12)-di-desmethyl-irciniastatin A (6) and Irciniastatin A (1) (in ethanol) 


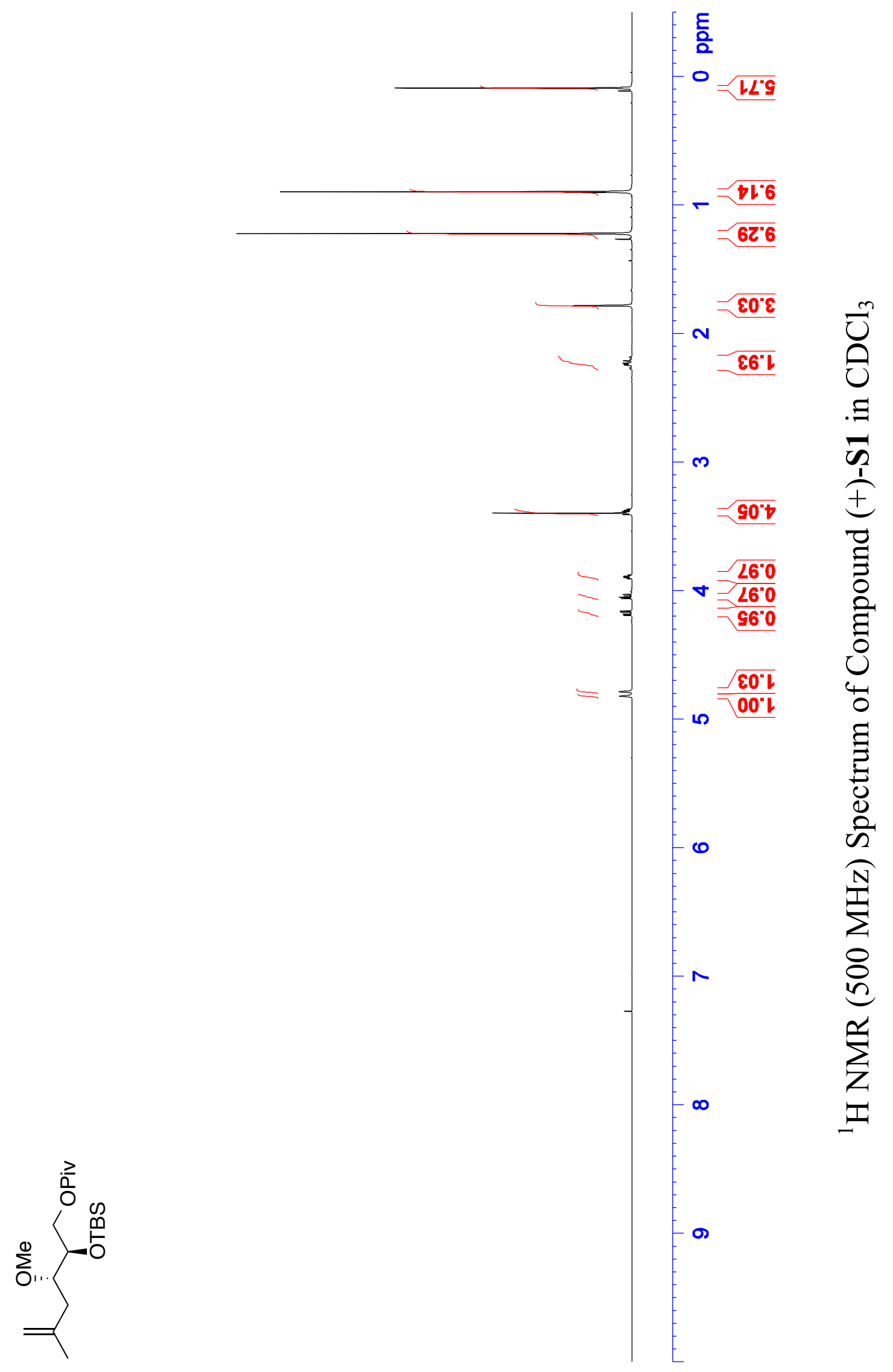




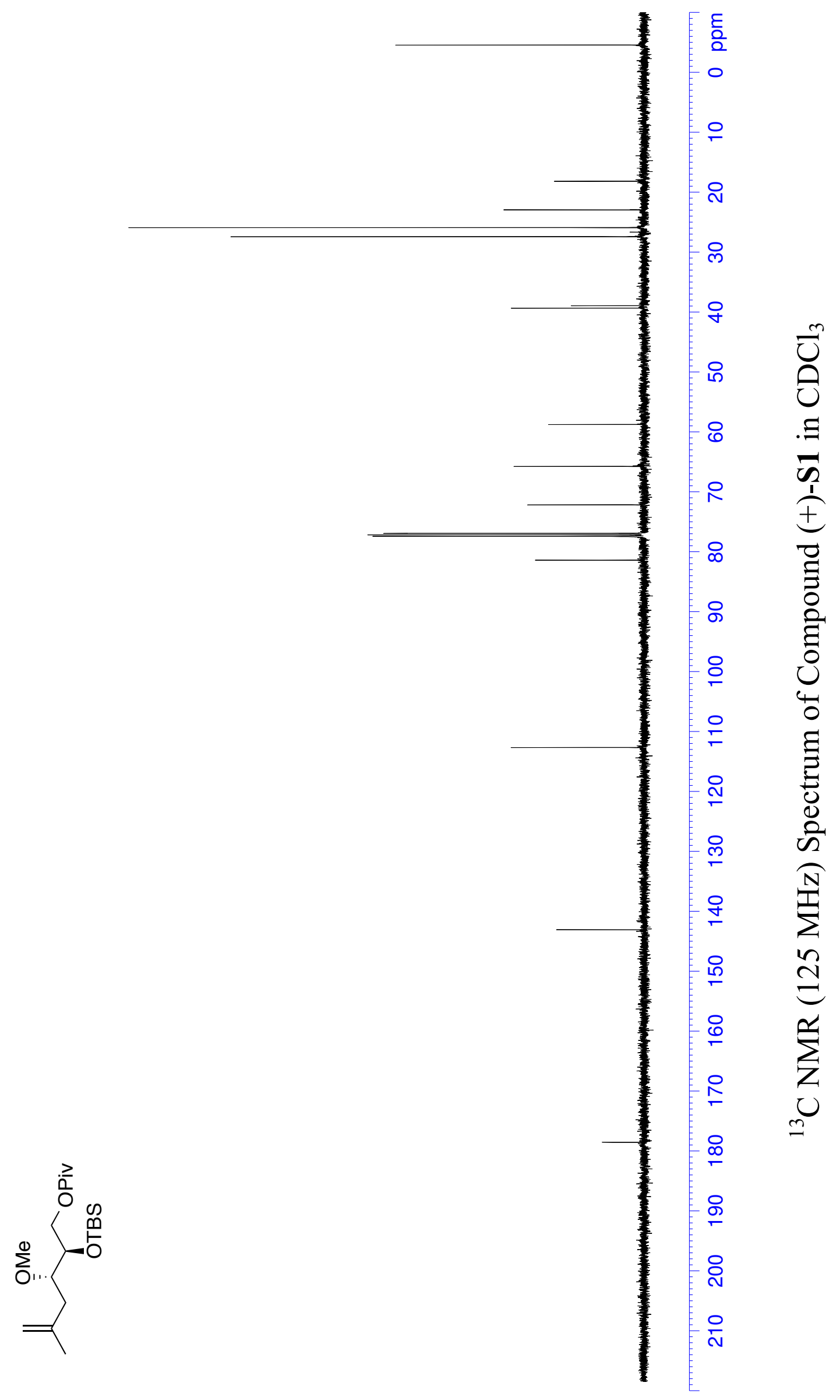




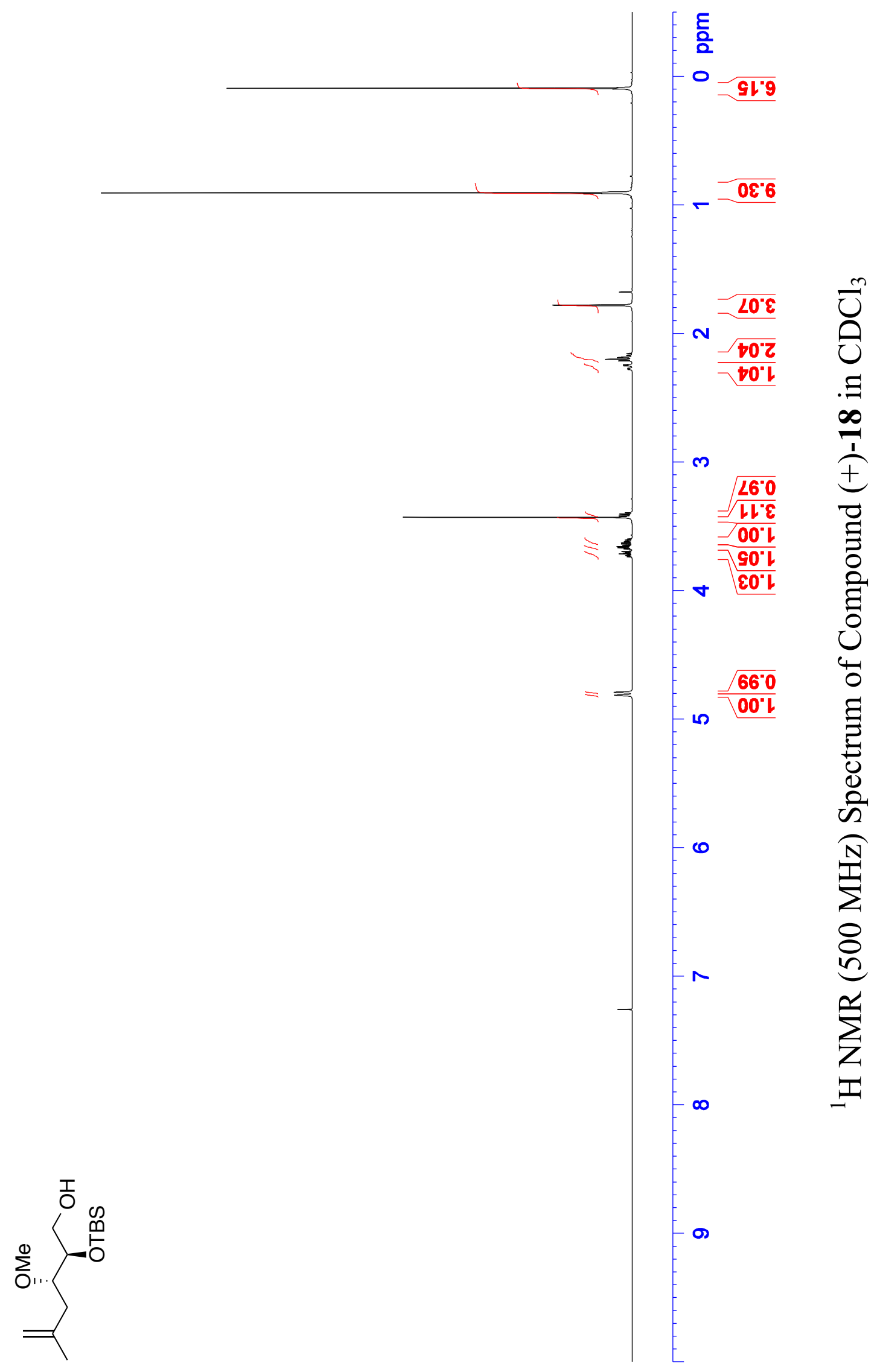




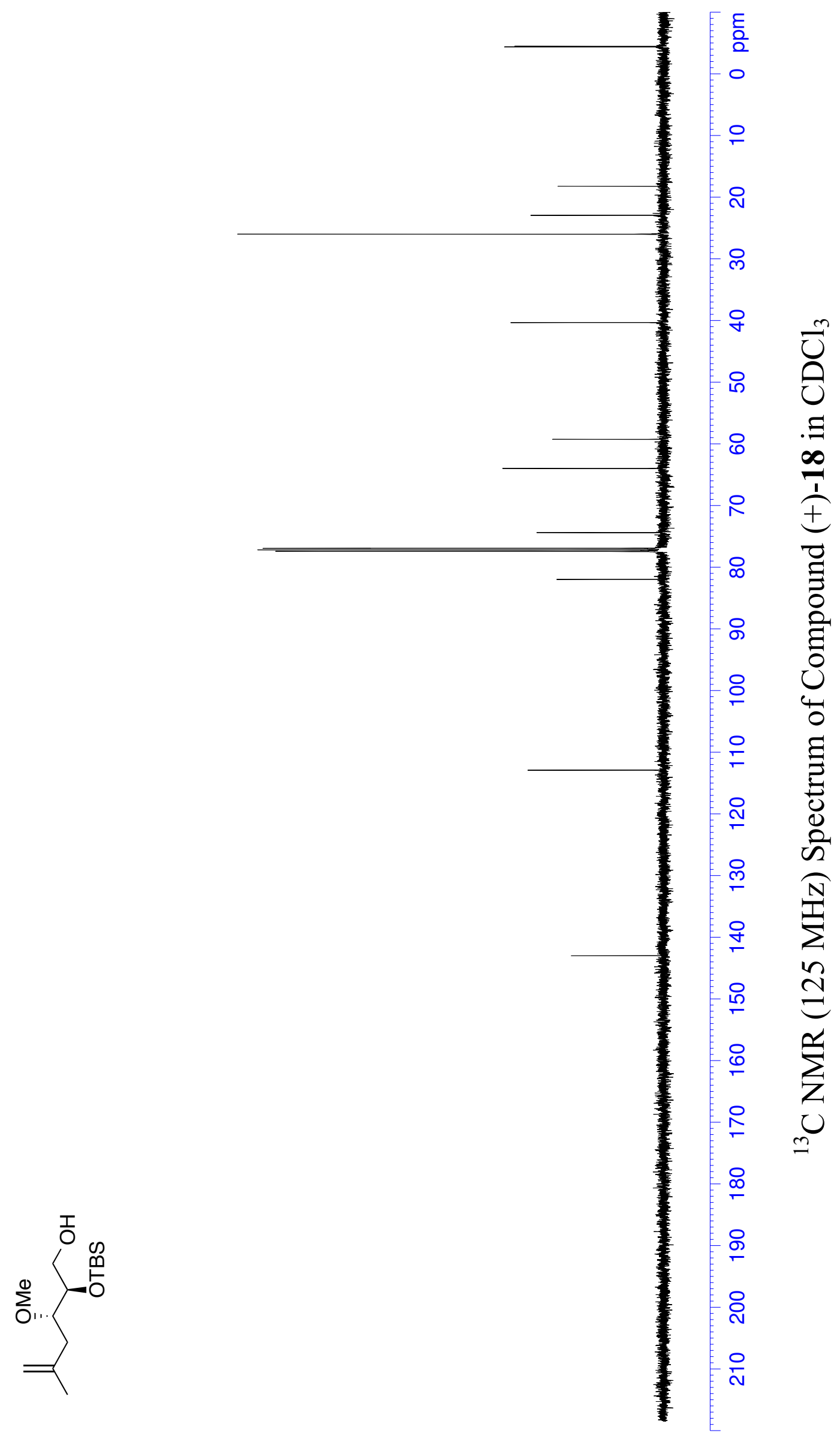




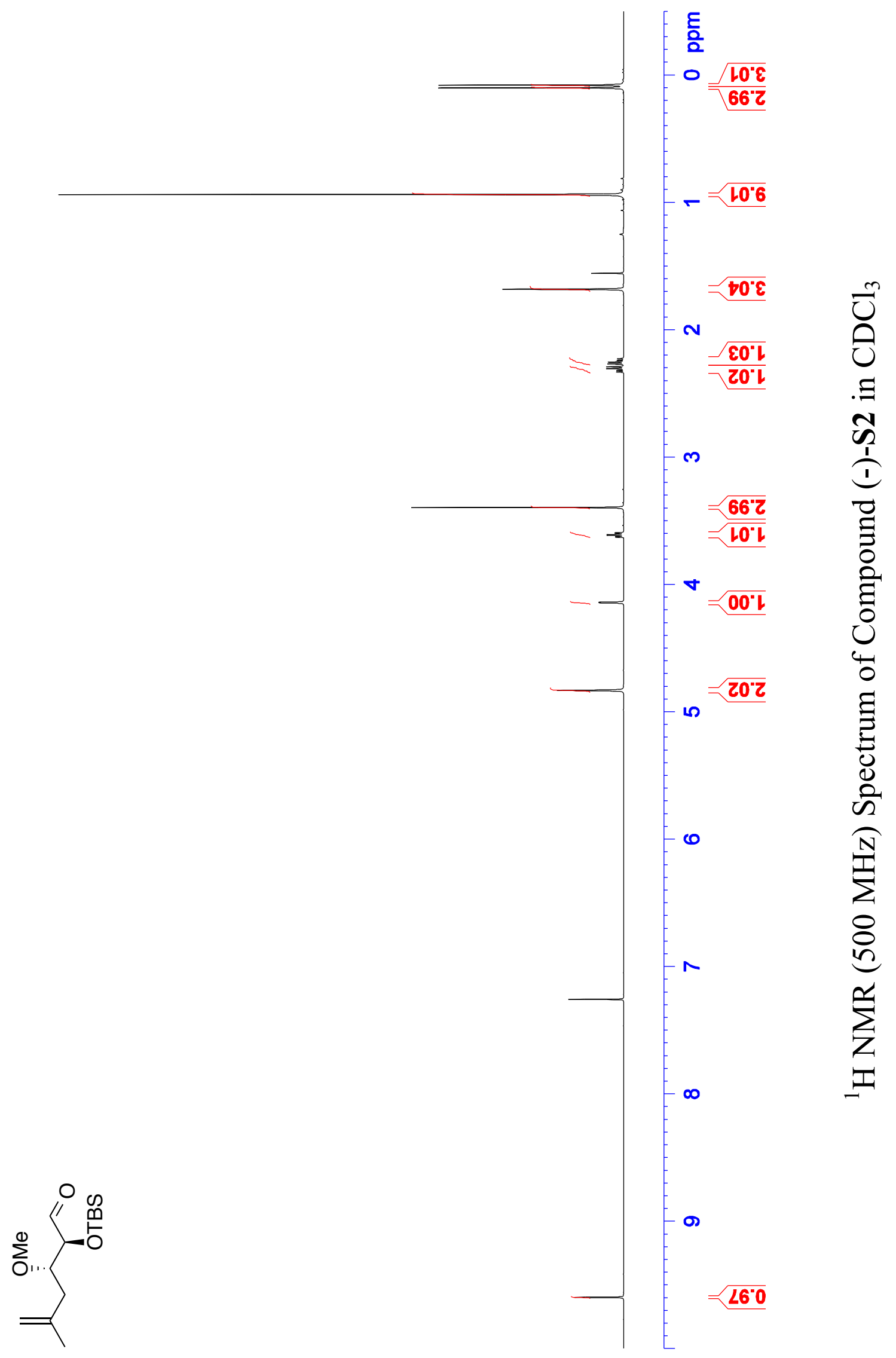




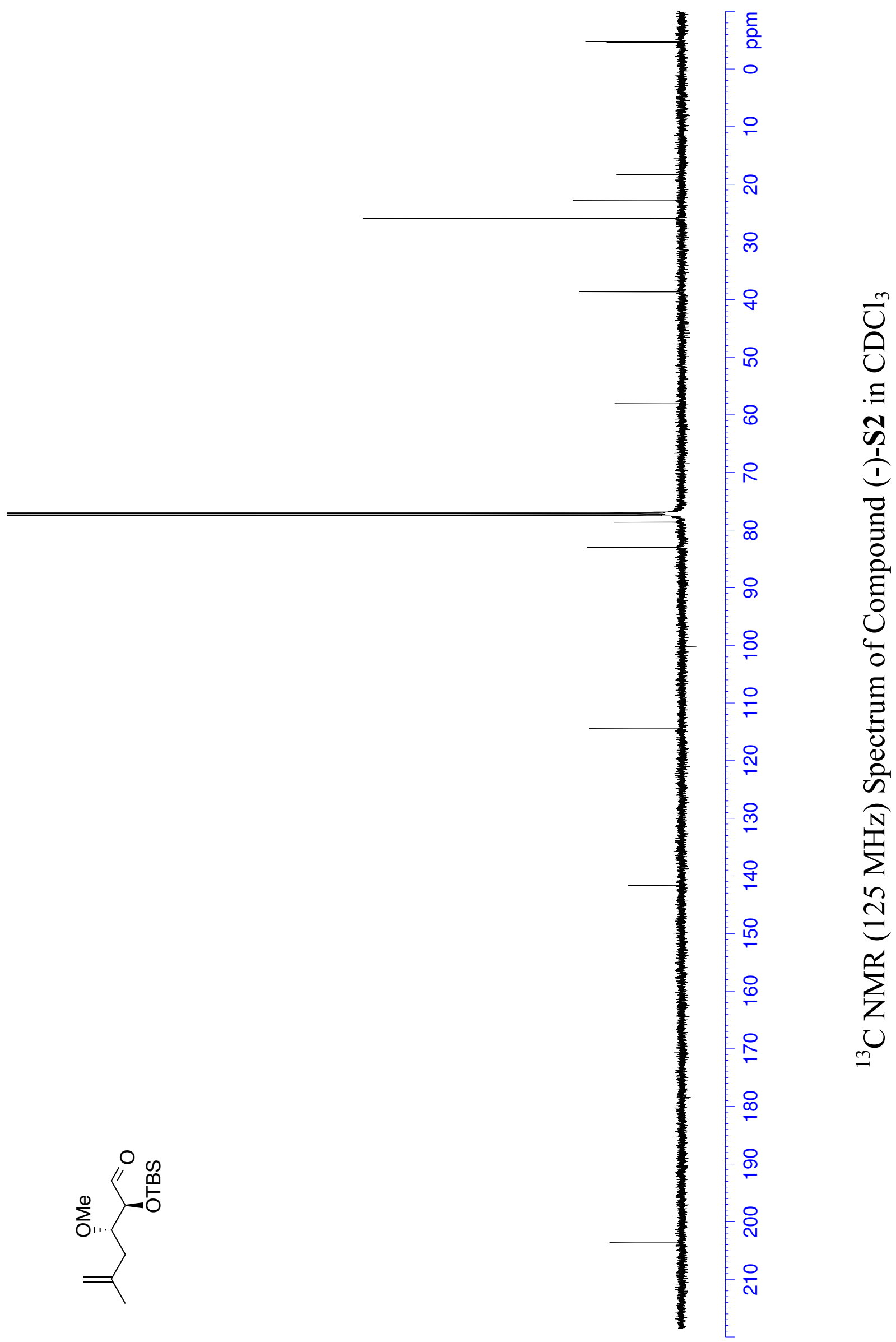




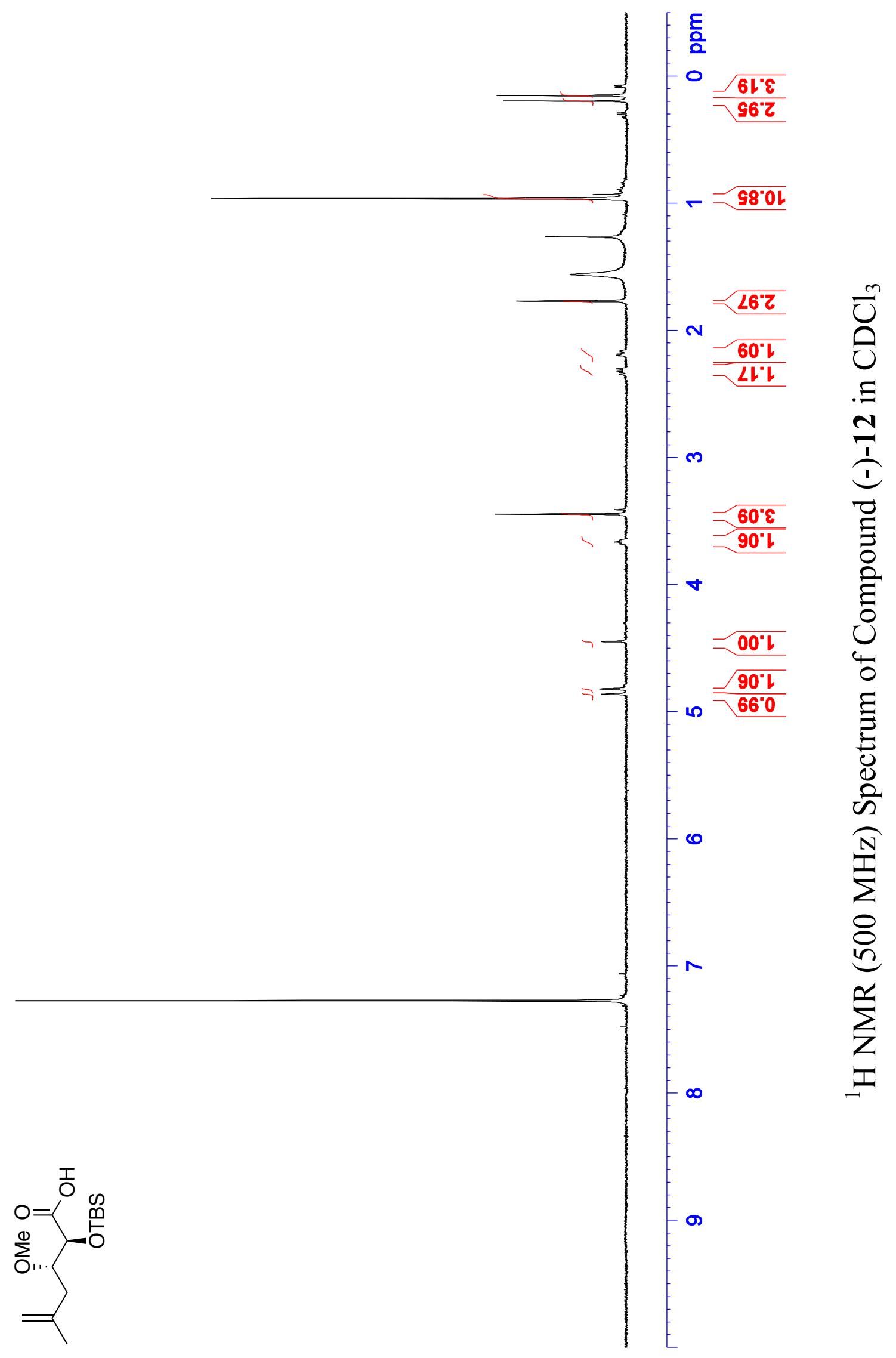




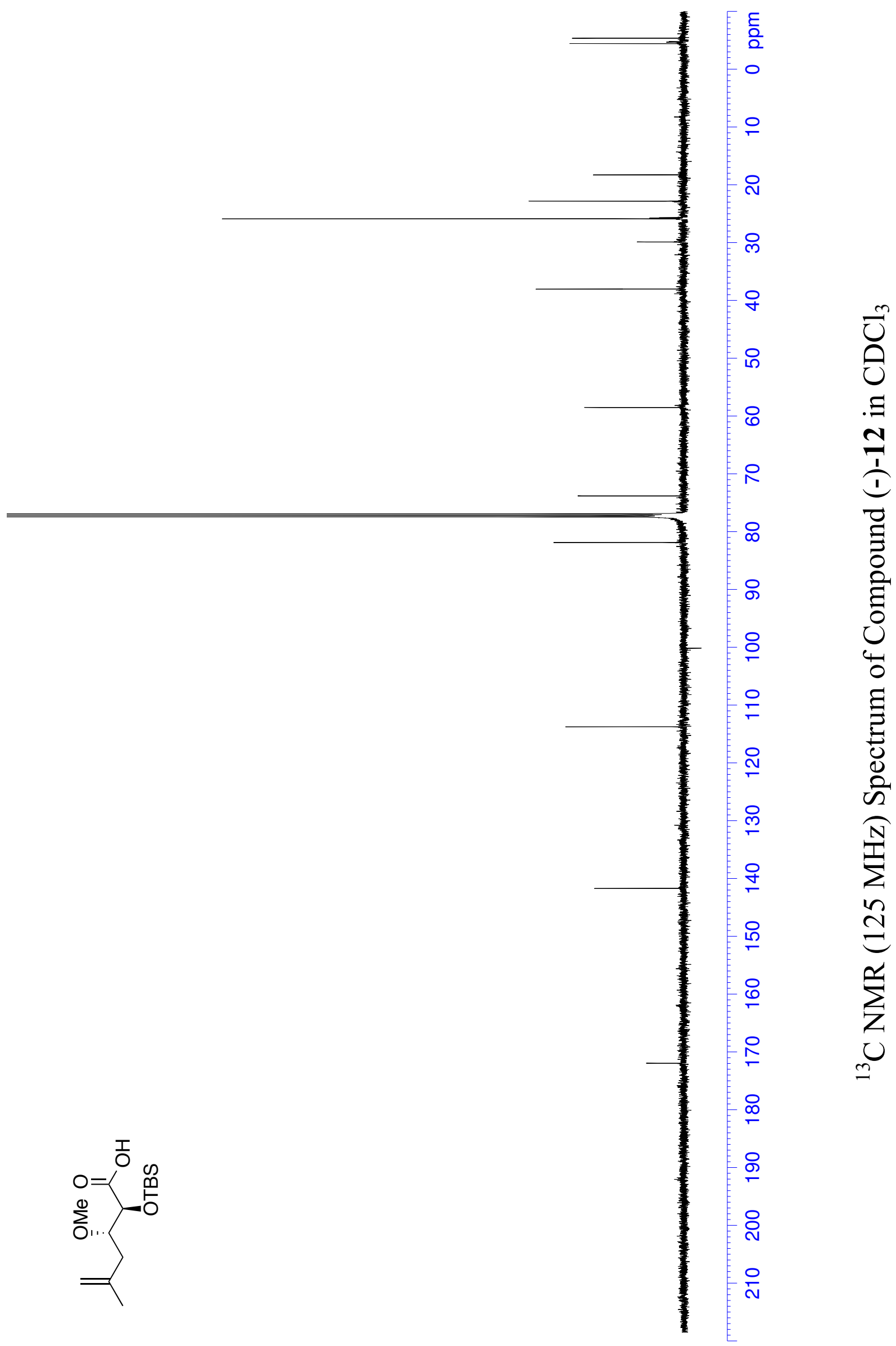




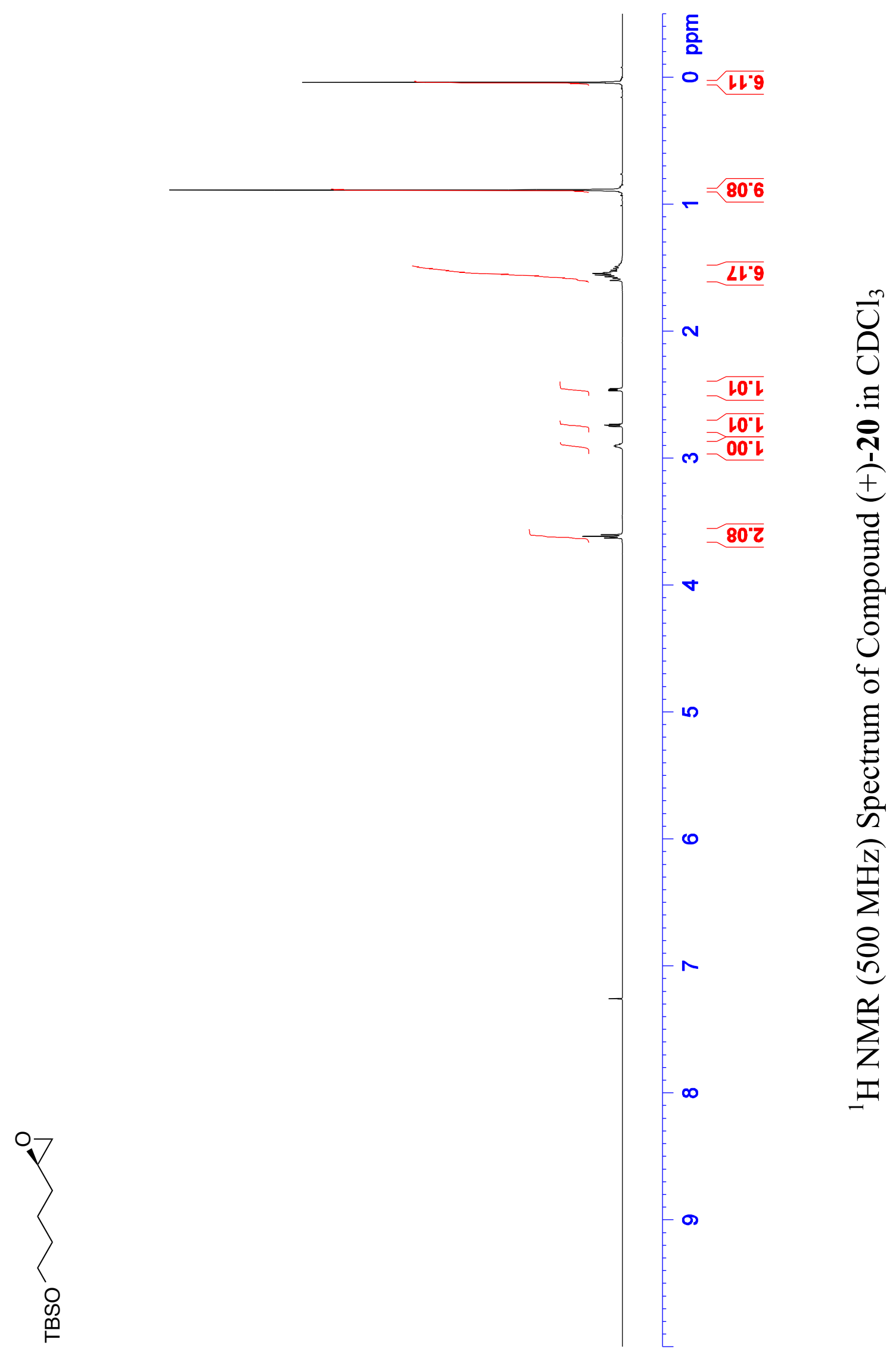




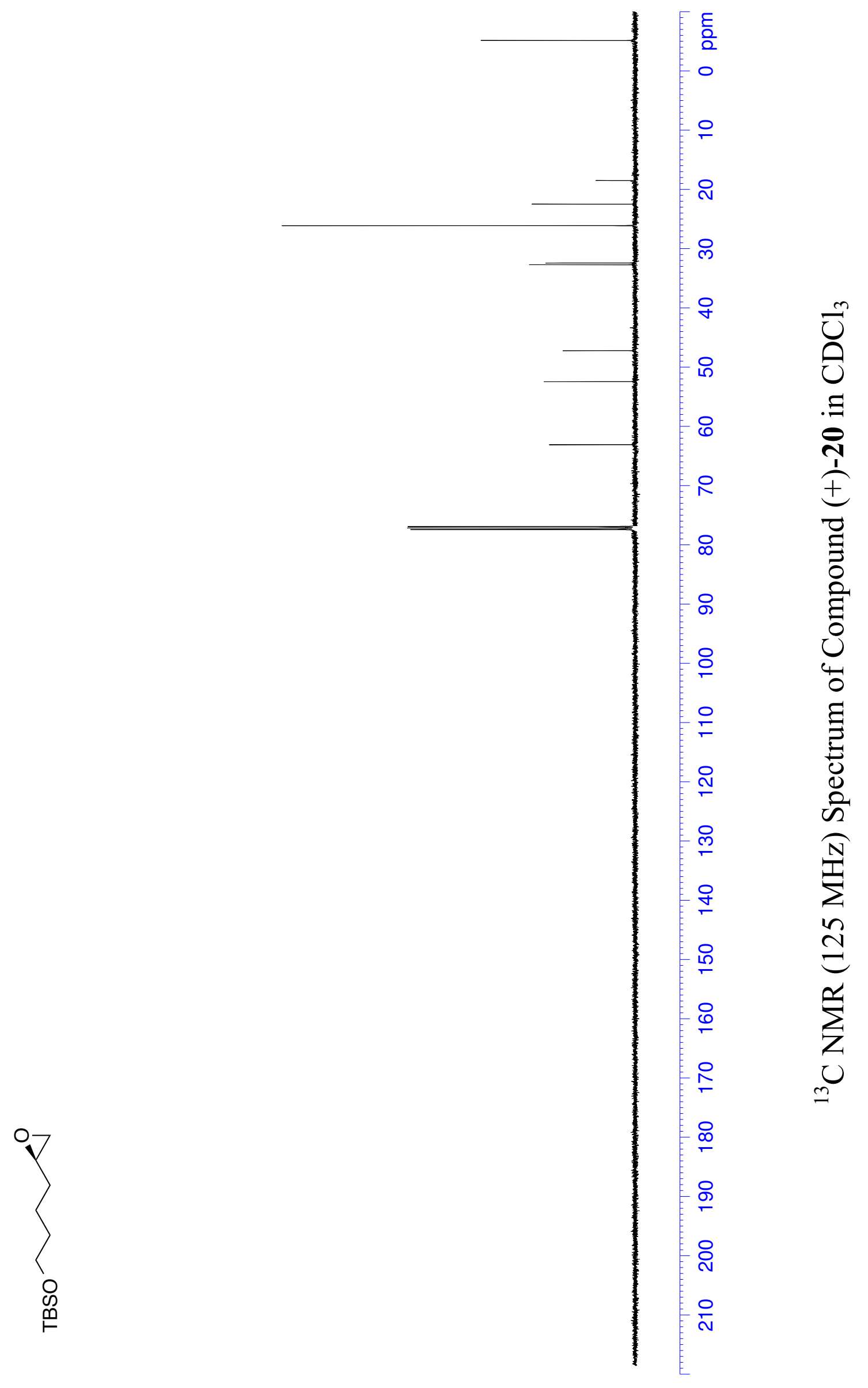




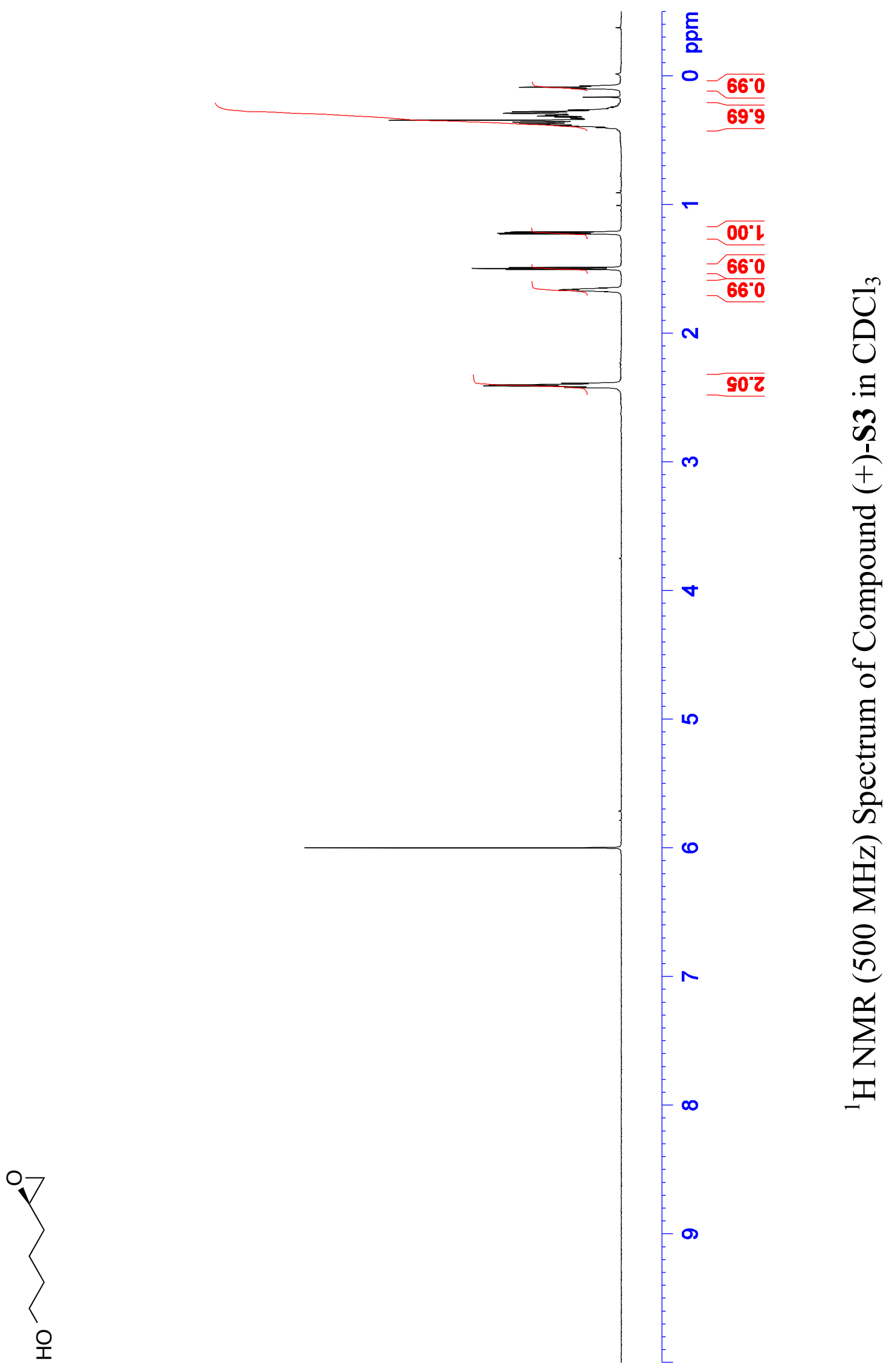




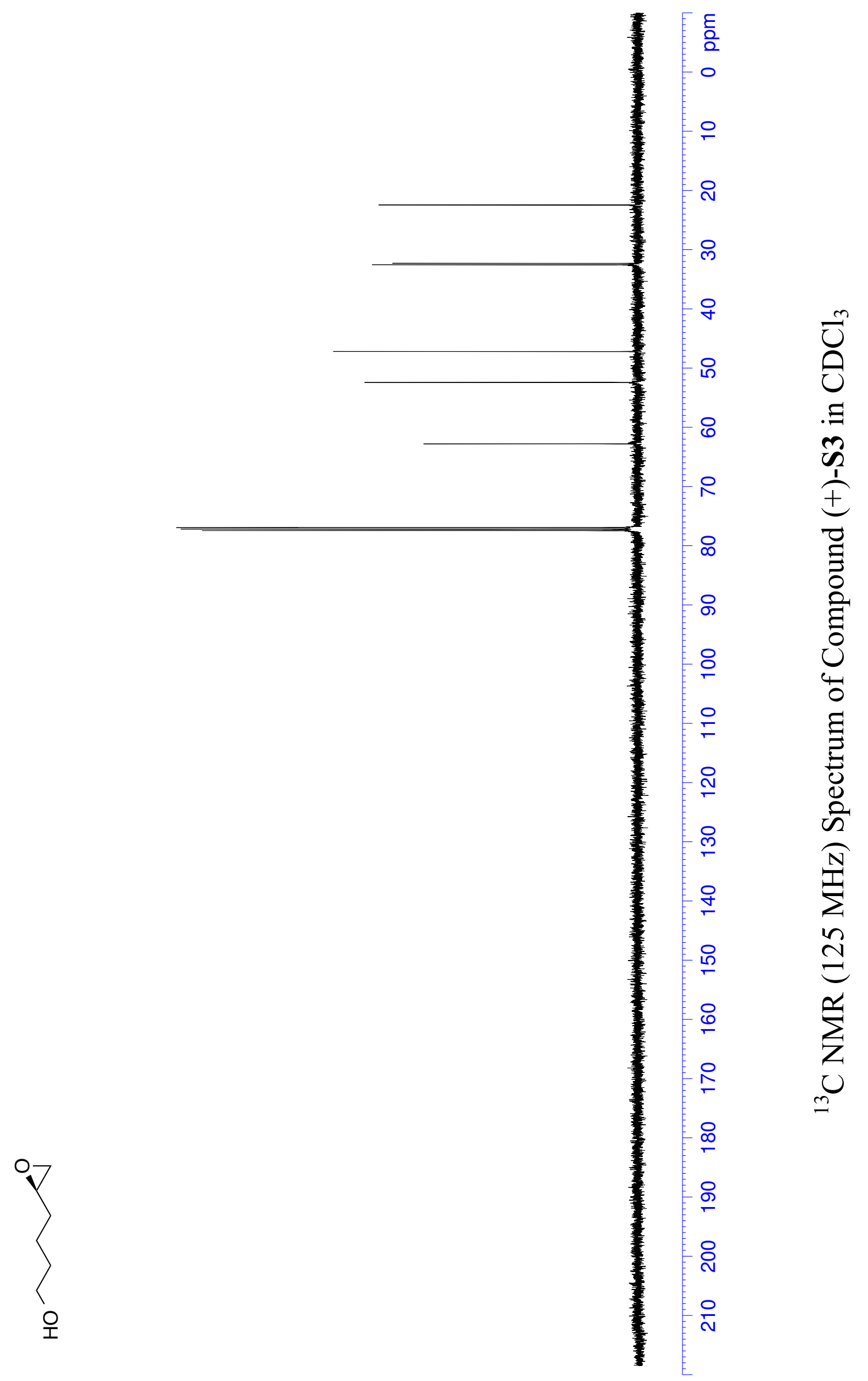




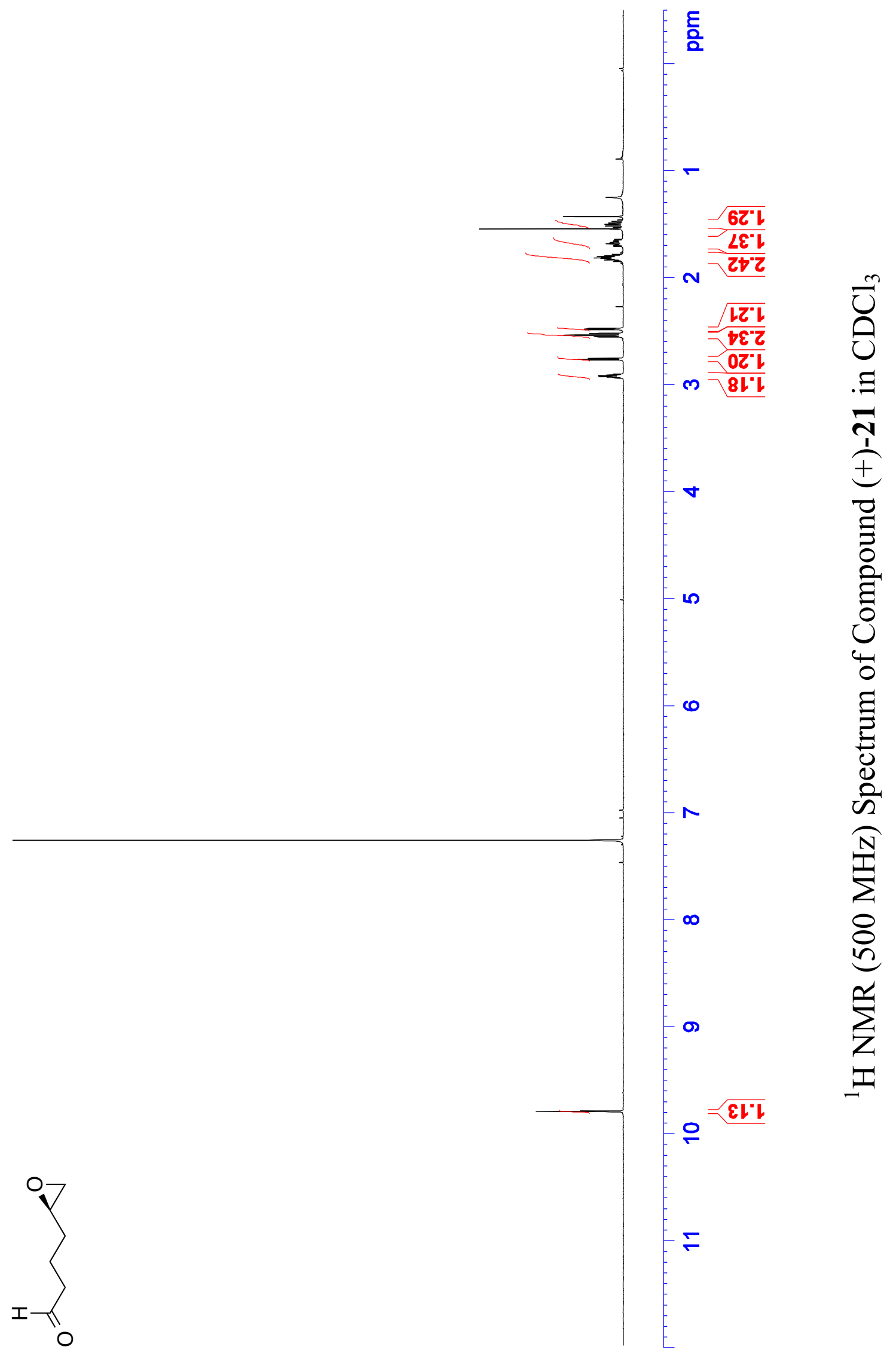




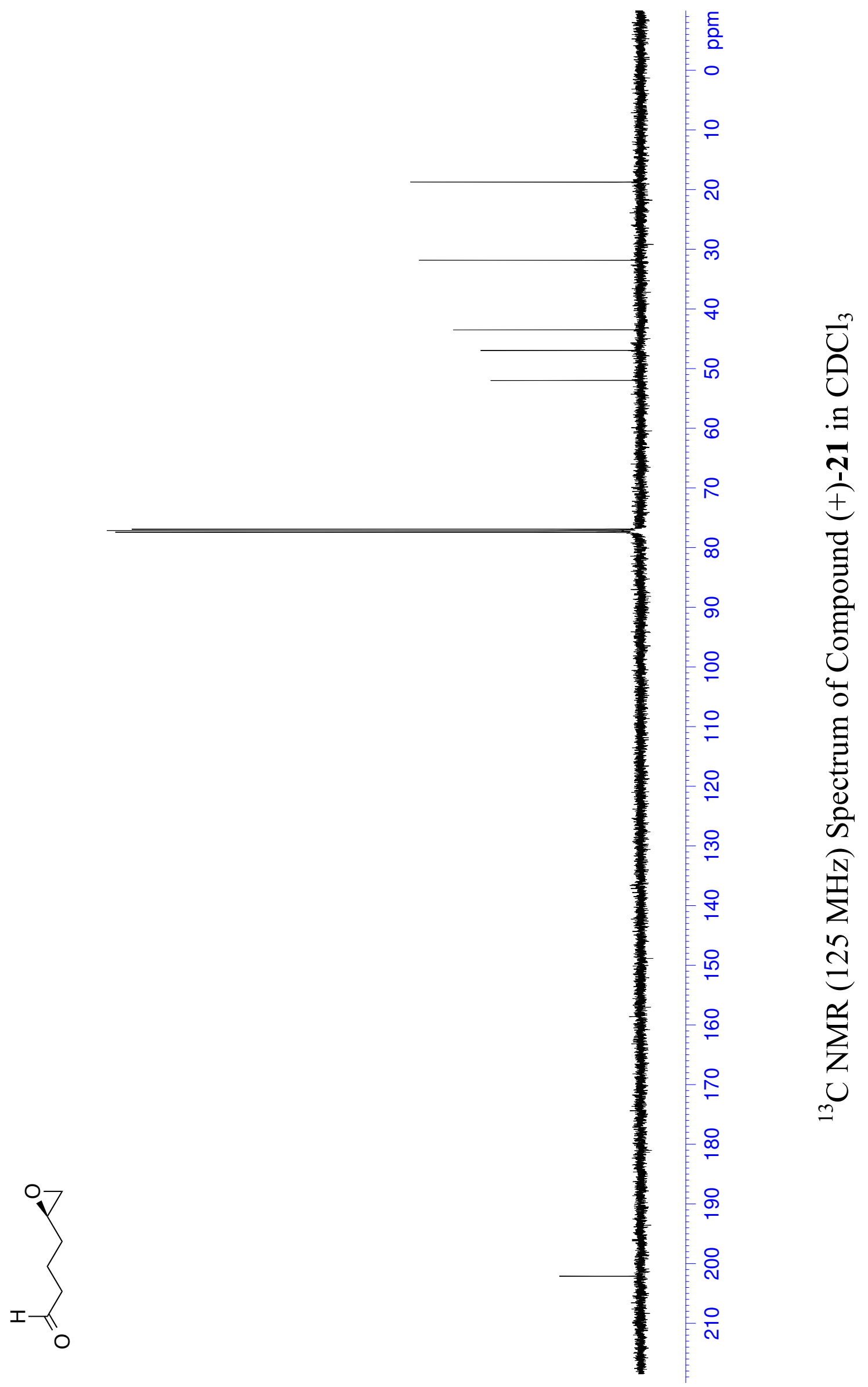




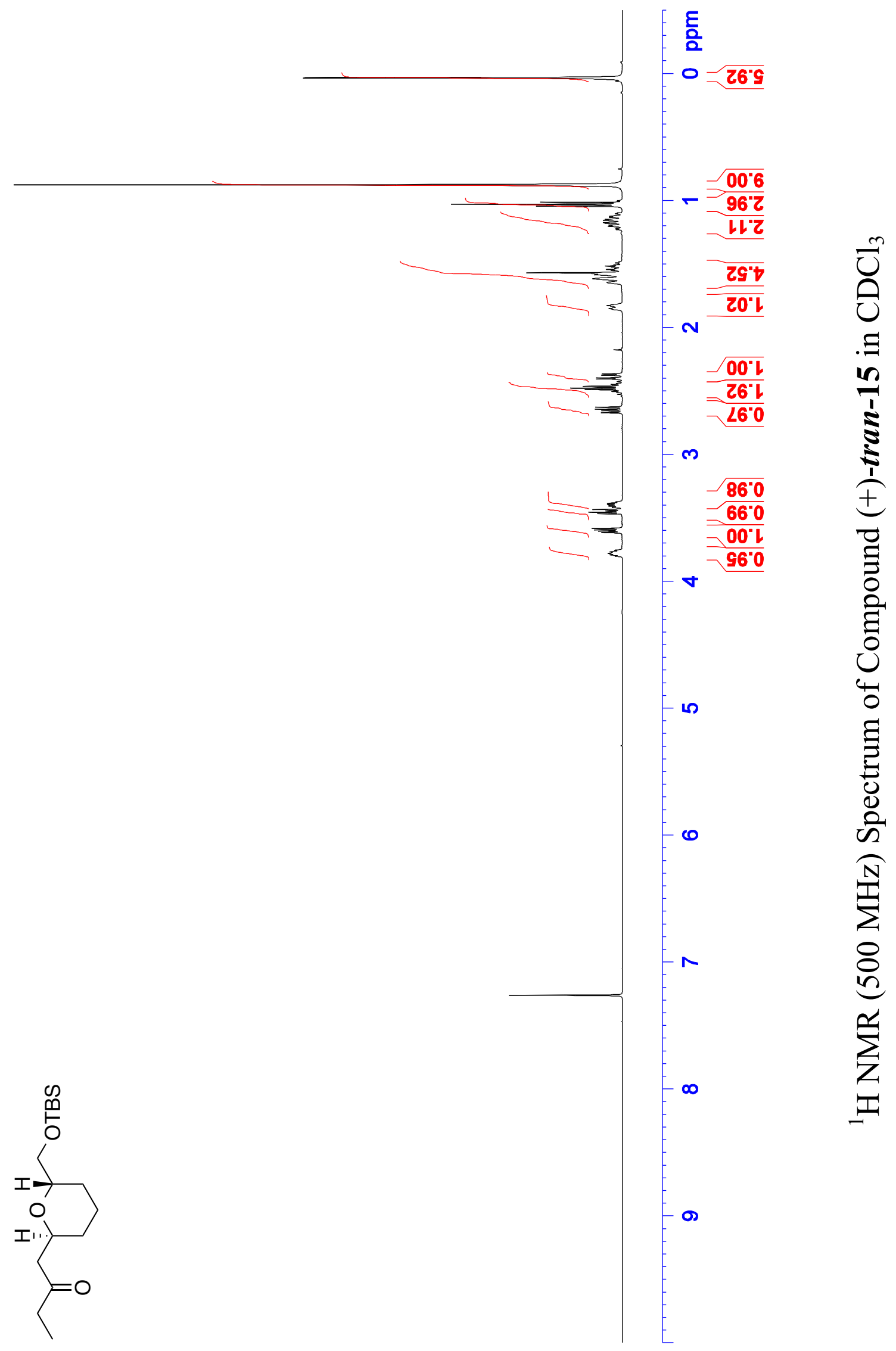




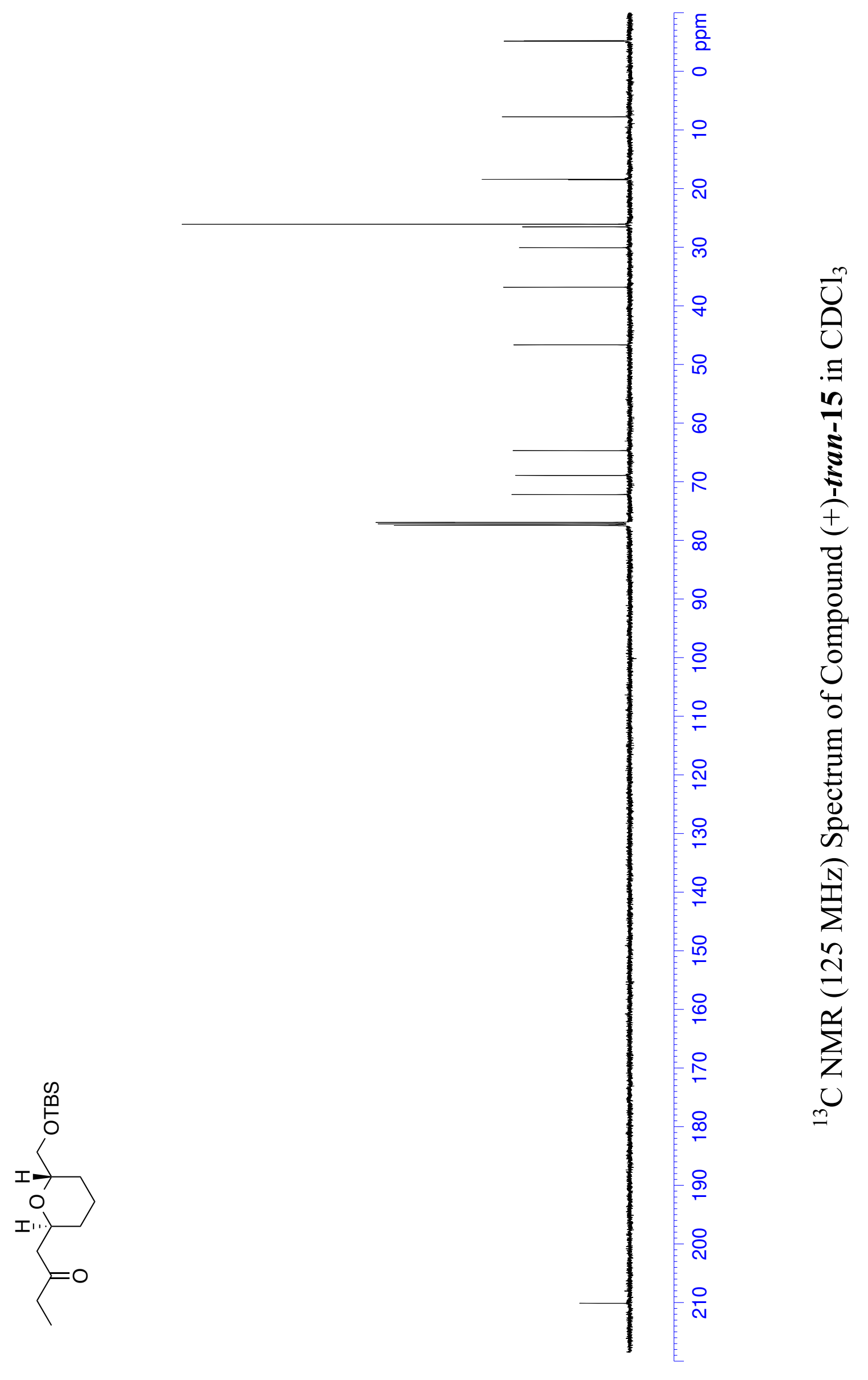




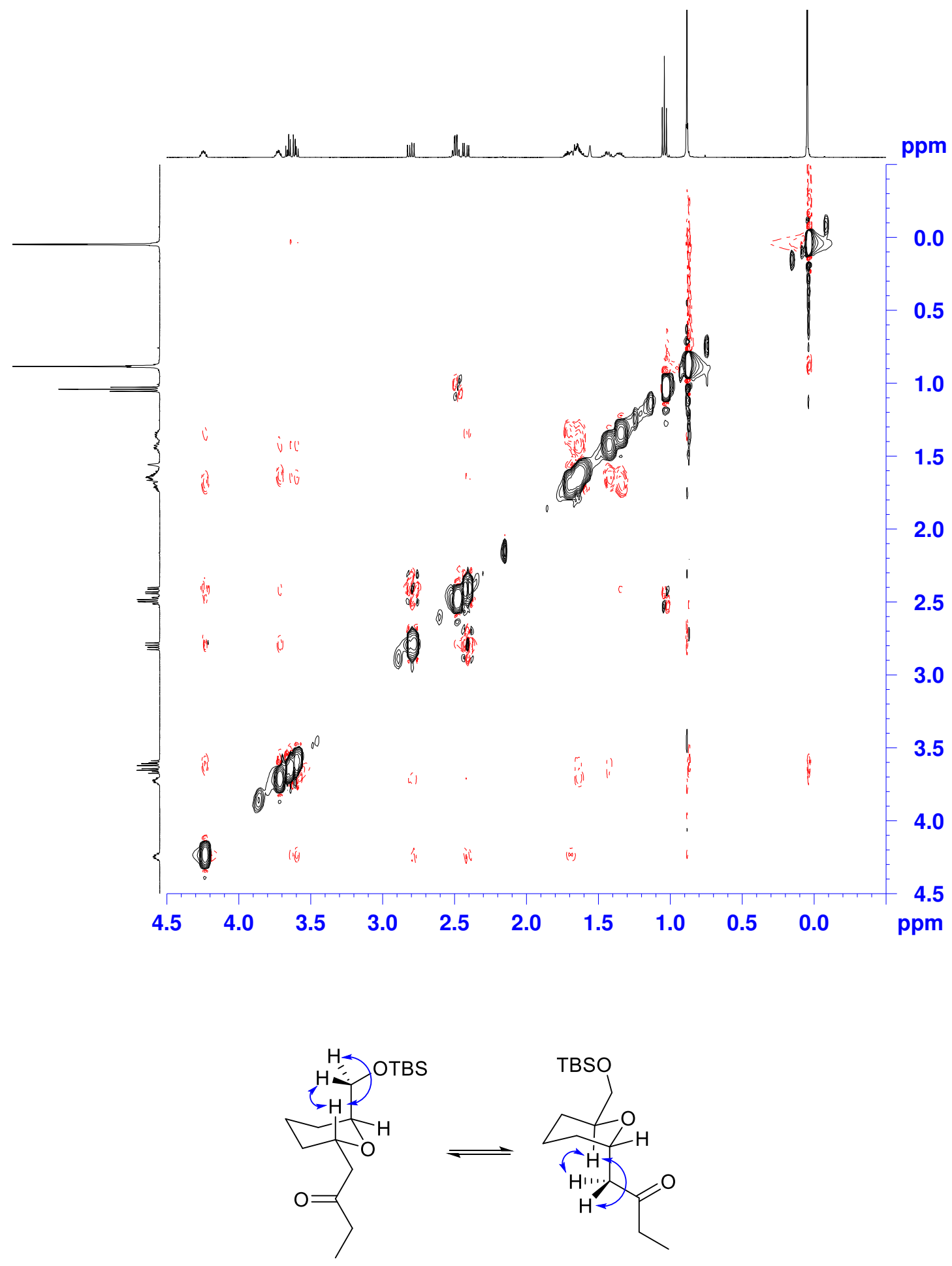

NOE Spectrum of Compound (+)-tran-15 in $\mathrm{CDCl}_{3}$ 


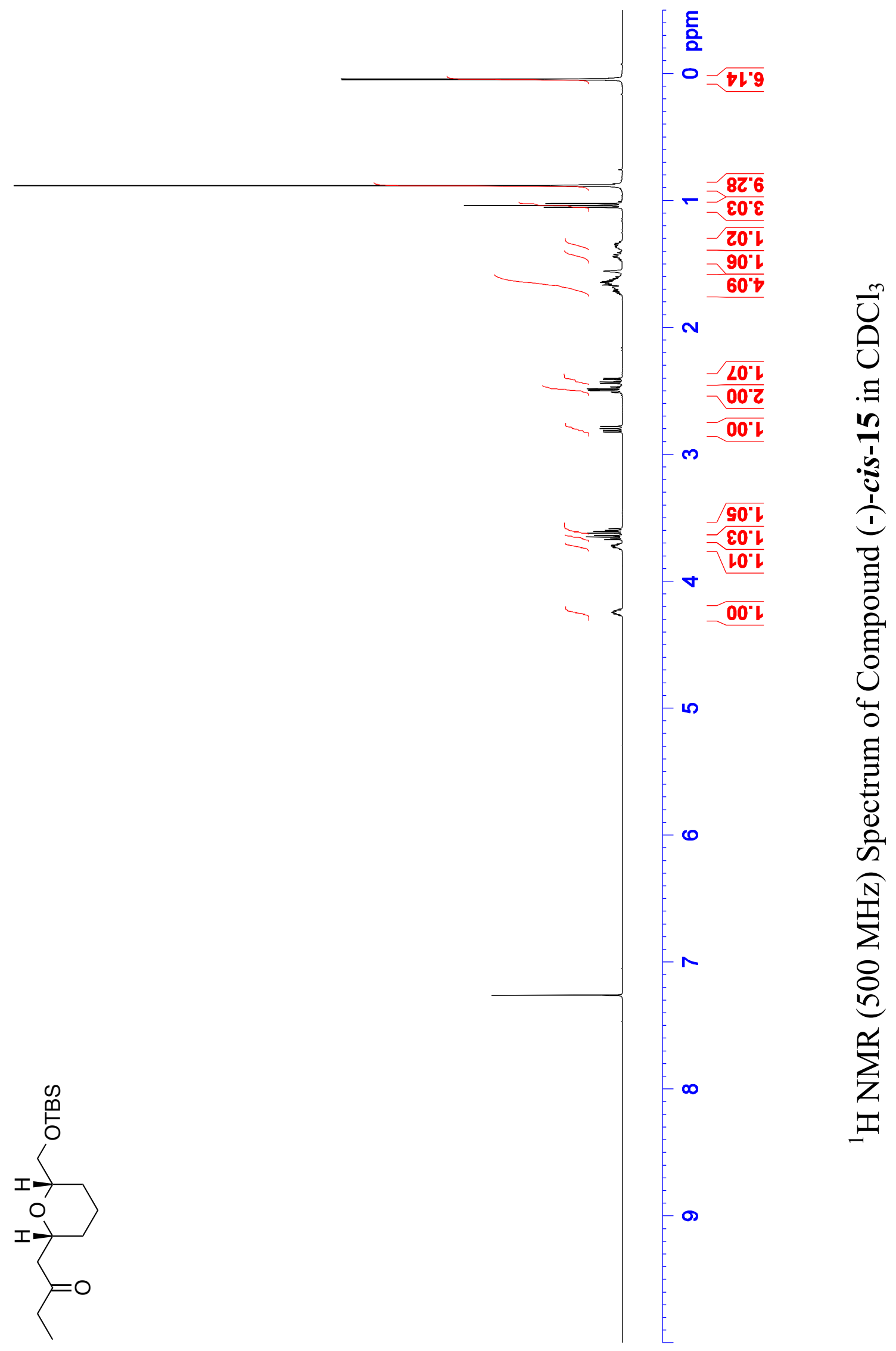




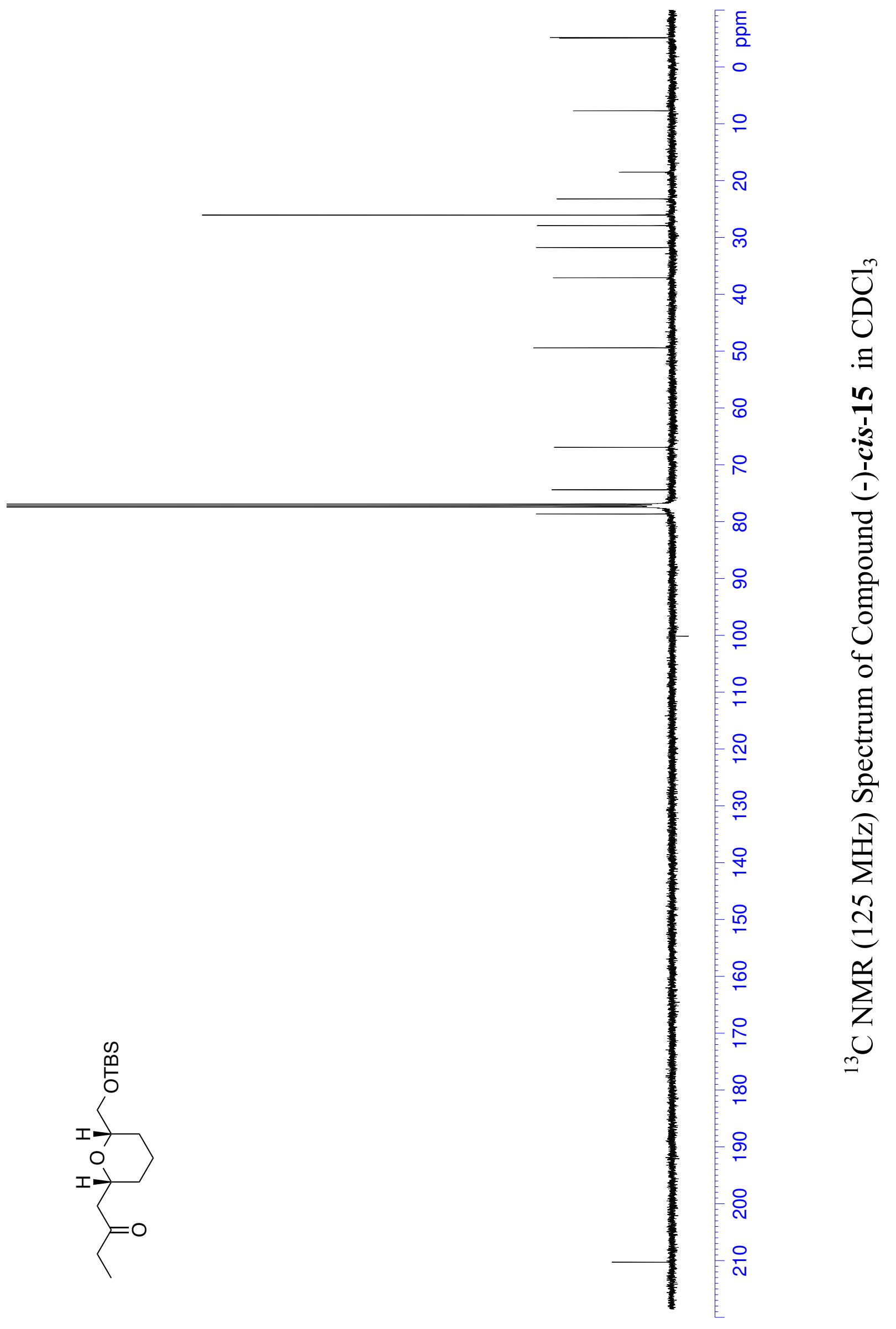




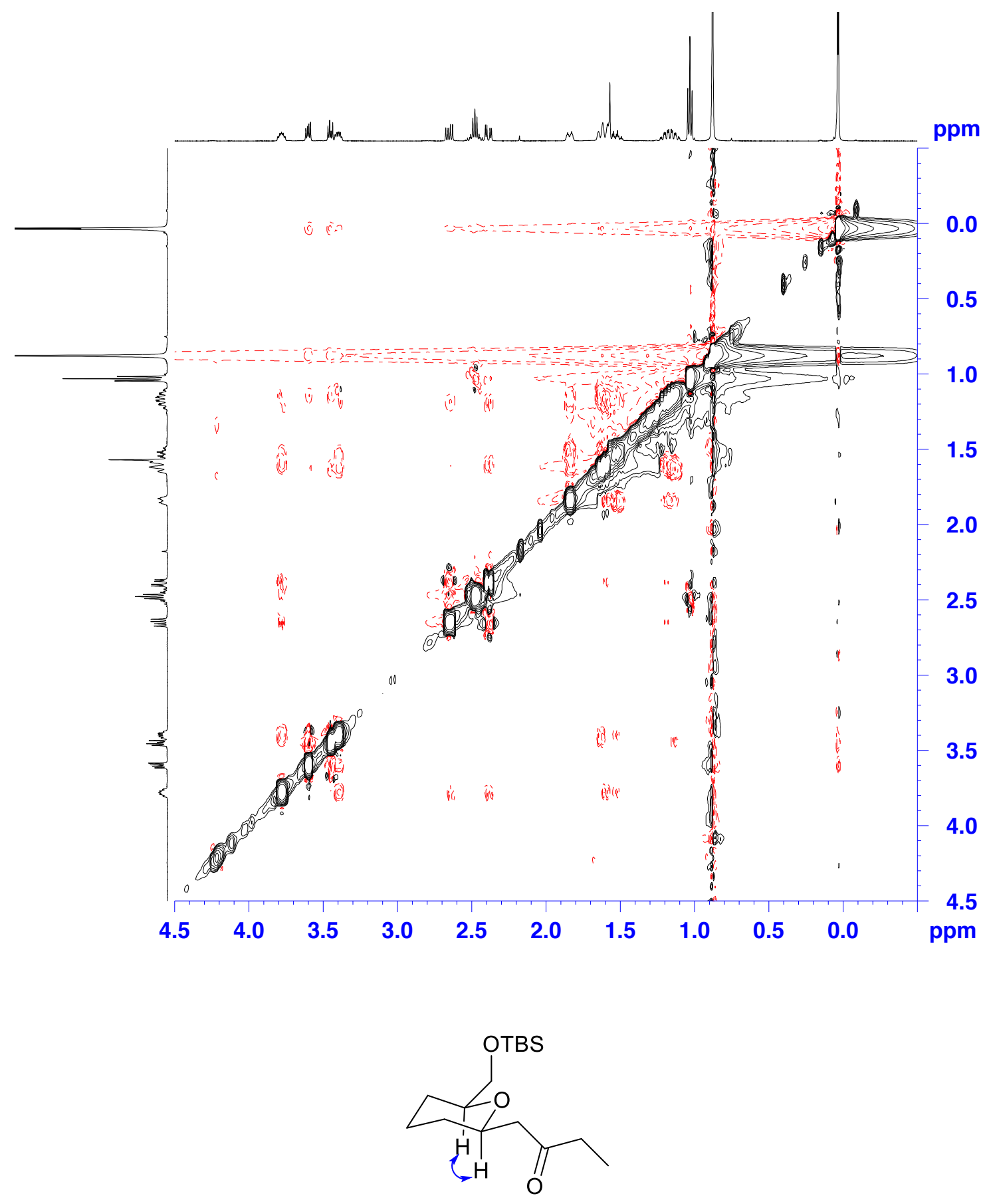

NOE Spectrum of Compound (-)-cis-15 in $\mathrm{CDCl}_{3}$ 


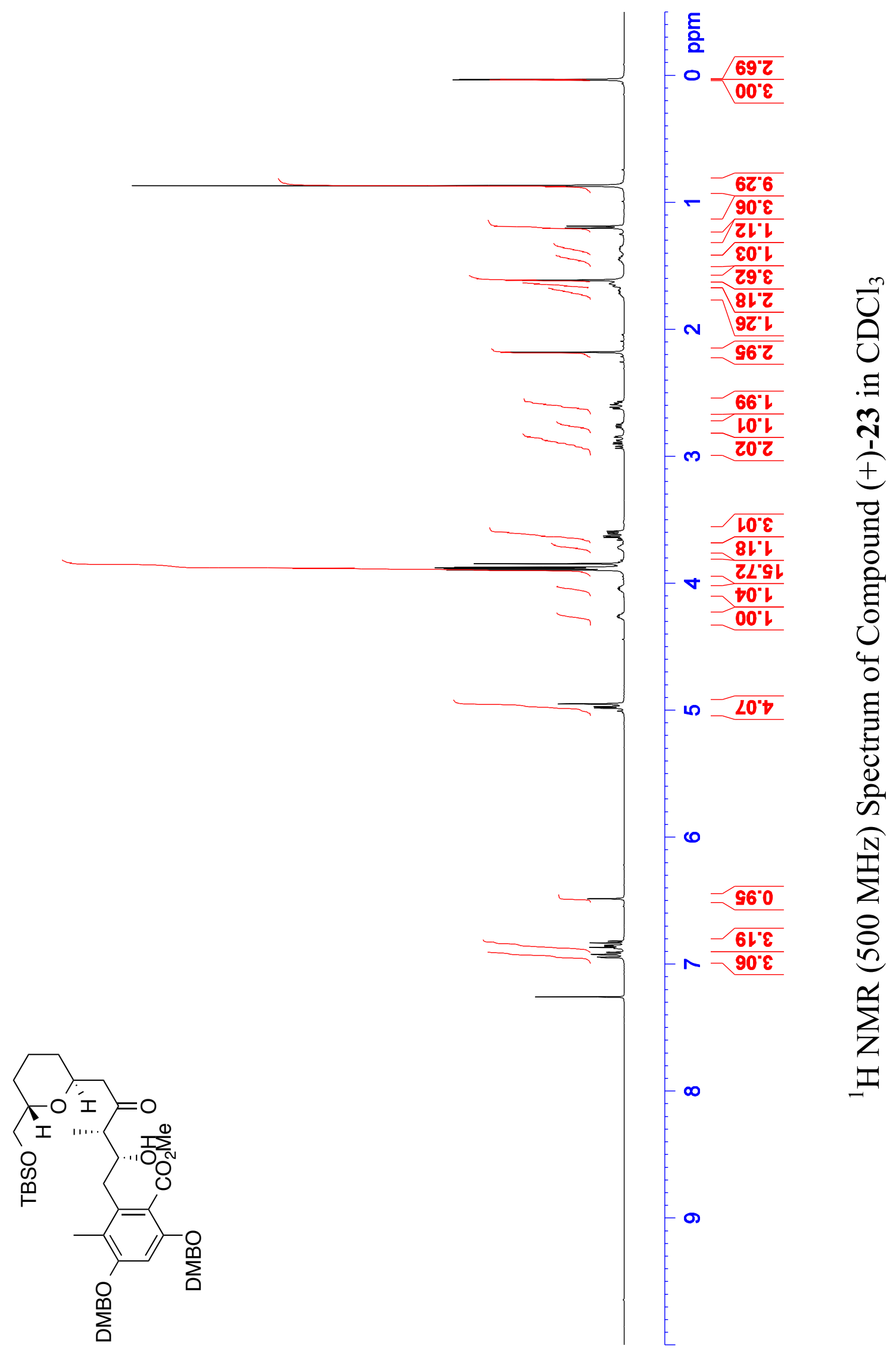




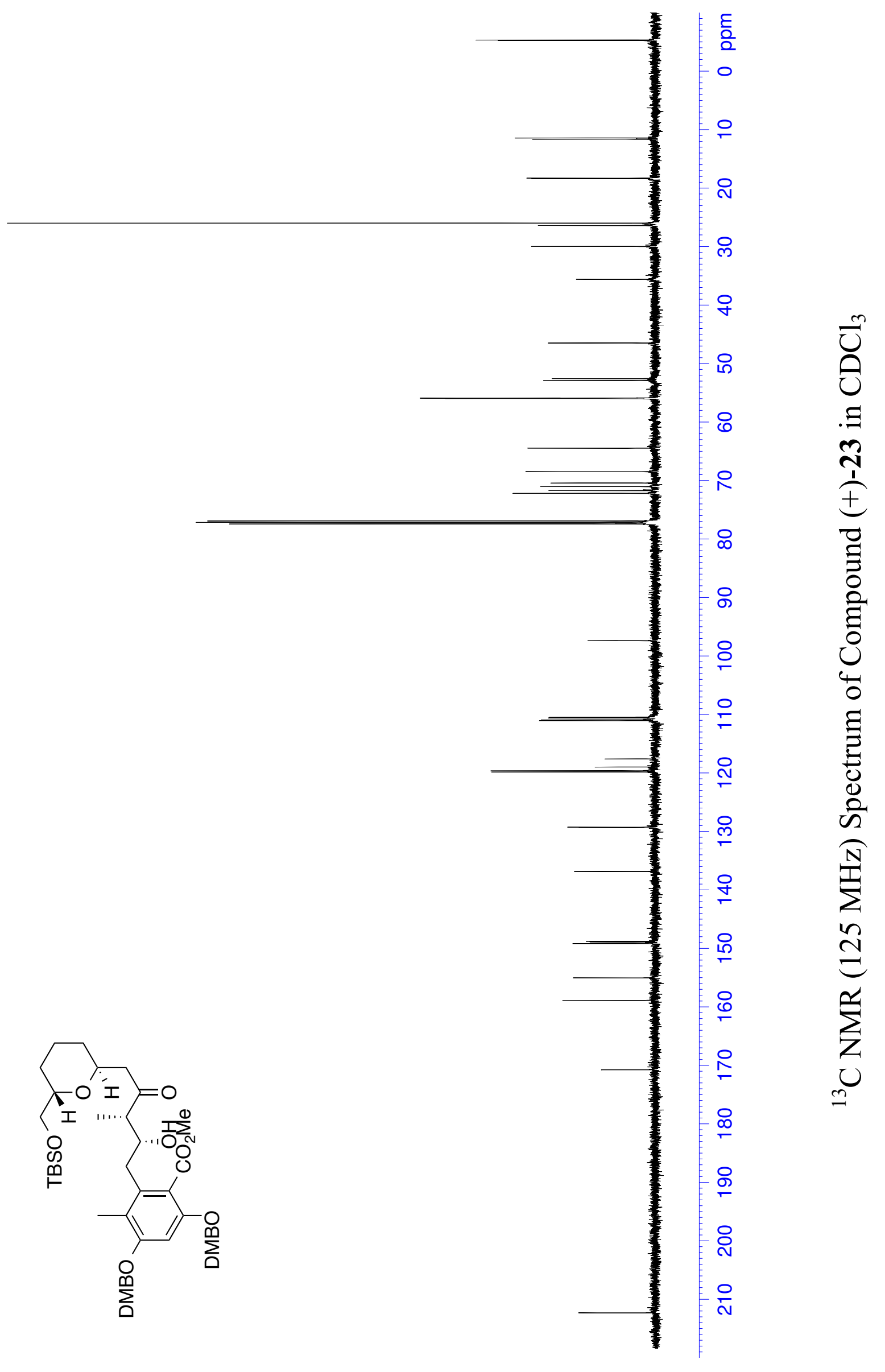




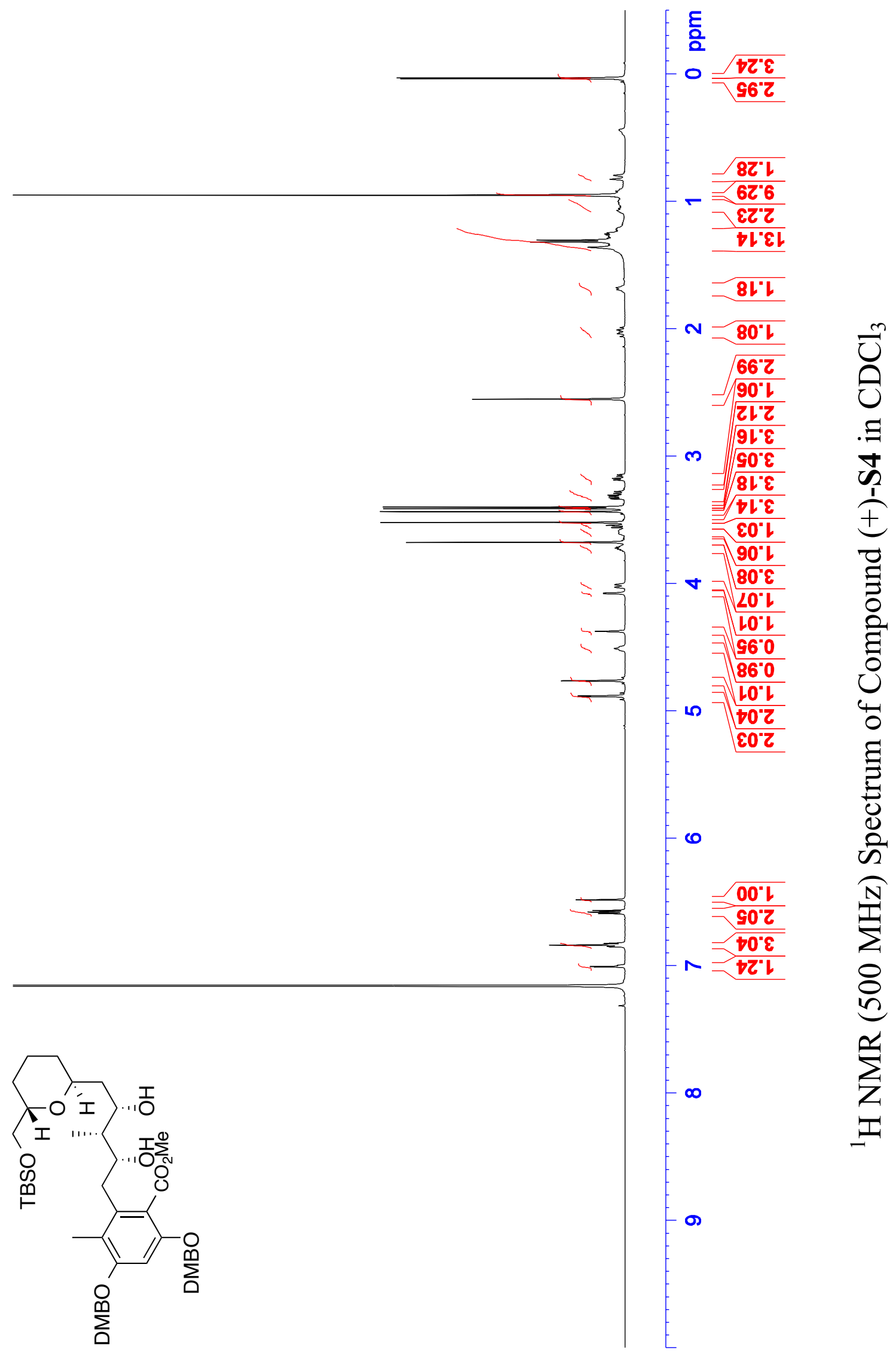




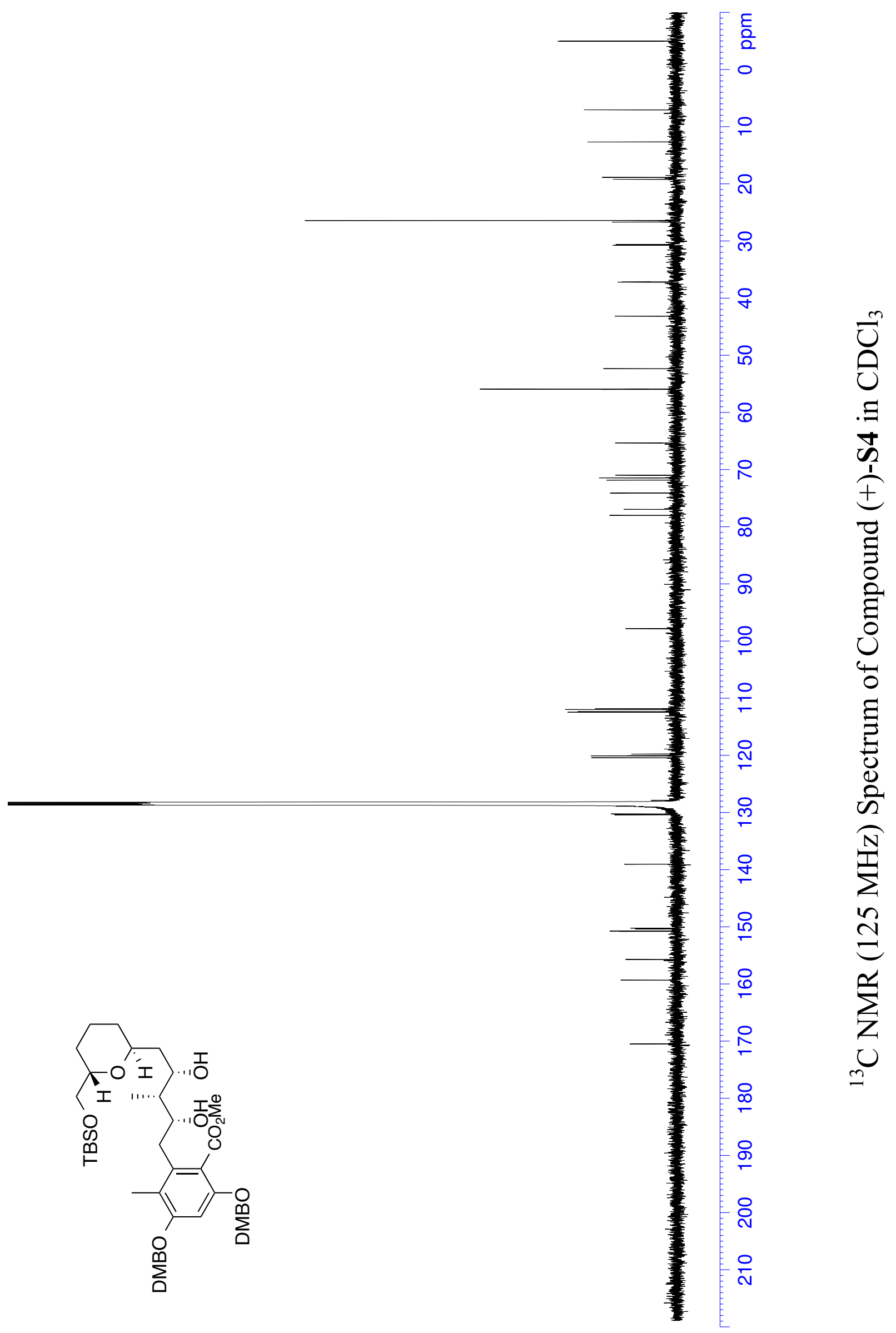




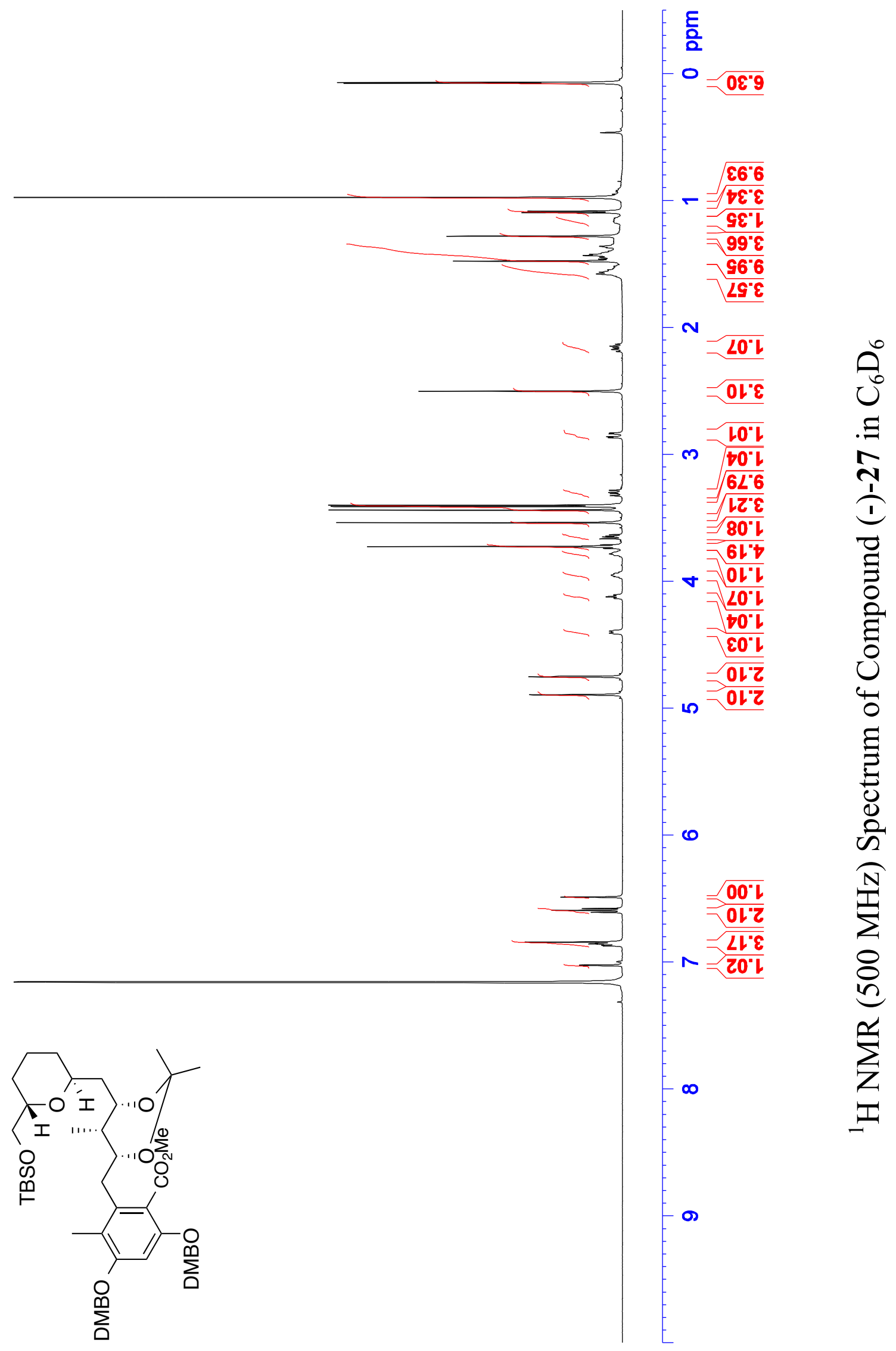




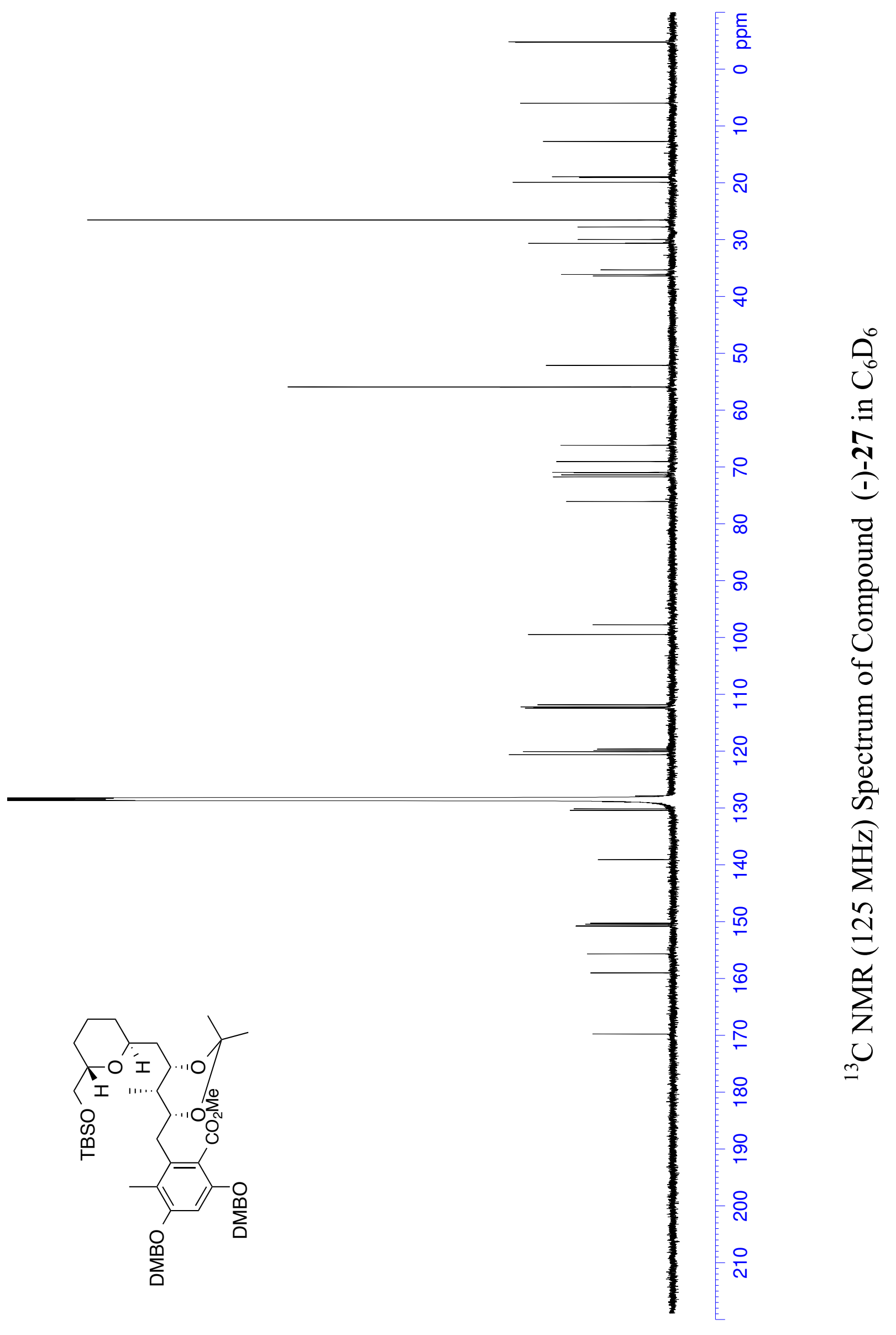



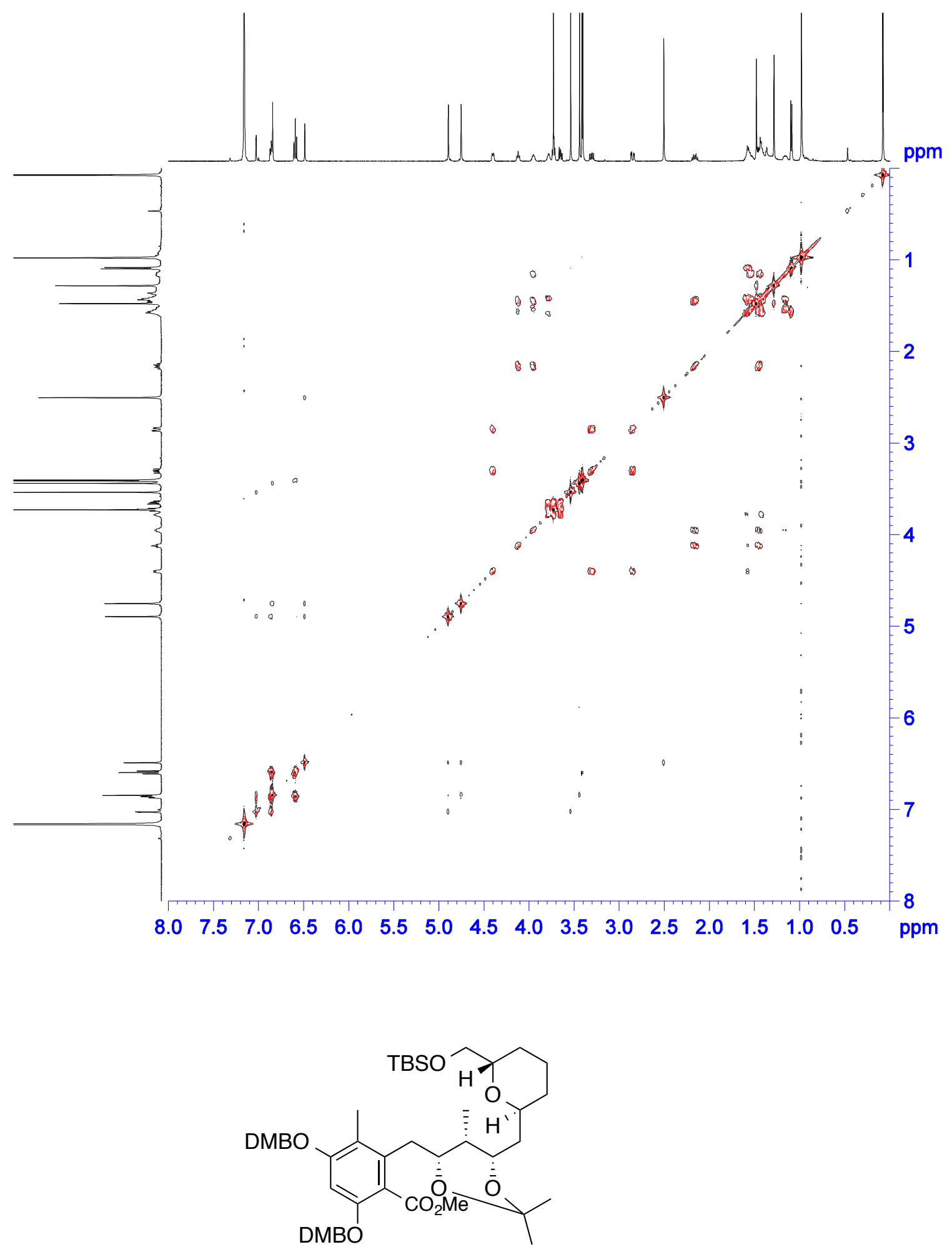

2D-COSY Spectrum of Compound (-)-27 in $\mathrm{C}_{6} \mathrm{D}_{6}$ 


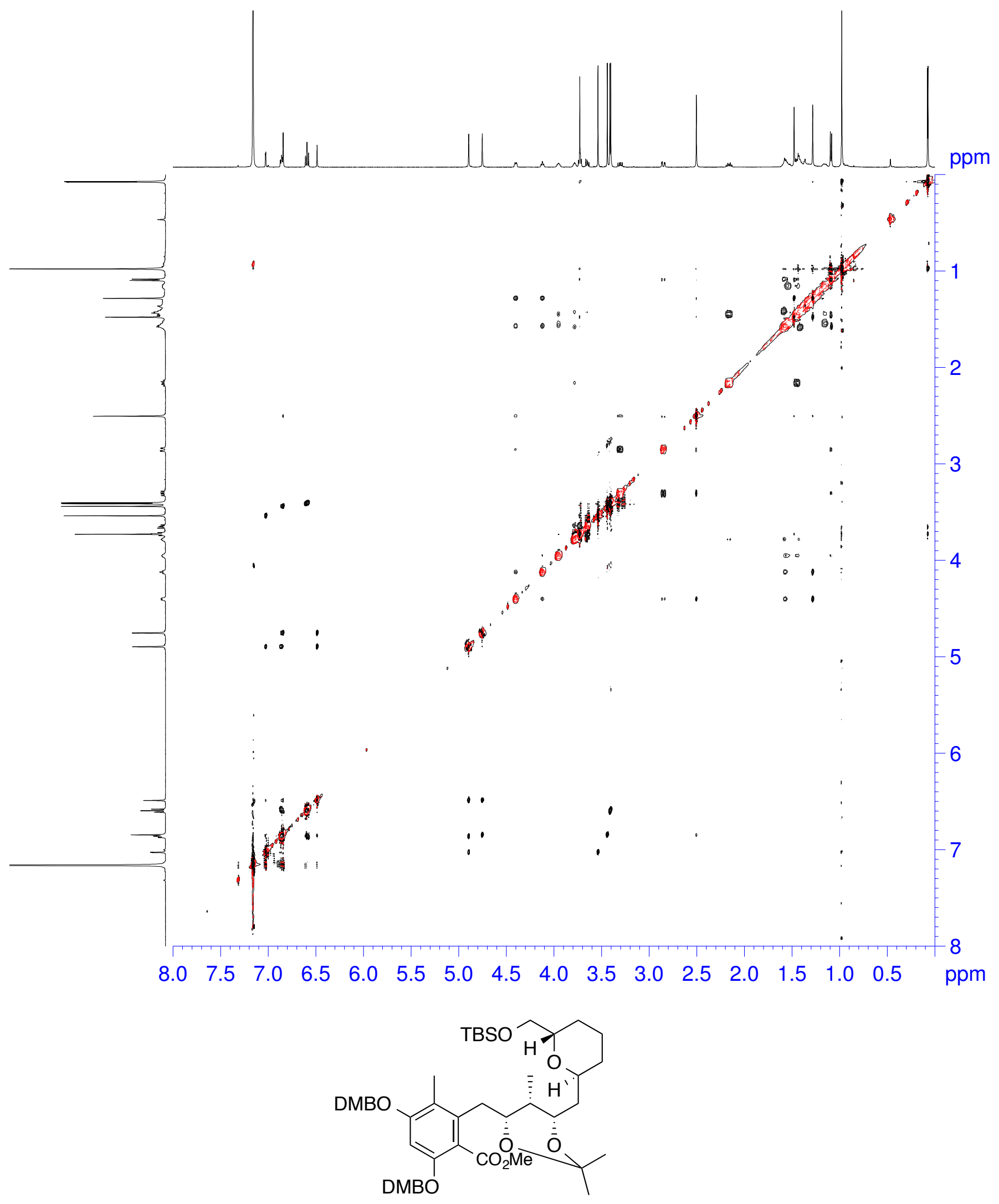

2D-ROESY Spectrum of Compound (-)-27 in $\mathrm{C}_{6} \mathrm{D}_{6}$ 


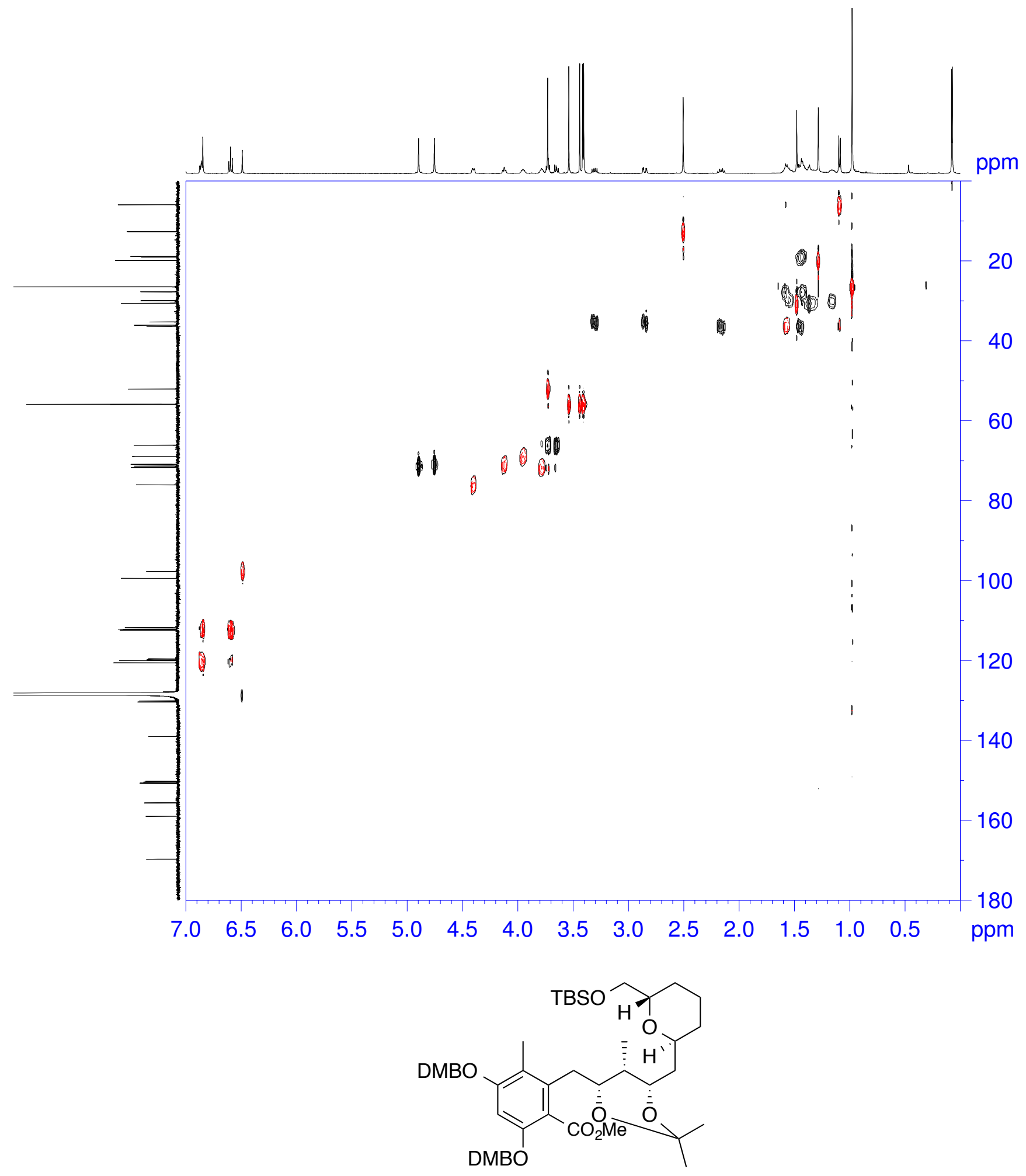

2D-HSQC Spectrum of Compound (-)-27 in $\mathrm{C}_{6} \mathrm{D}_{6}$ 


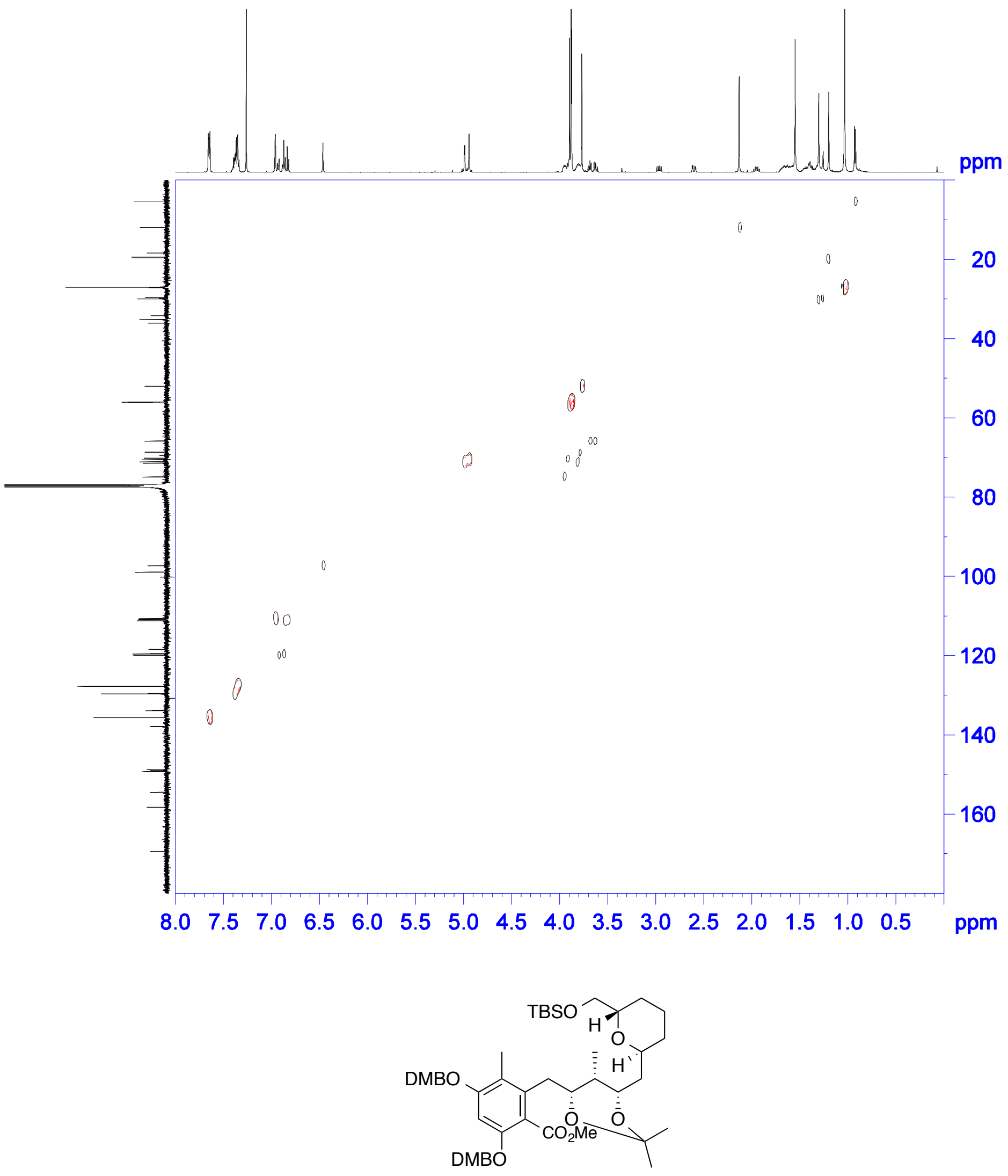

2D-HSQC Spectrum of Compound (-)-27 in $\mathrm{CDCl}_{3}$ 


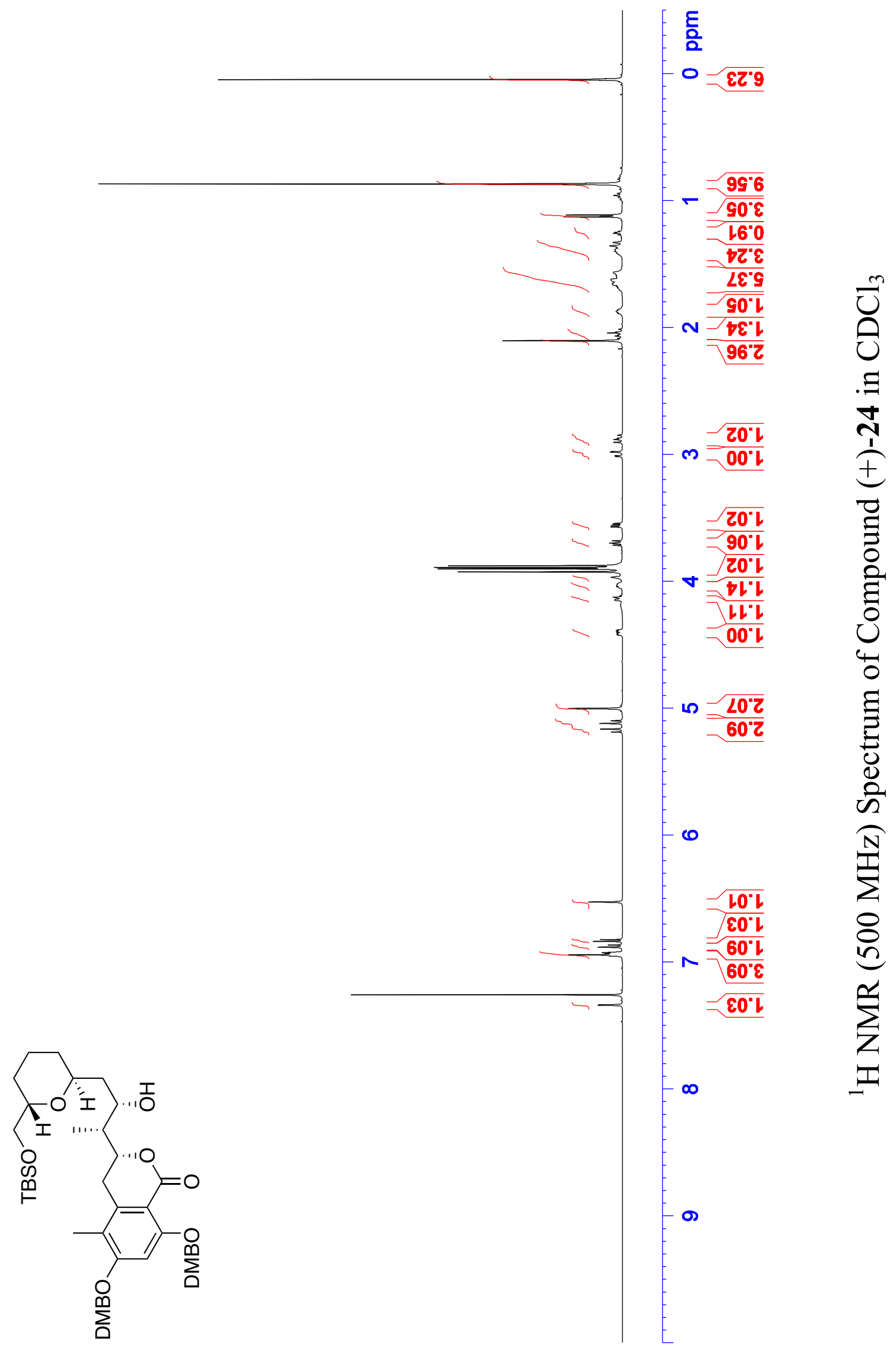




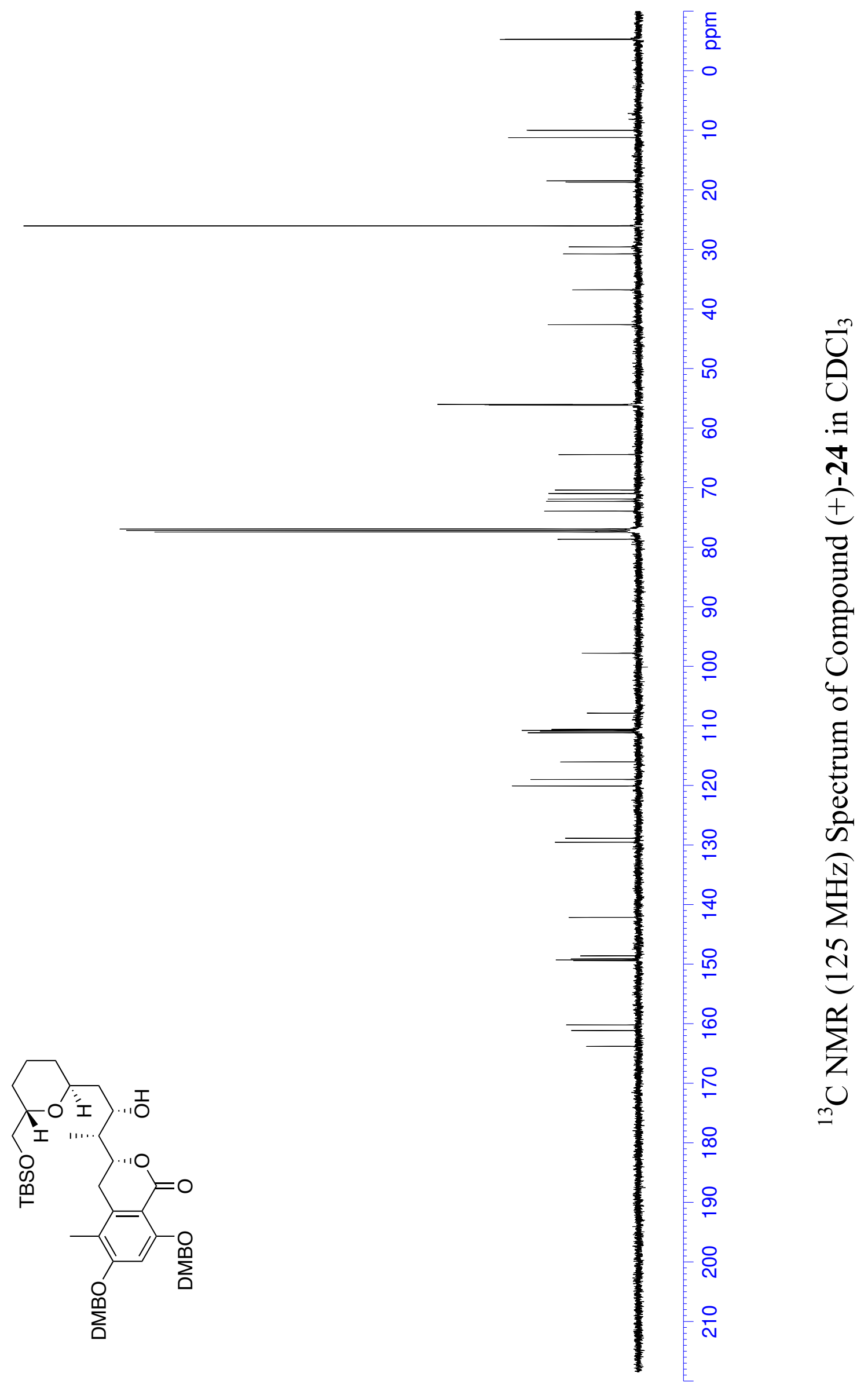




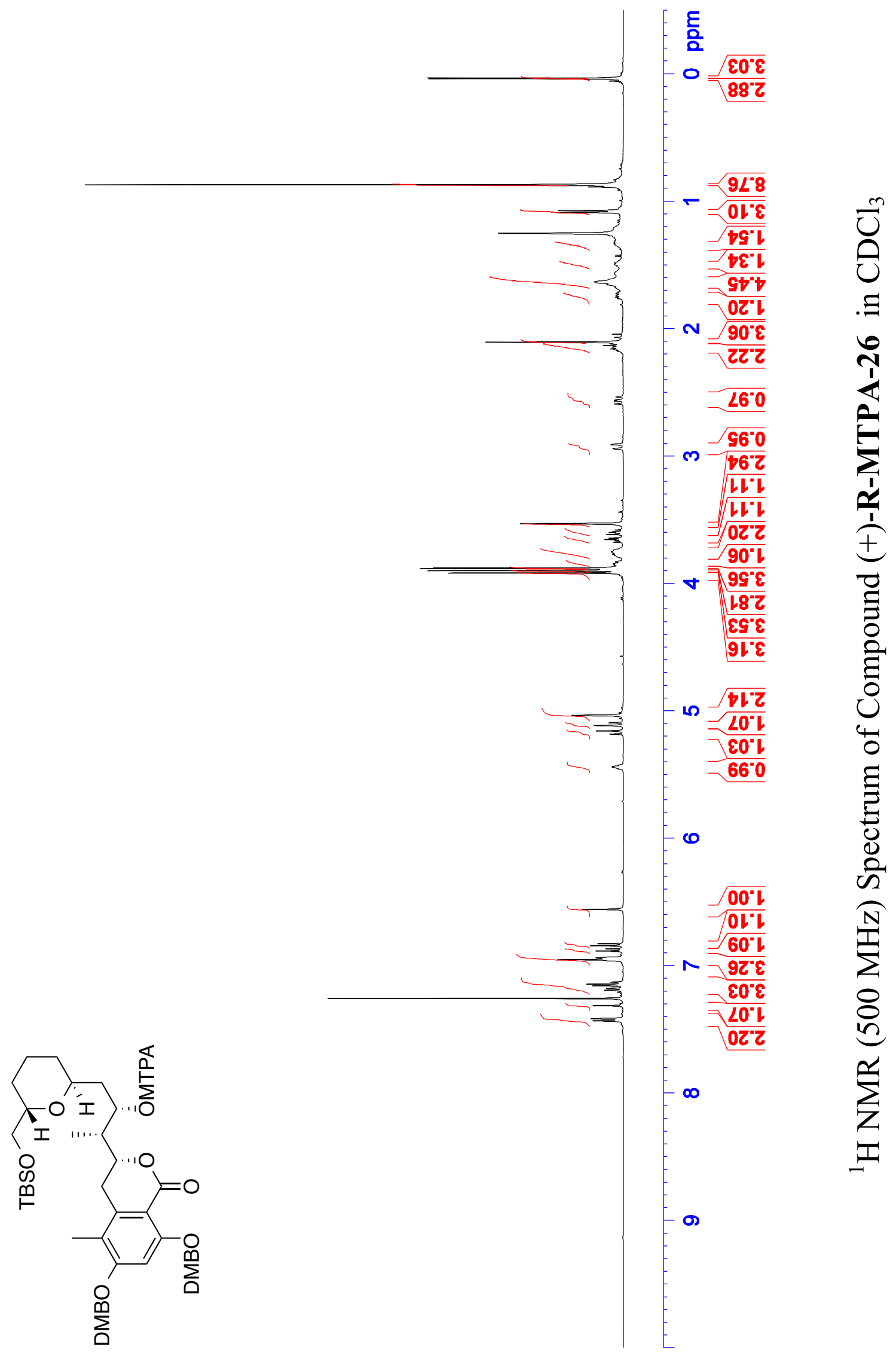




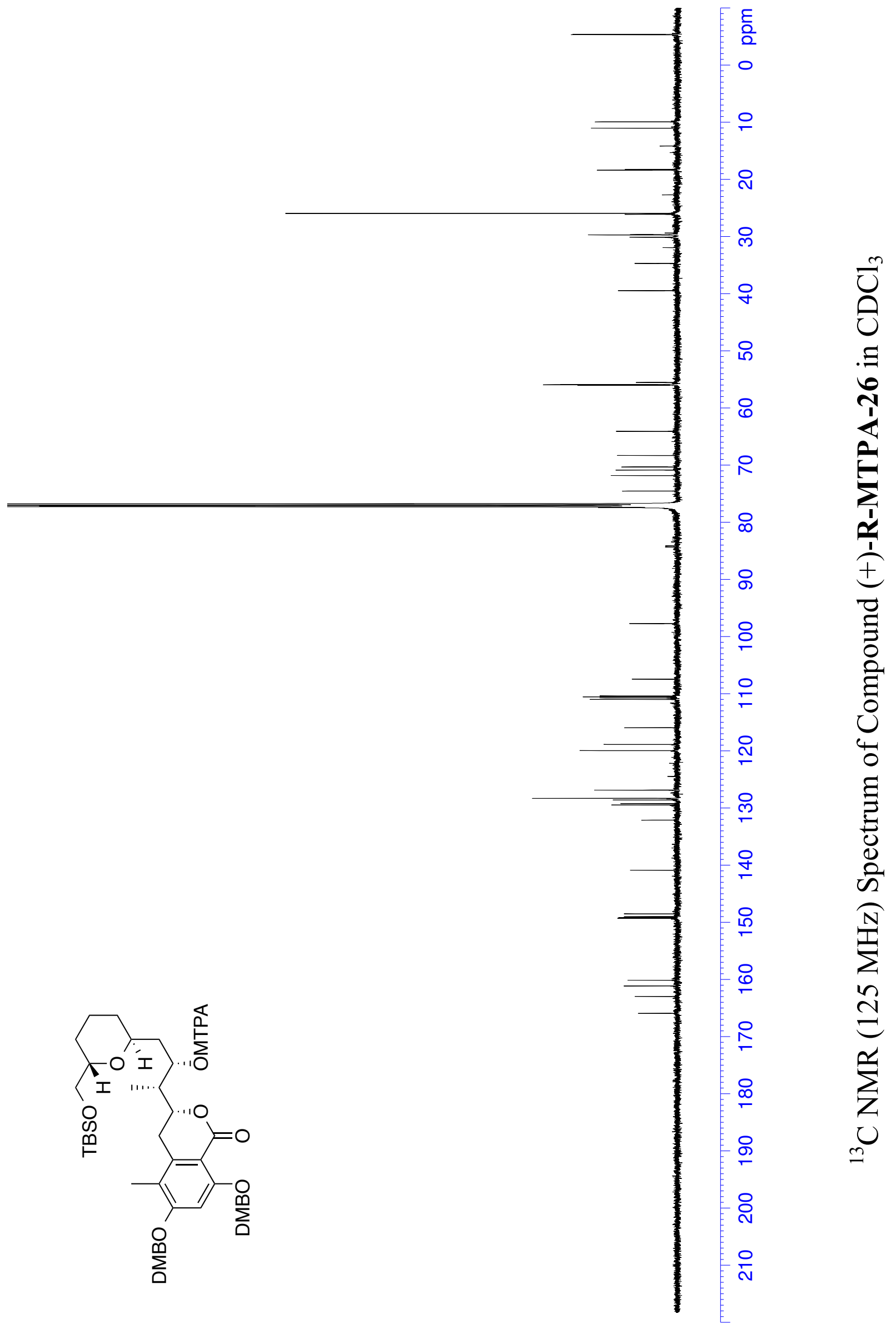




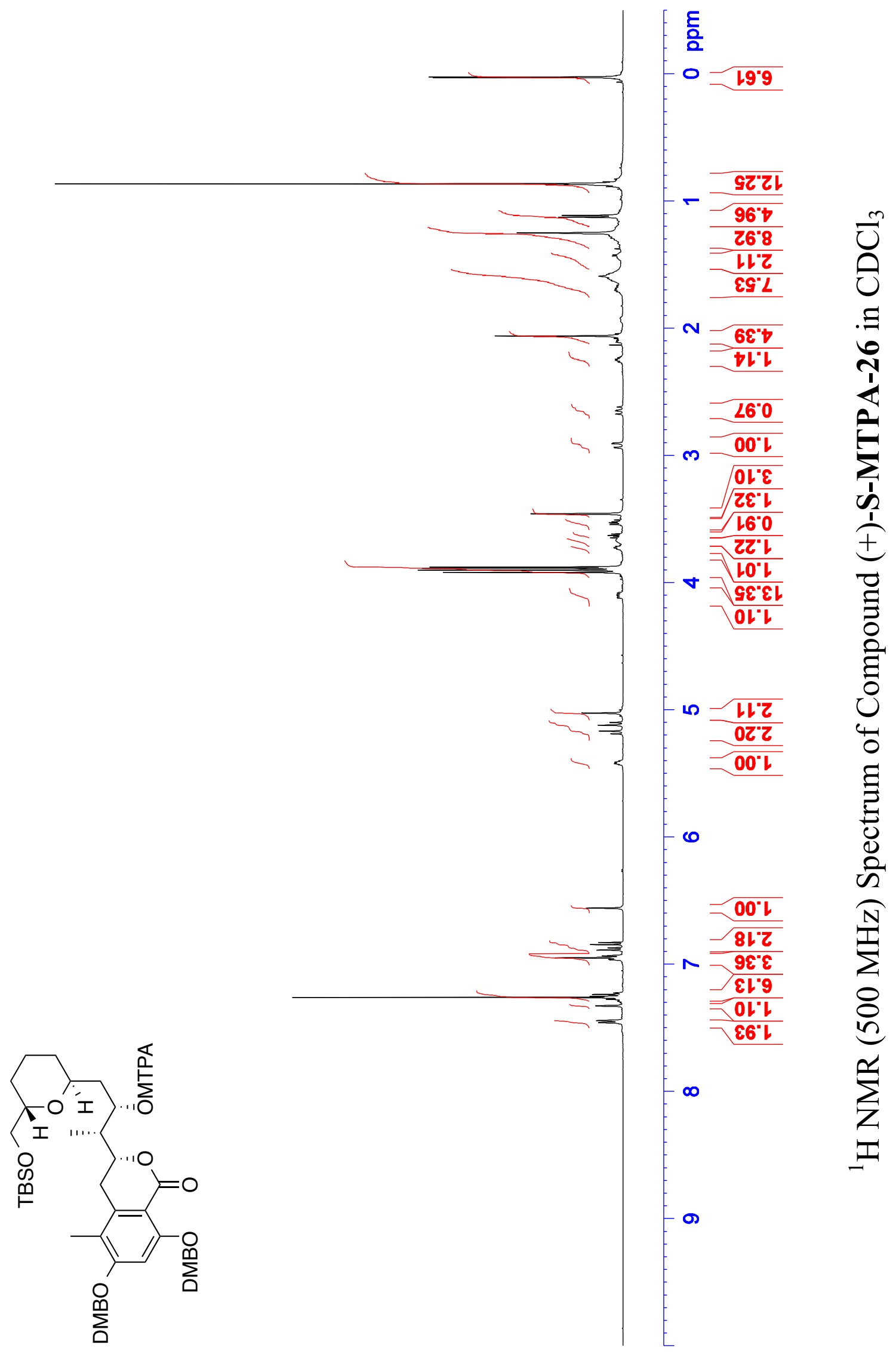




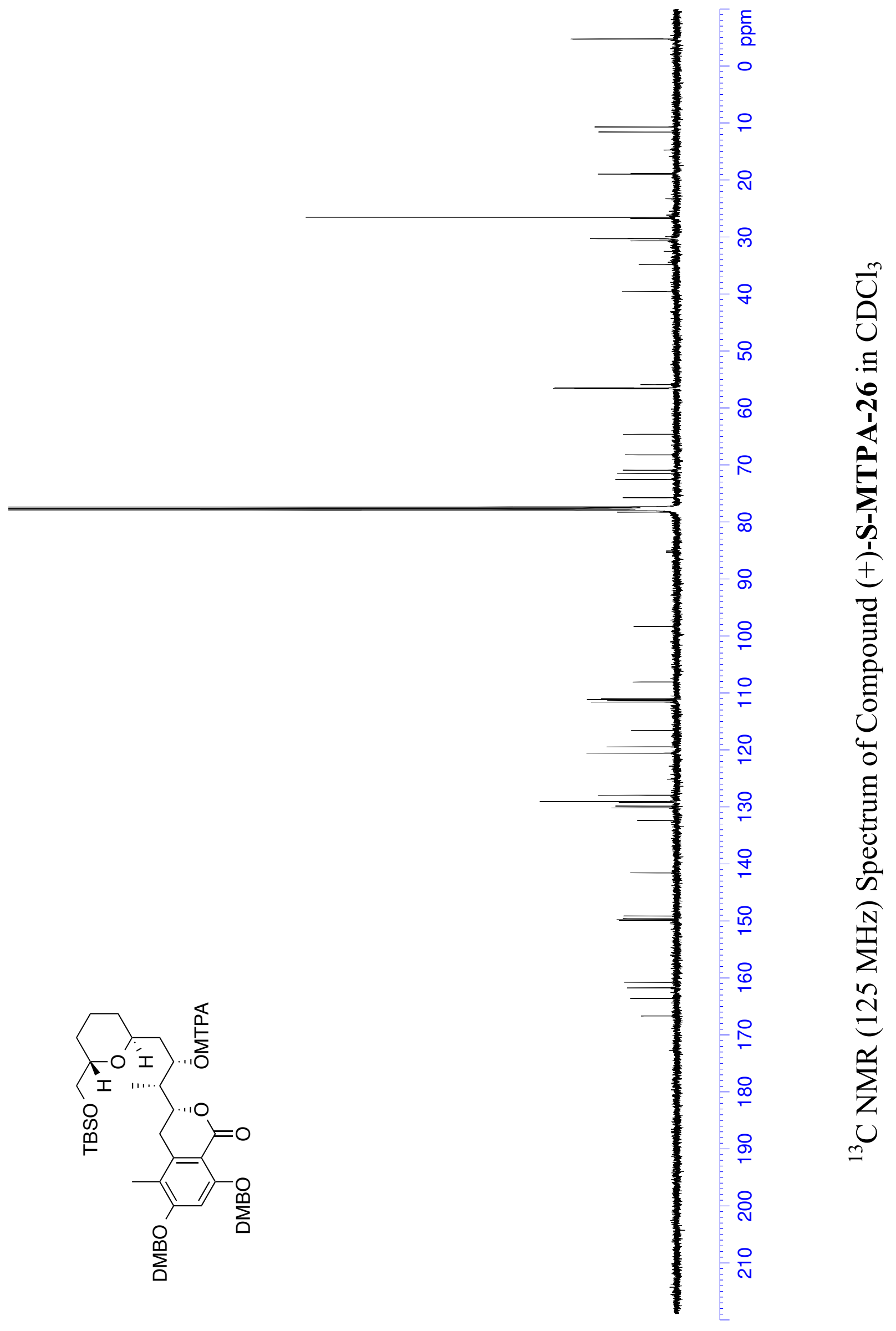




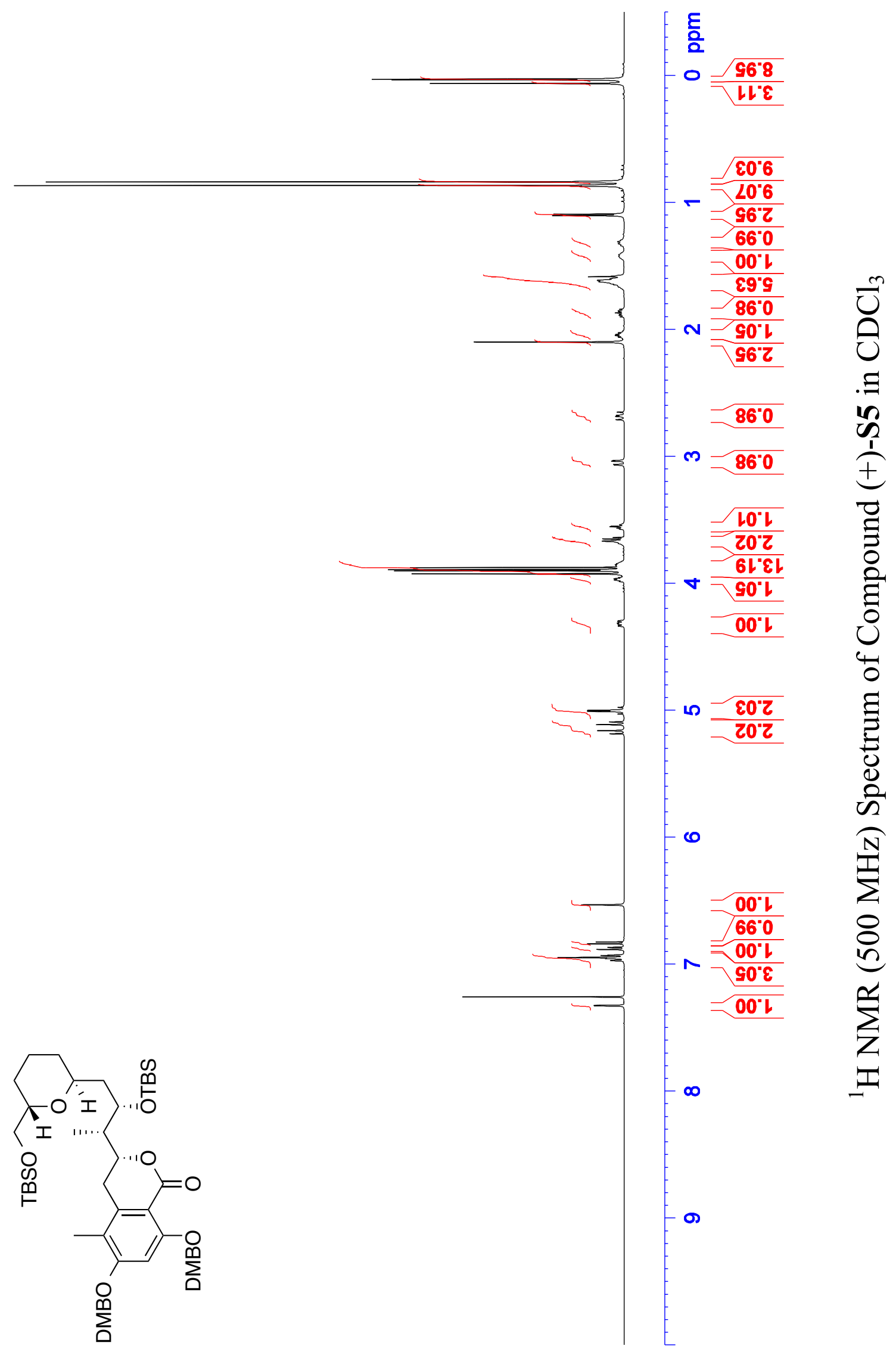




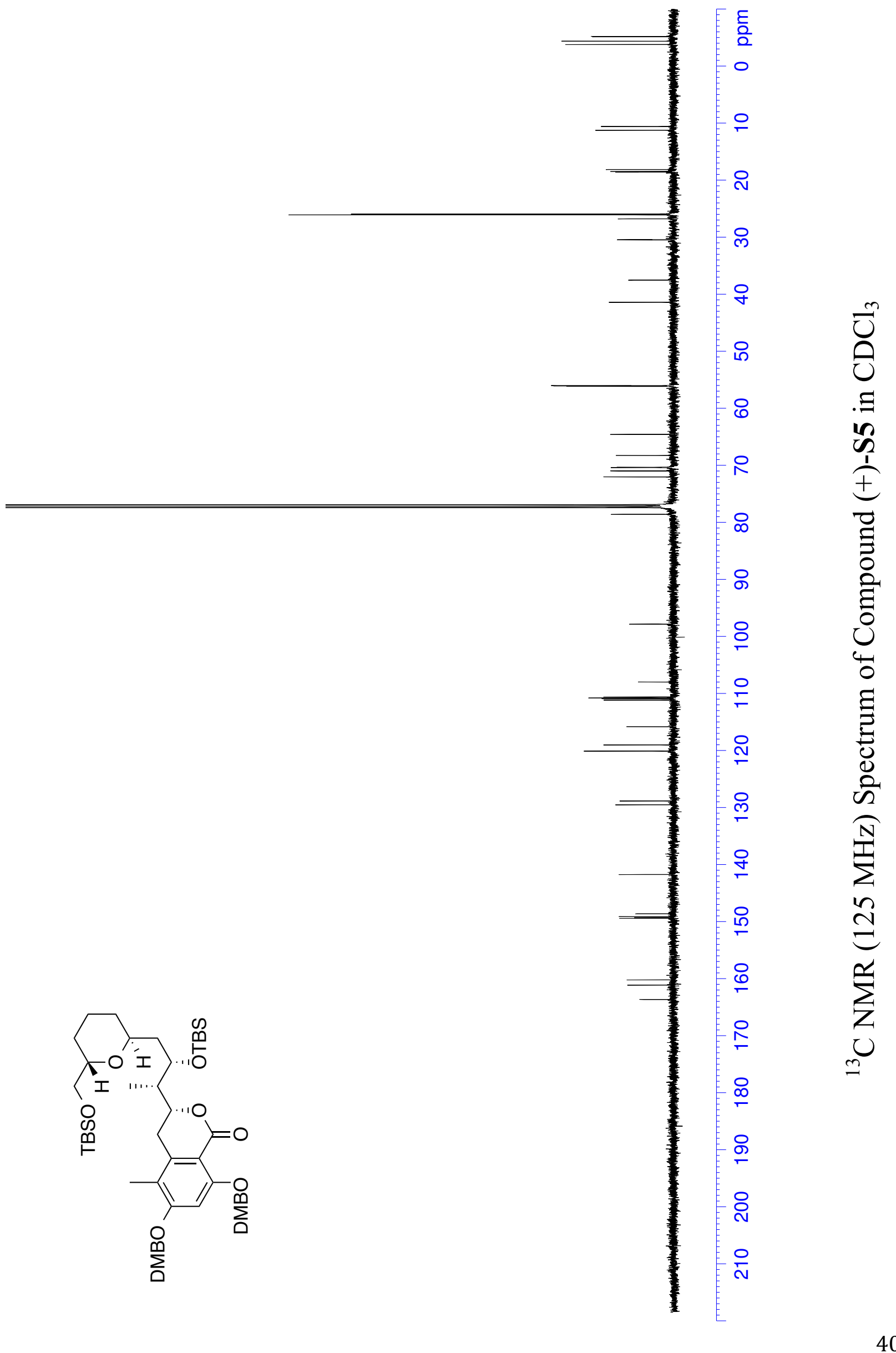




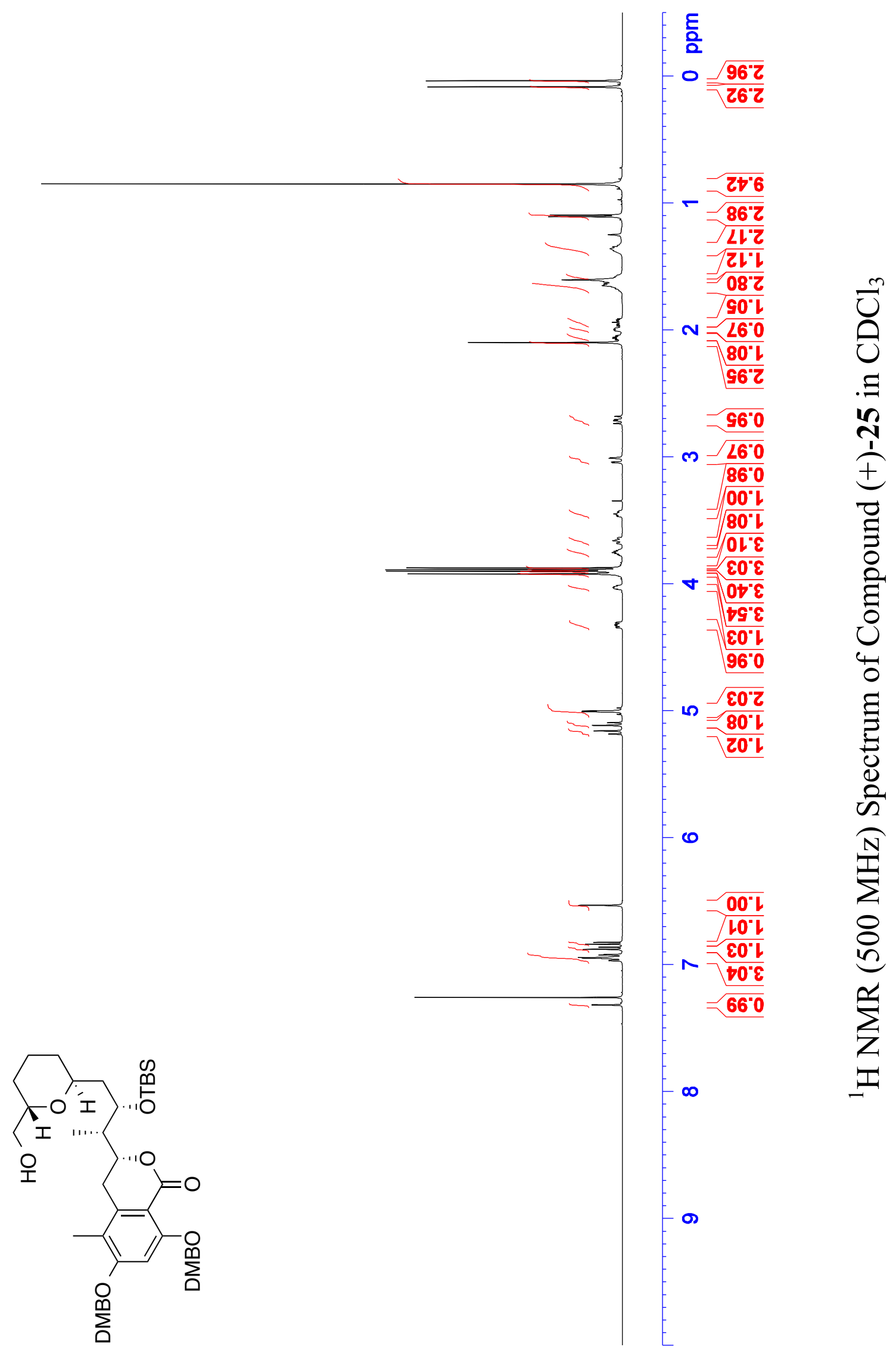




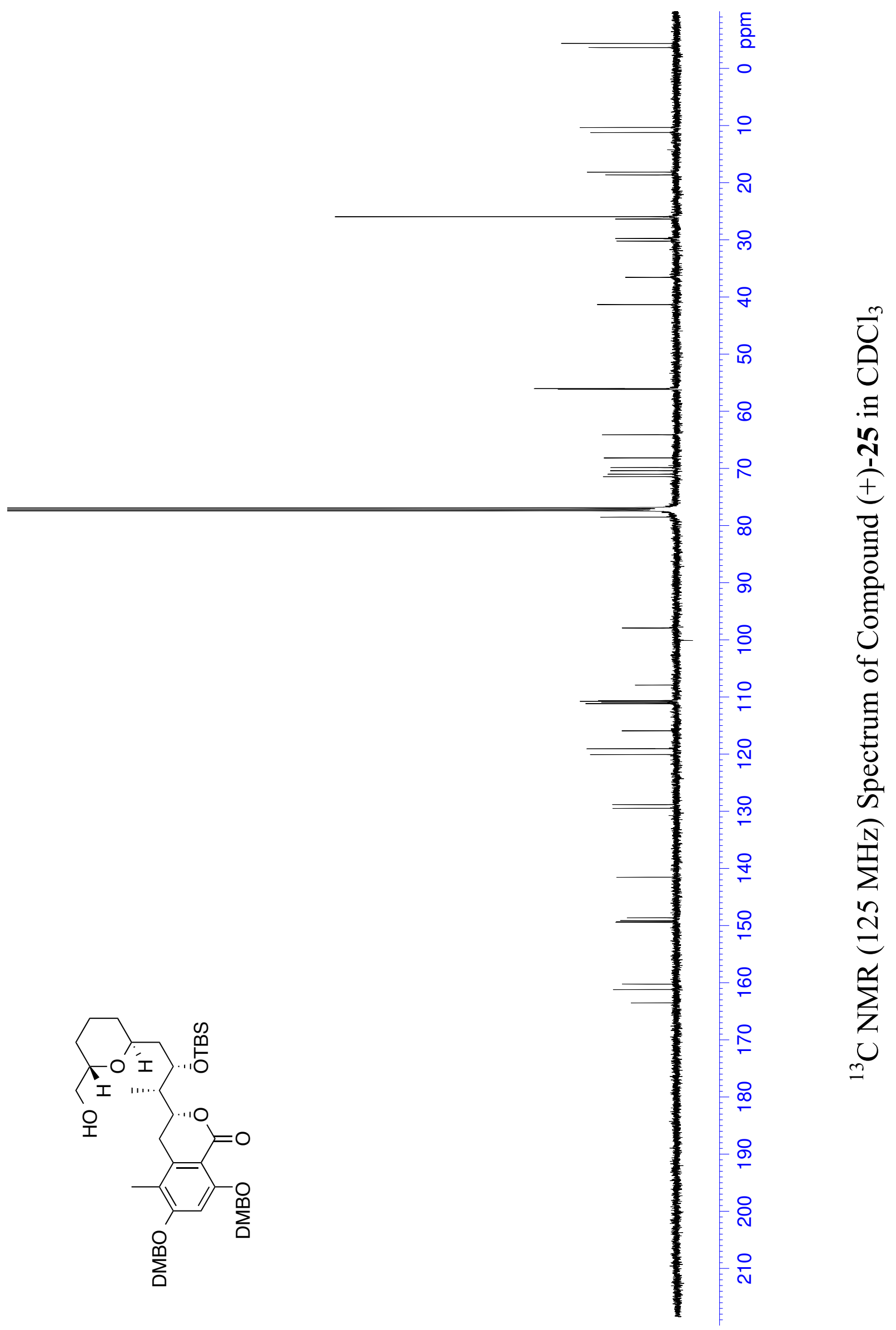




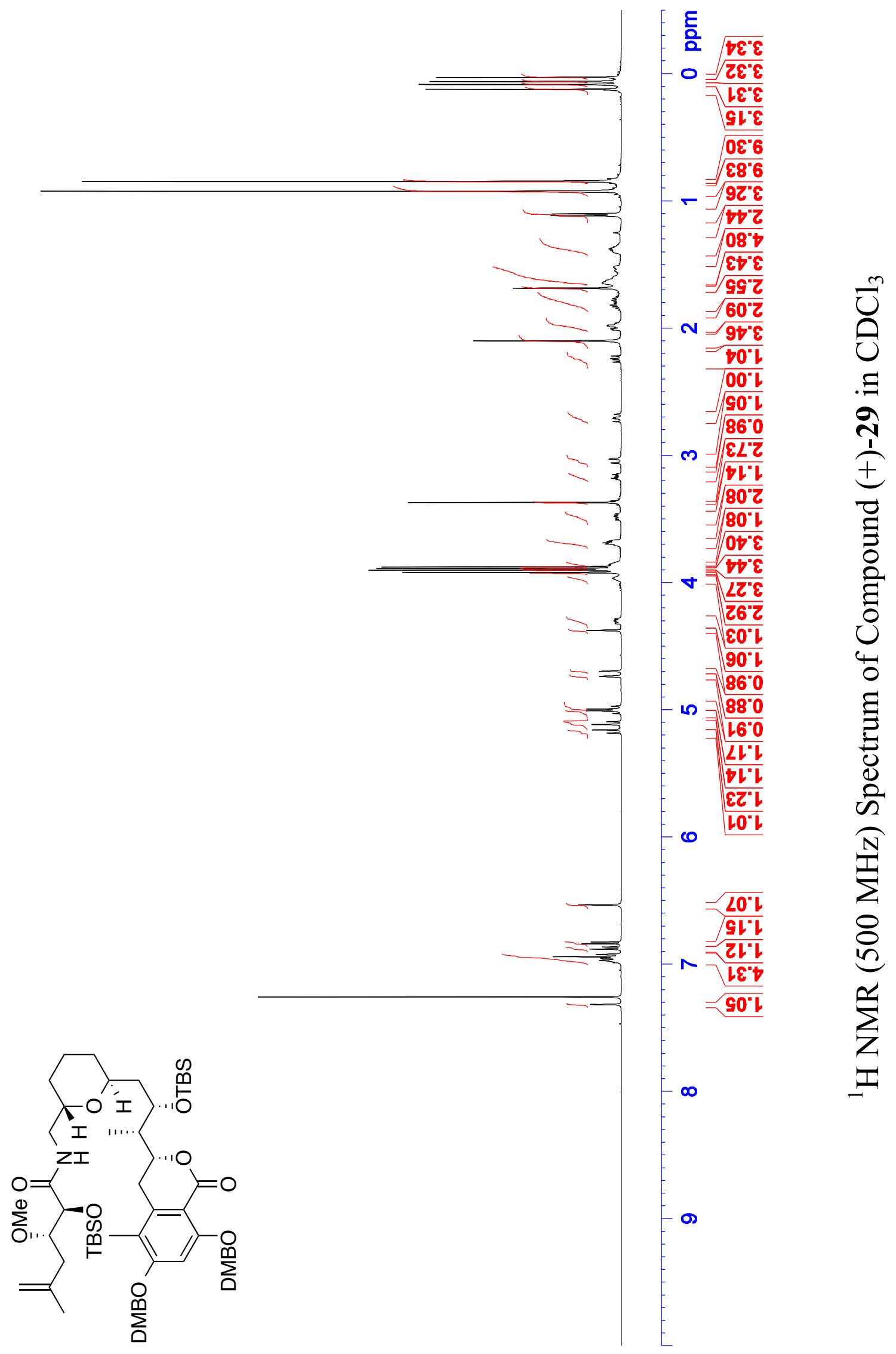




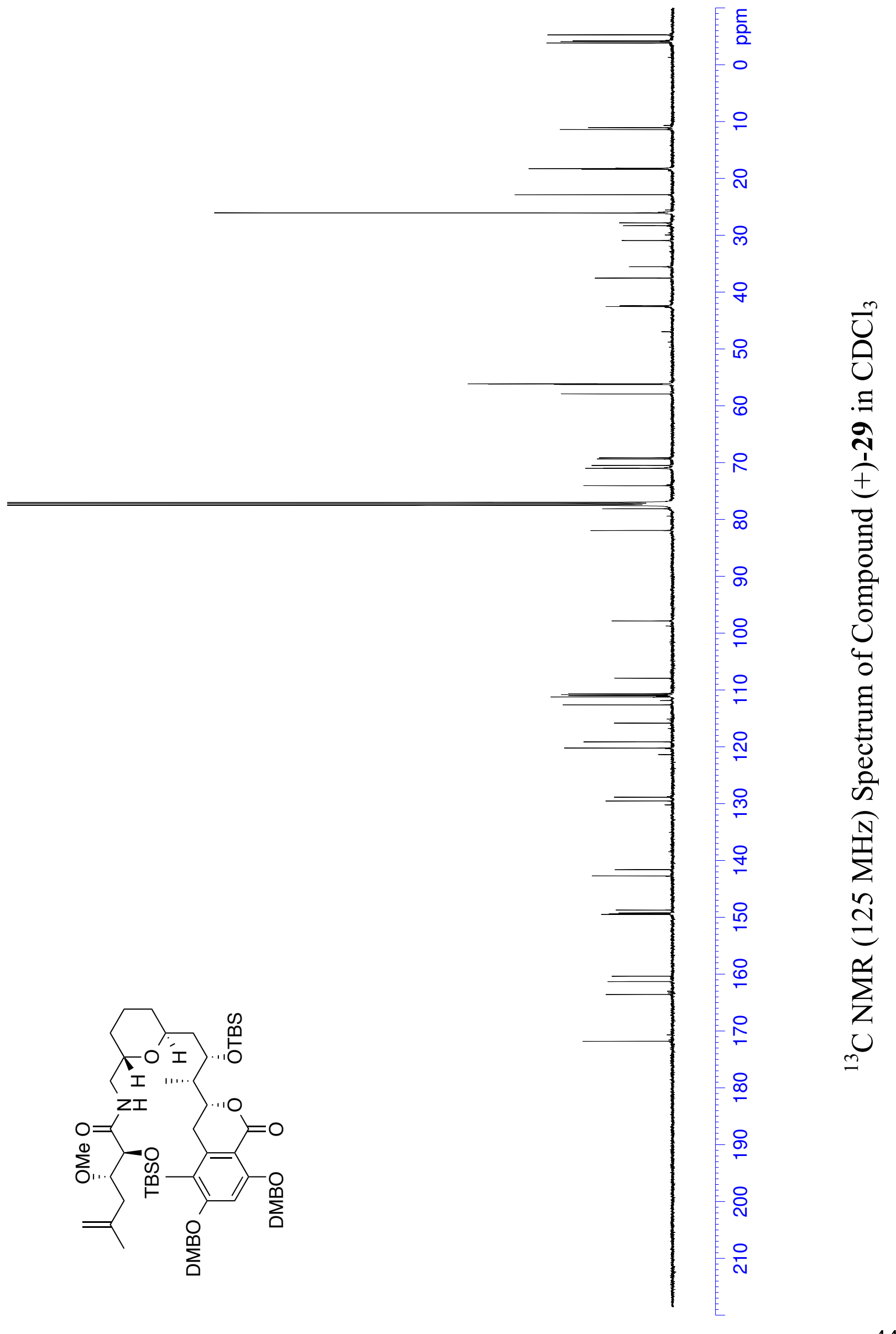




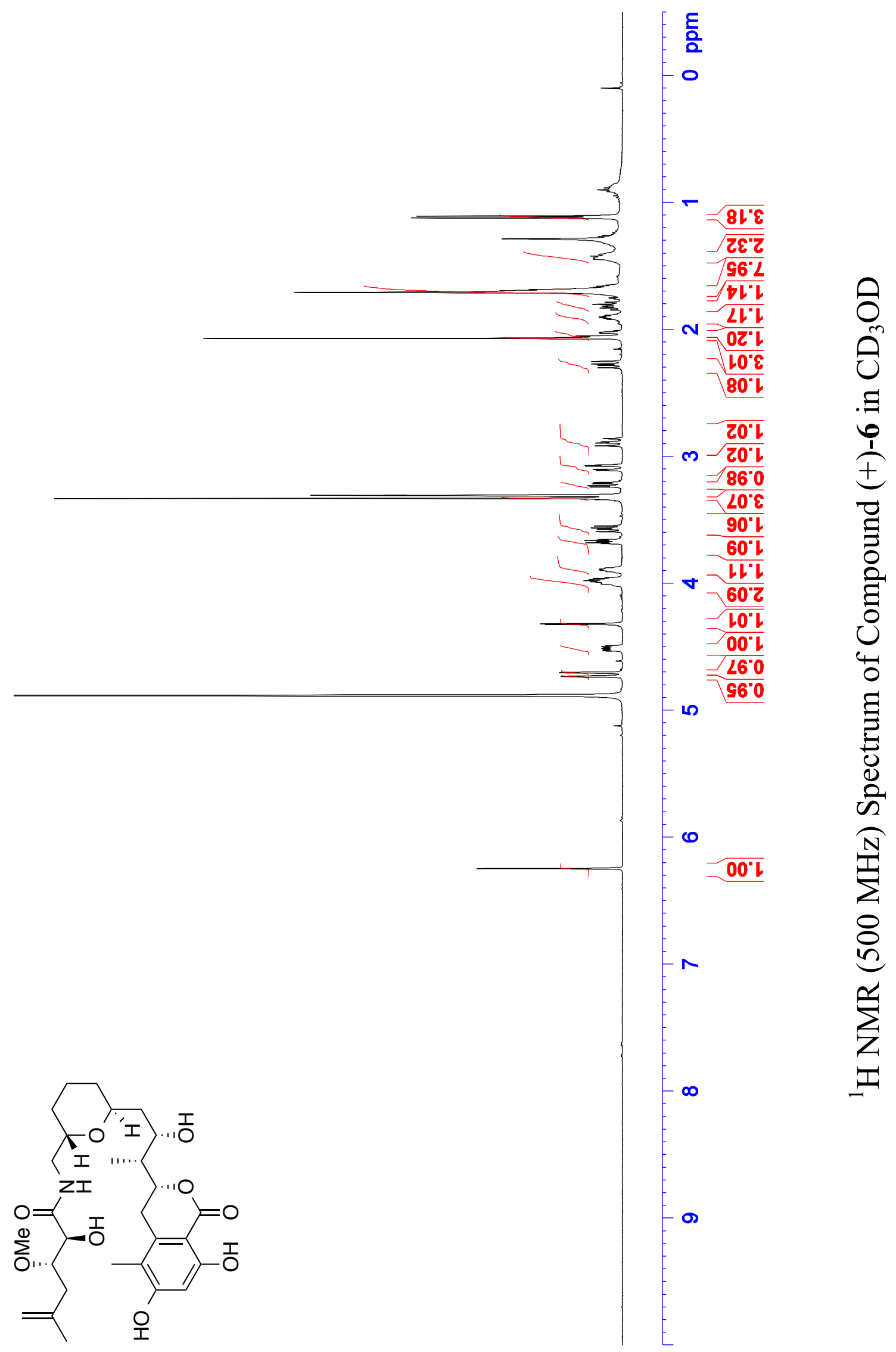




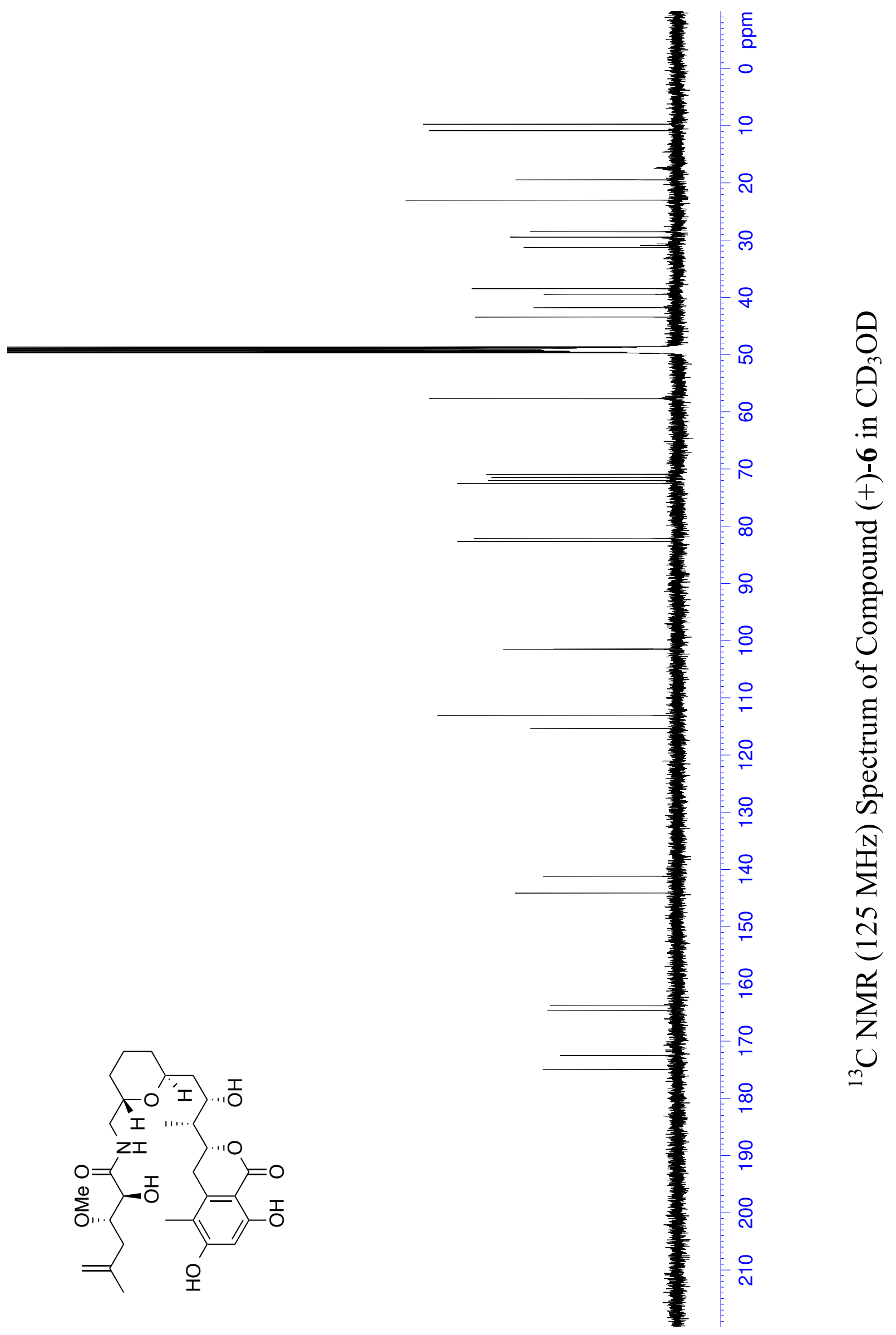




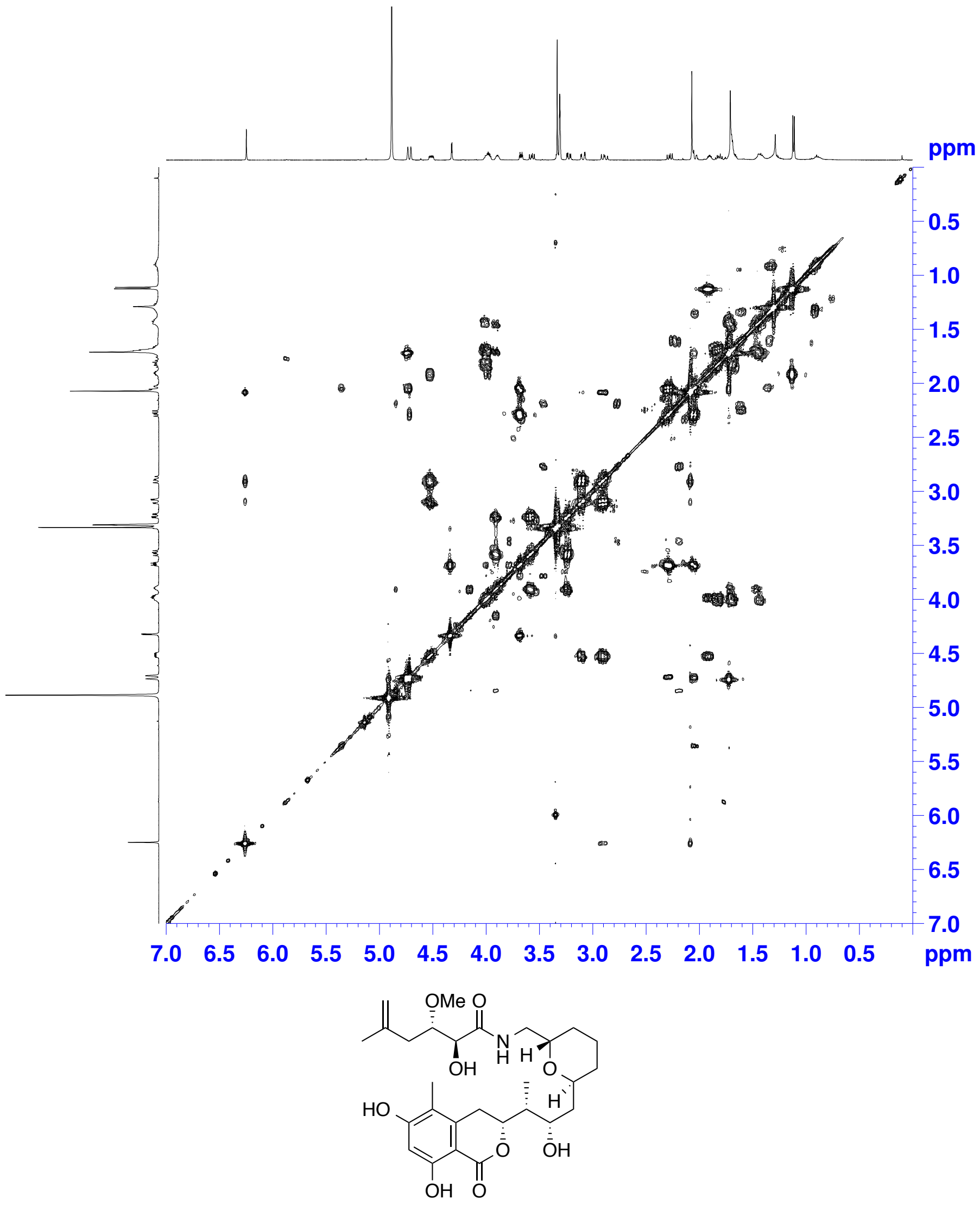

2D-COSY Spectrum of Compound (-)-6 in $\mathrm{CD}_{3} \mathrm{OD}$ 


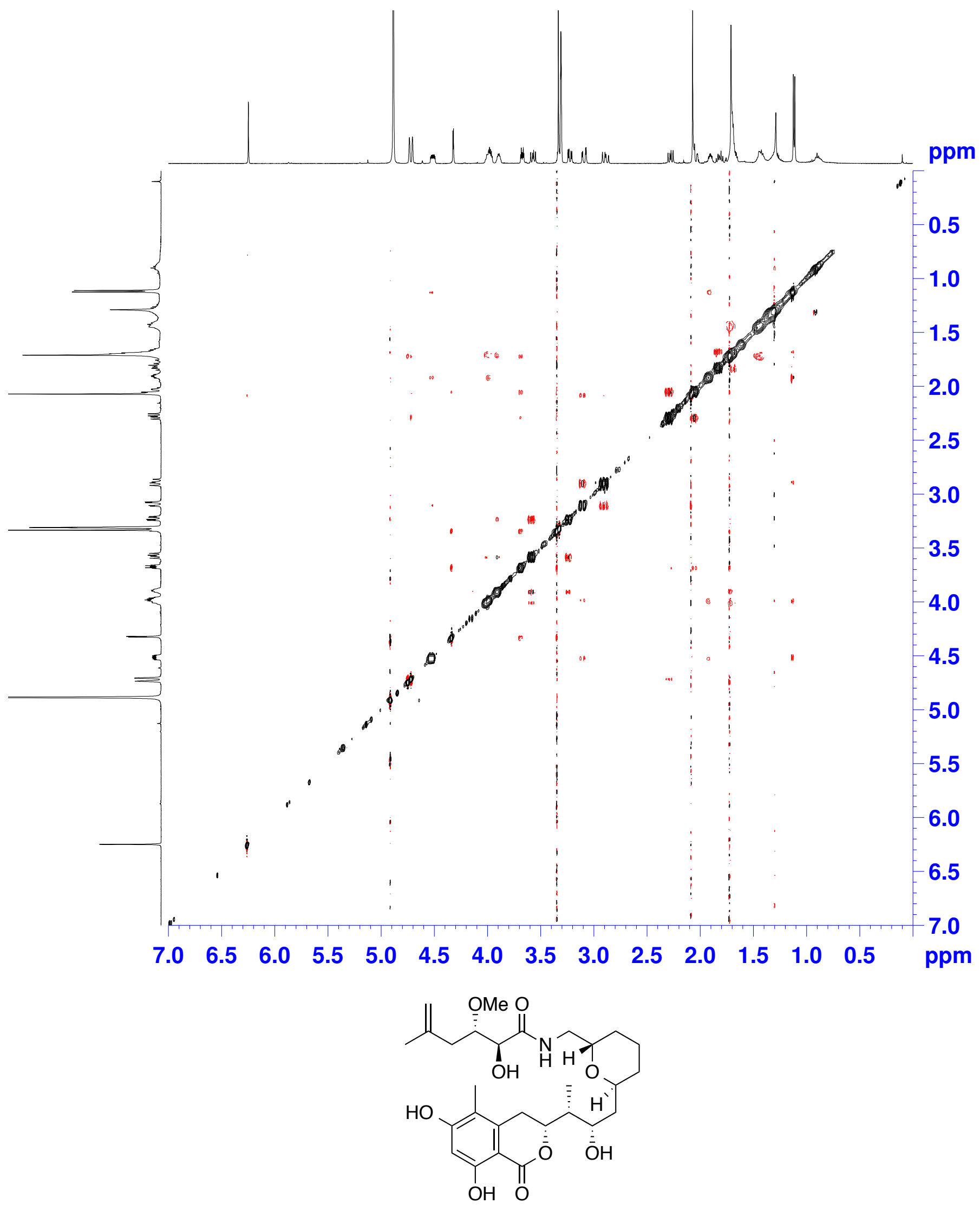

2D-ROESY Spectrum of Compound (-)-6 in $\mathrm{CD}_{3} \mathrm{OD}$ 


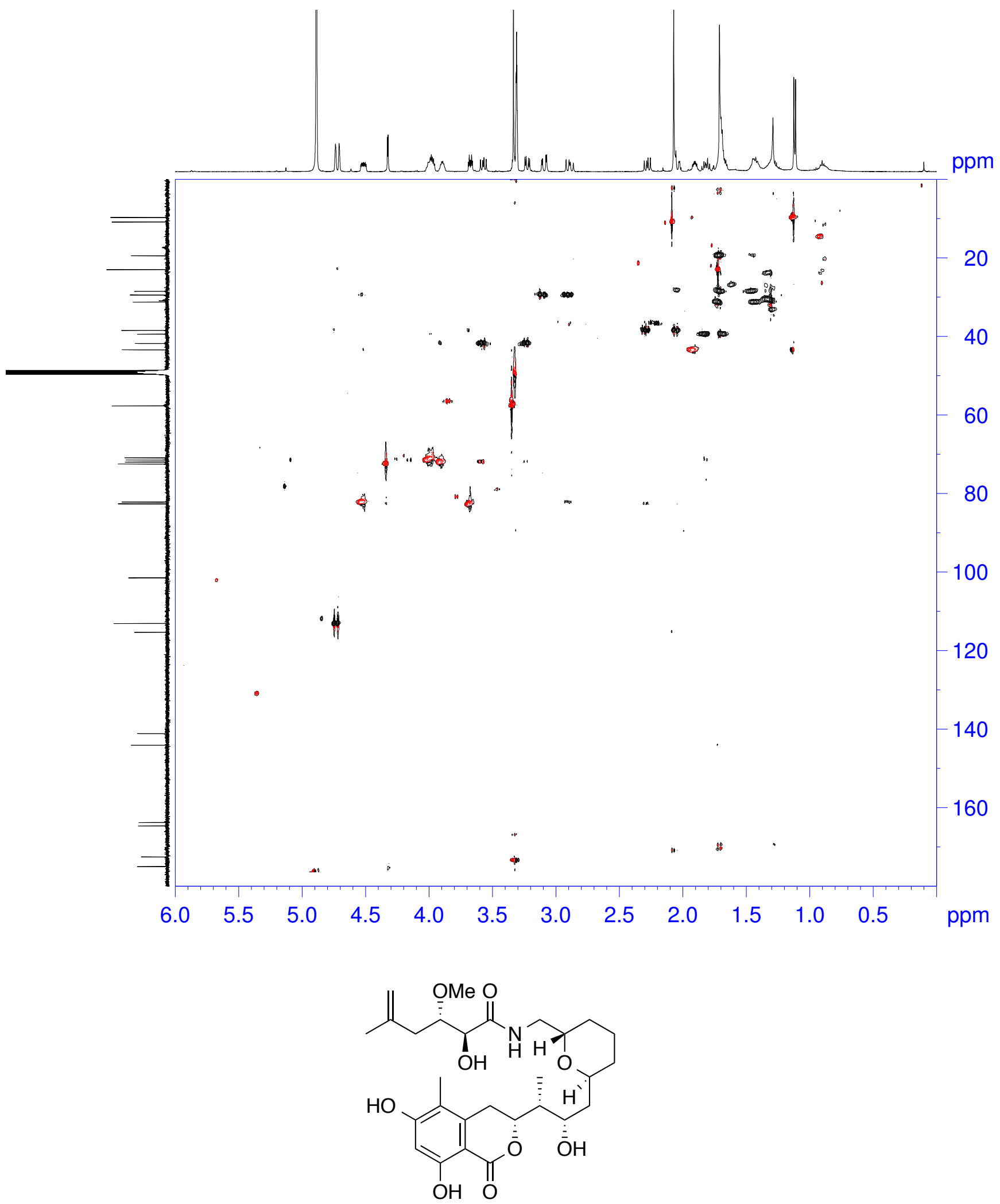

2D-HSQC Spectrum of Compound (-)-6 in $\mathrm{CD}_{3} \mathrm{OD}$ 


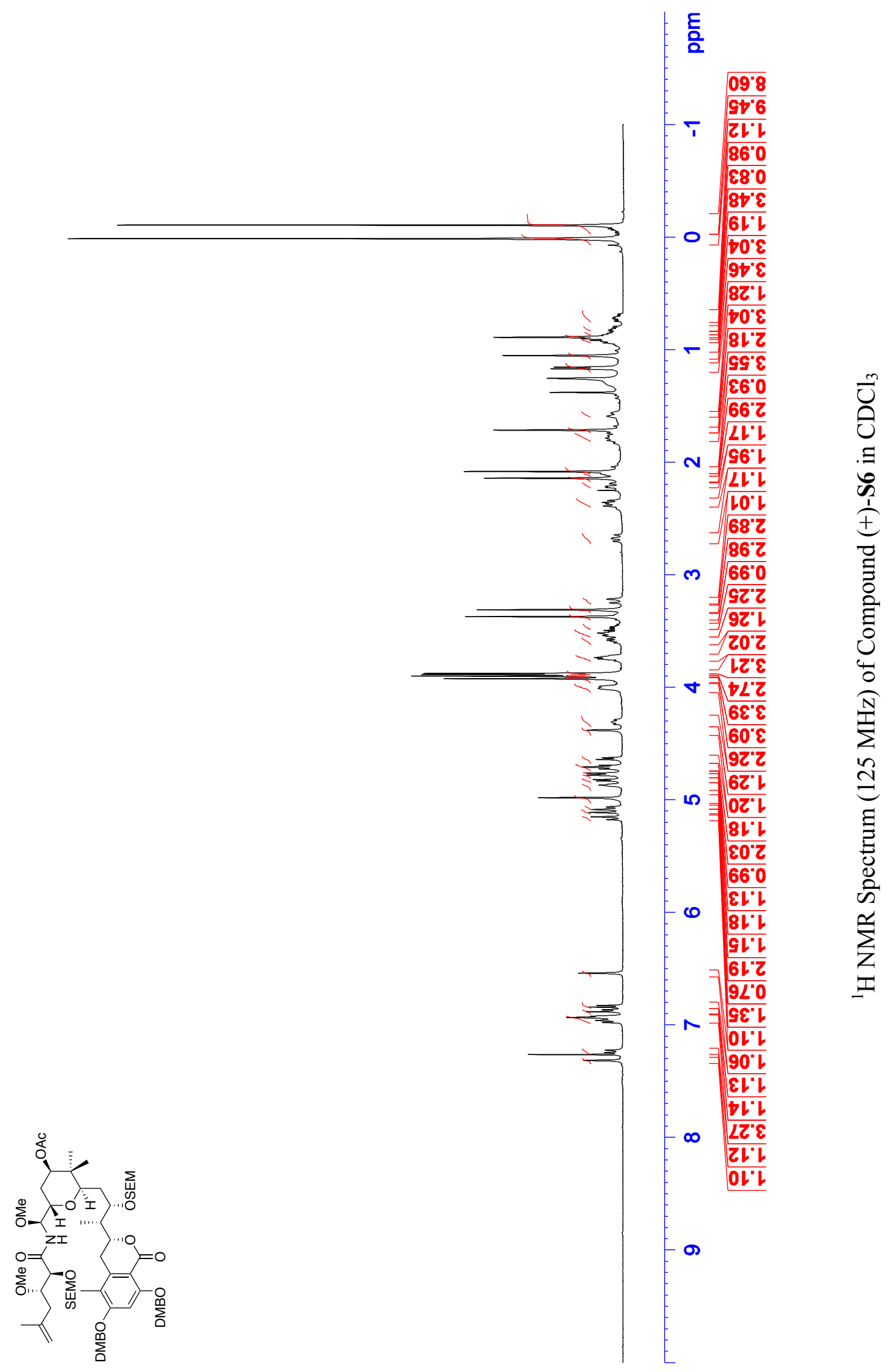




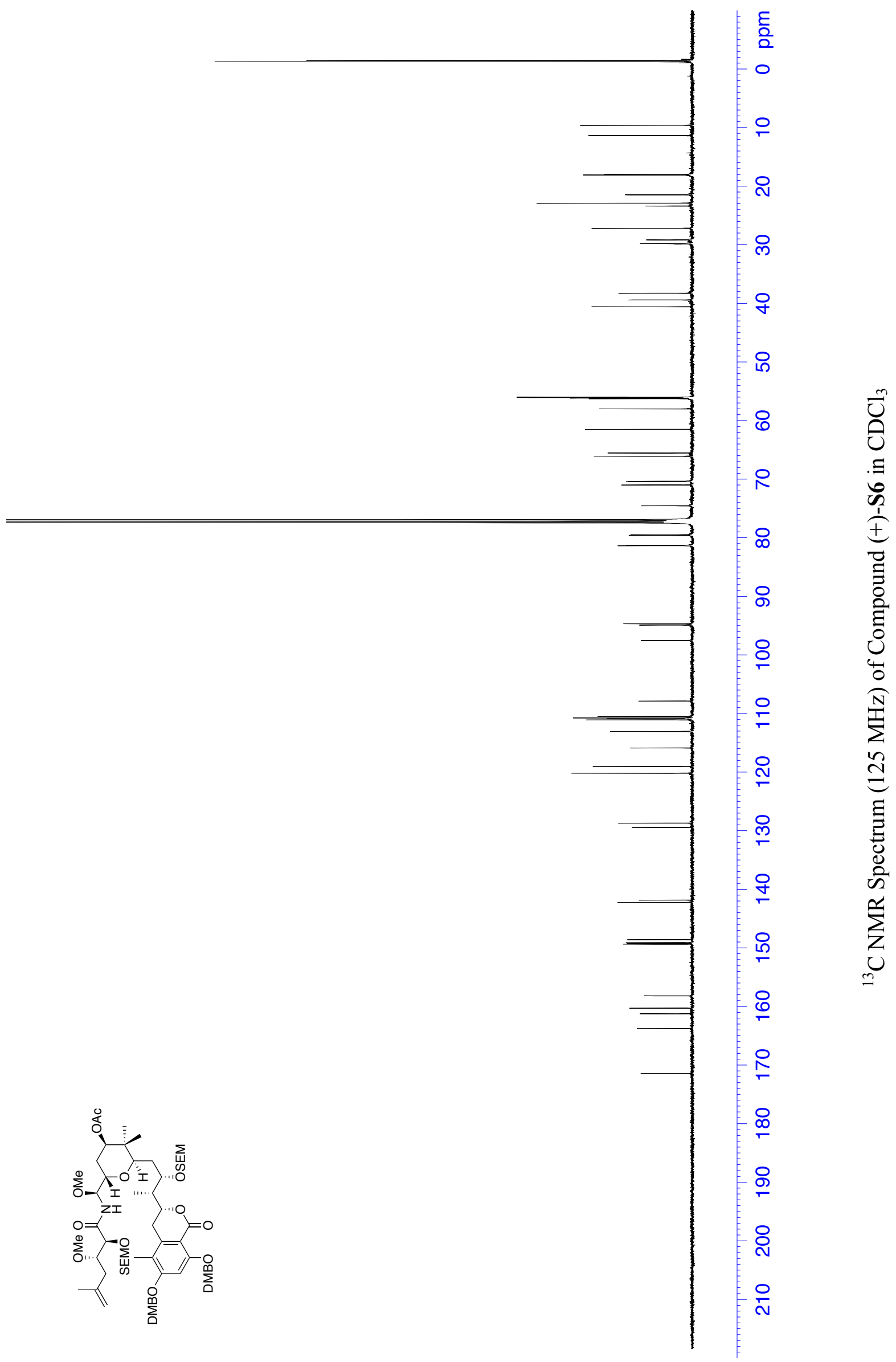




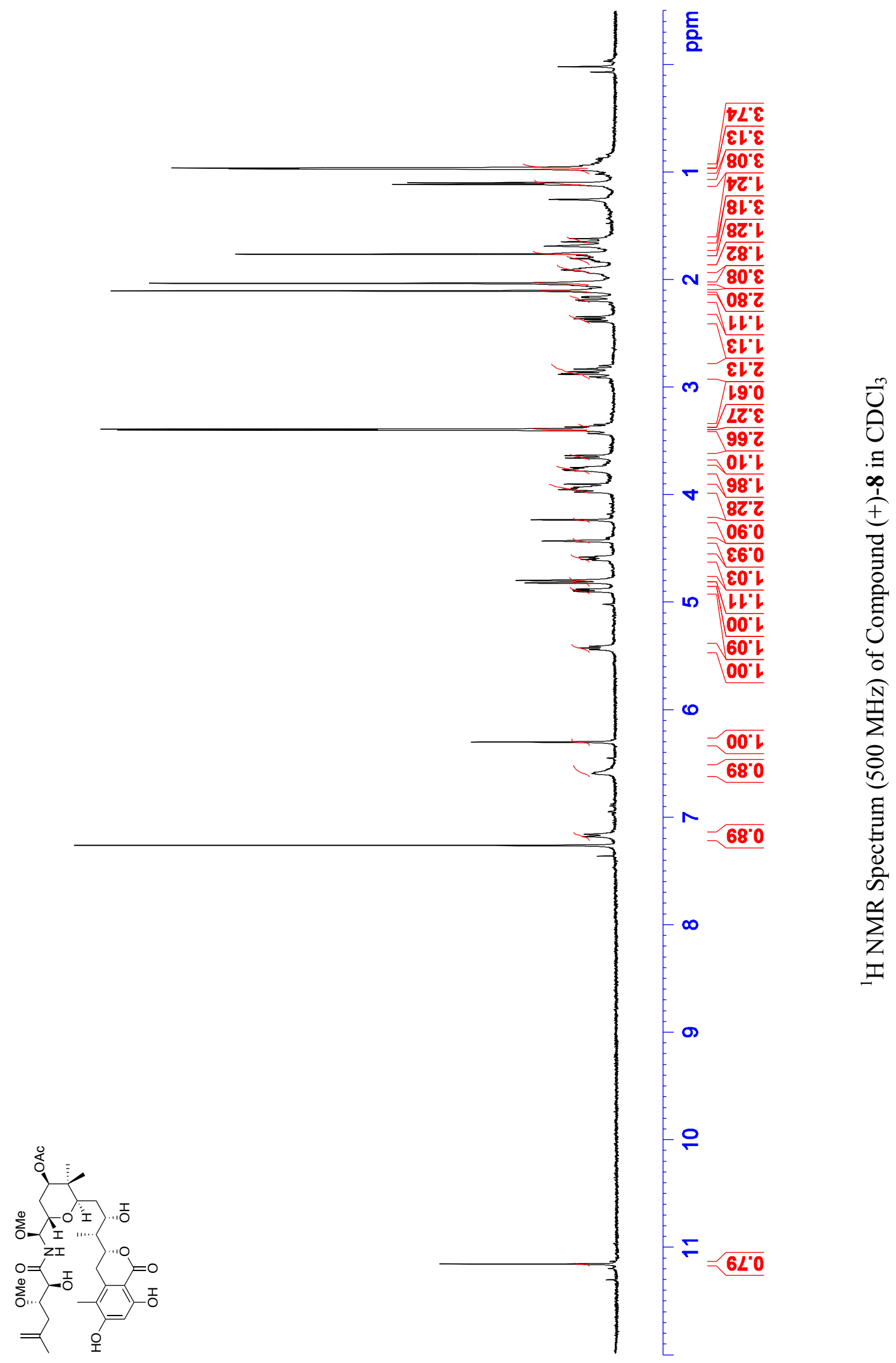




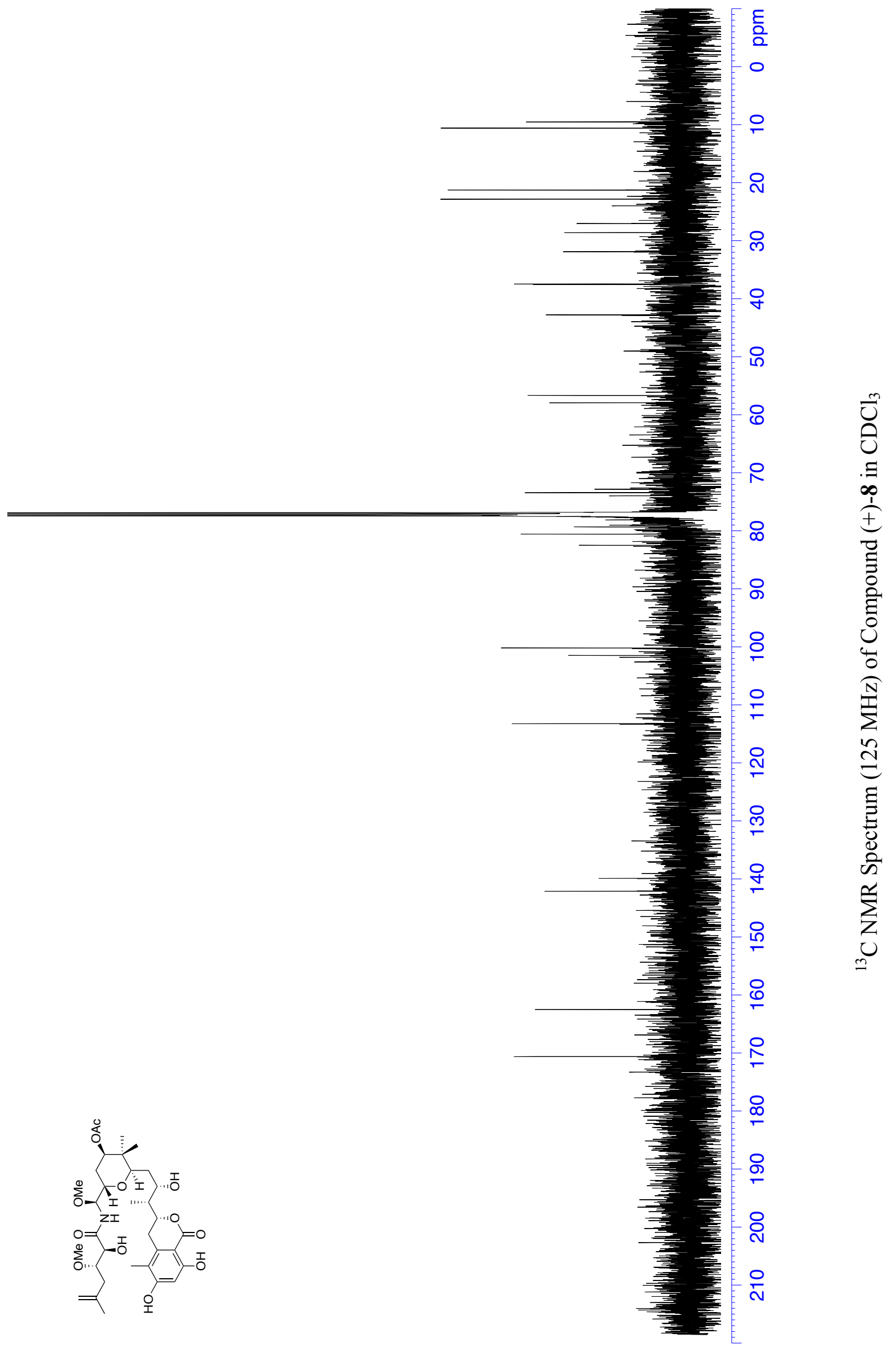




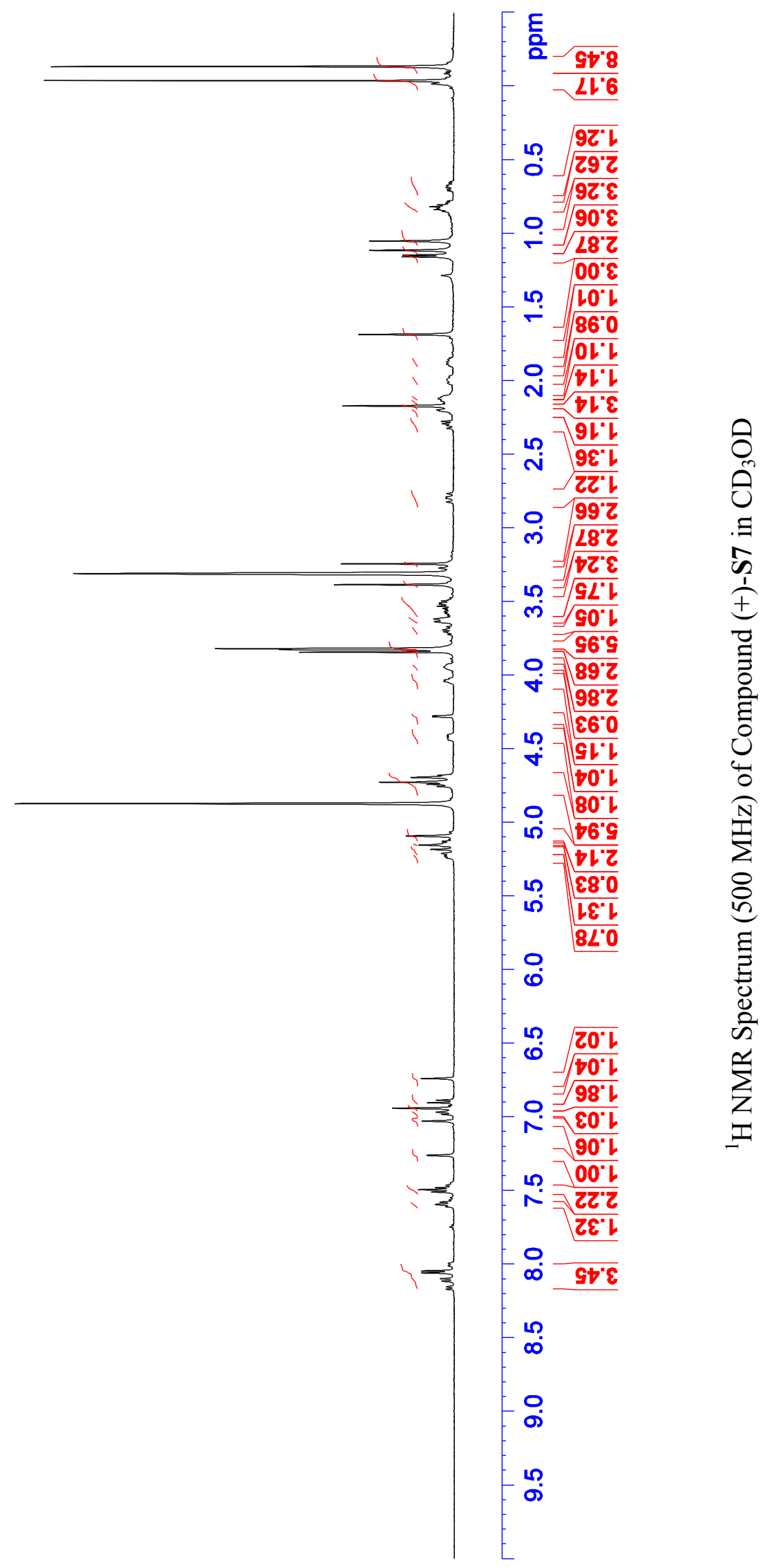




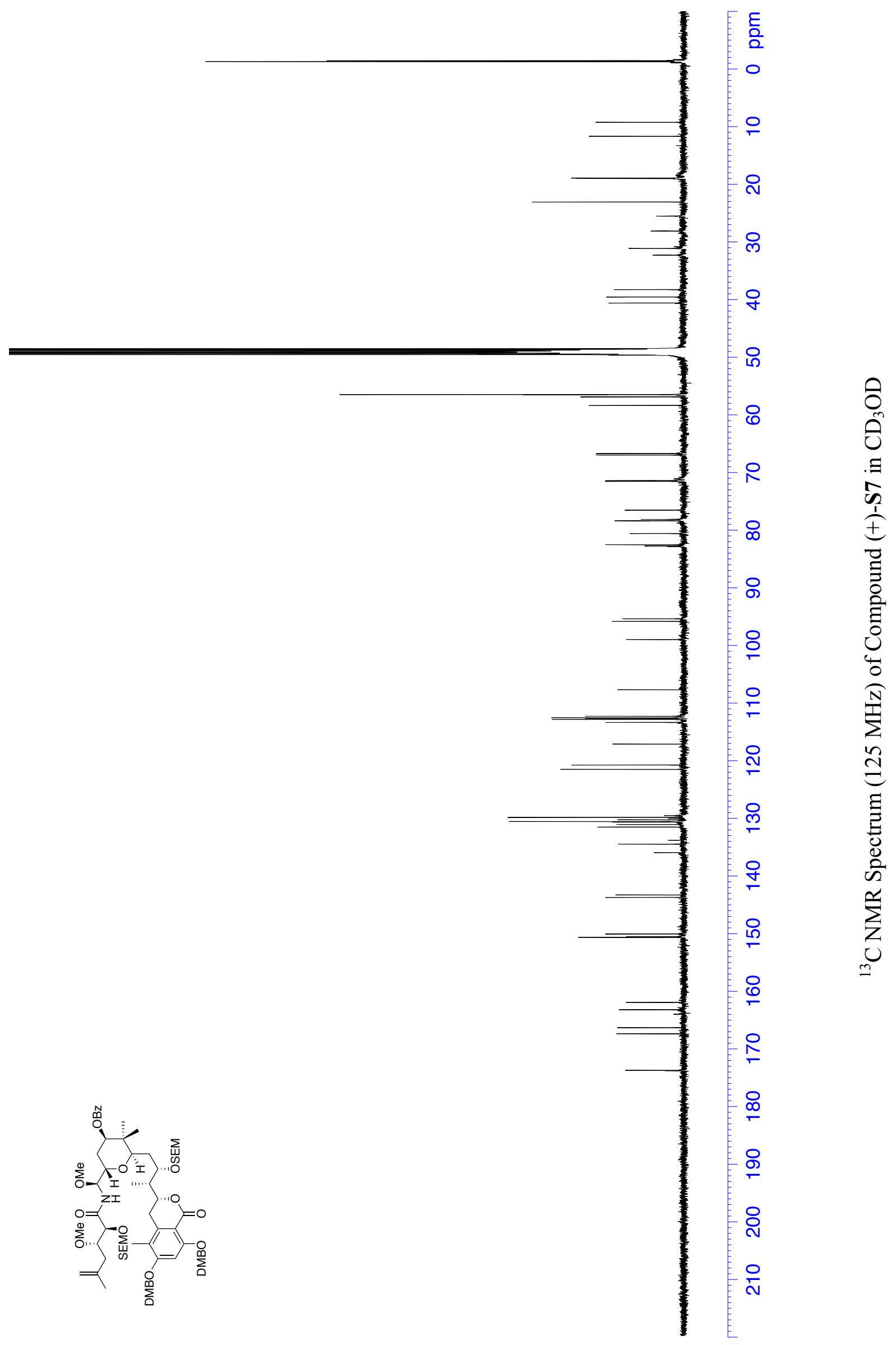




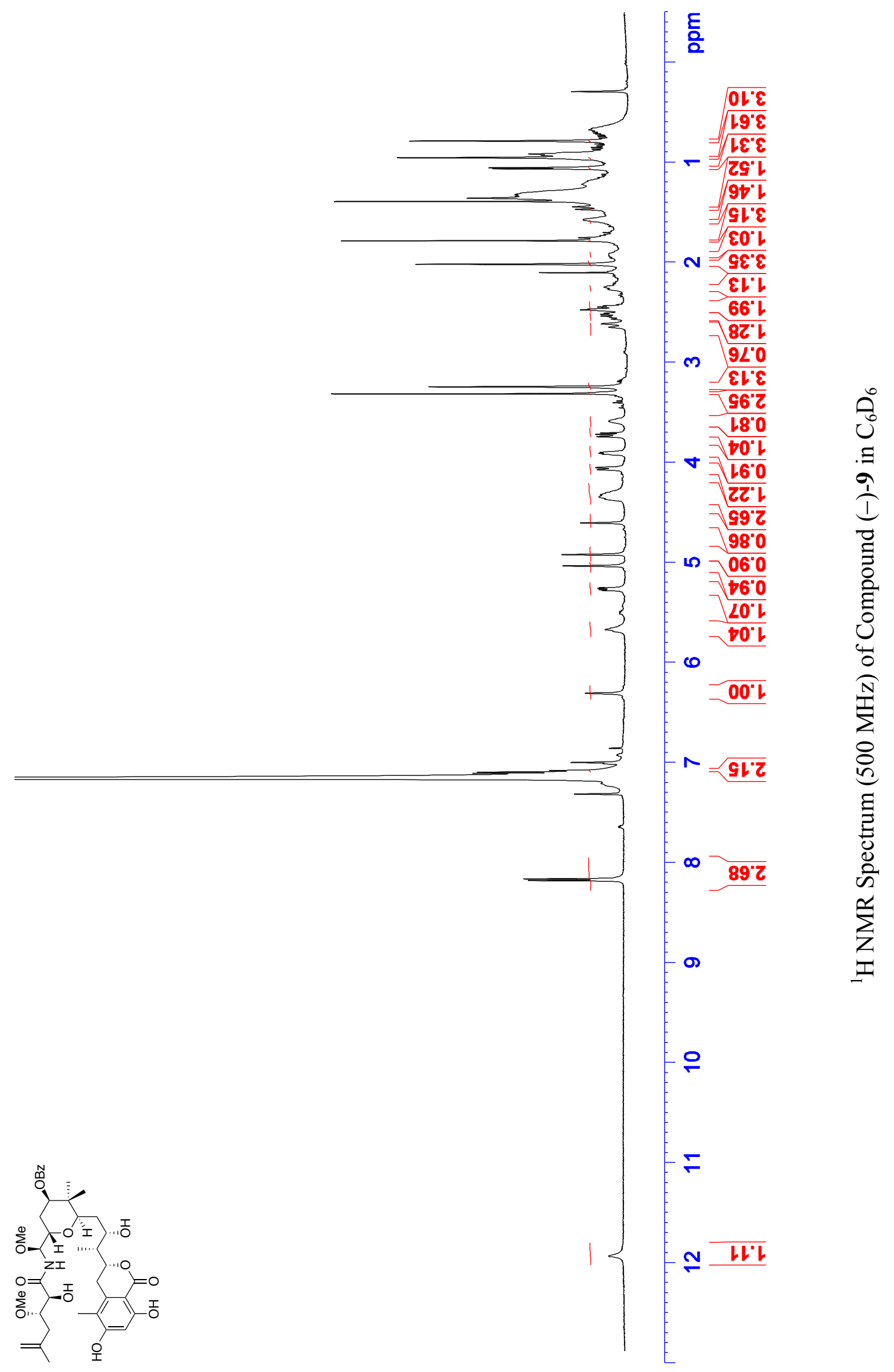




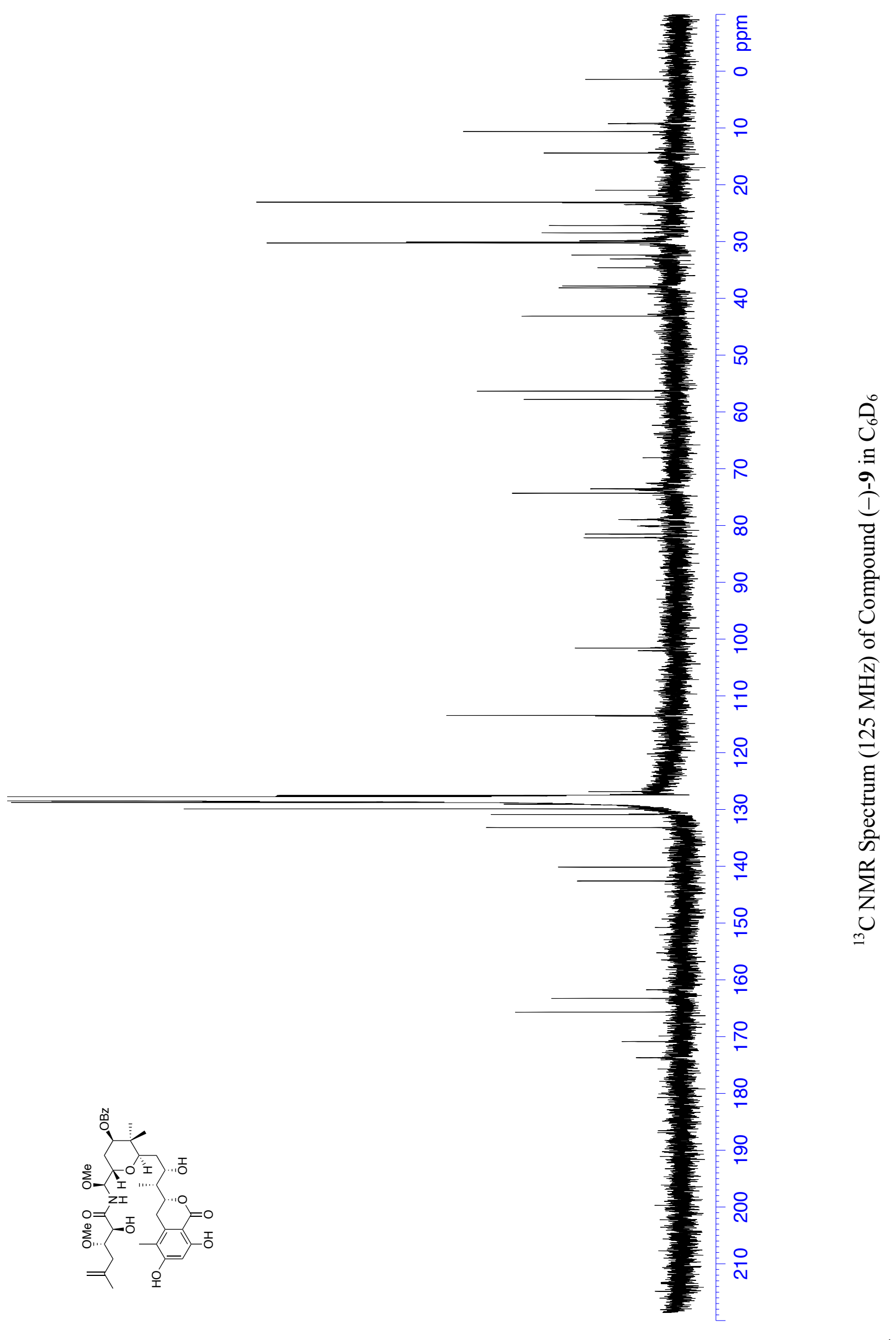




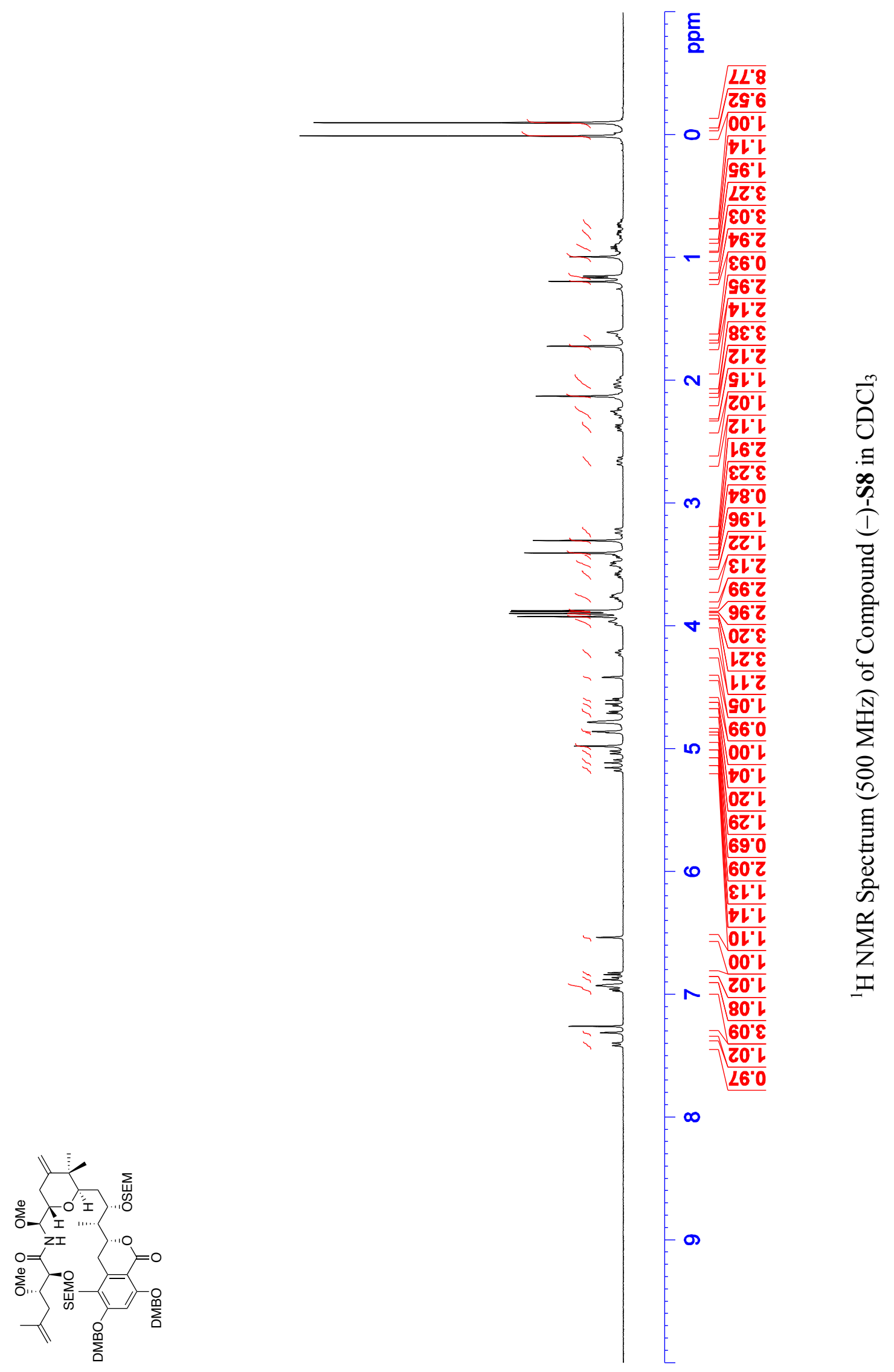




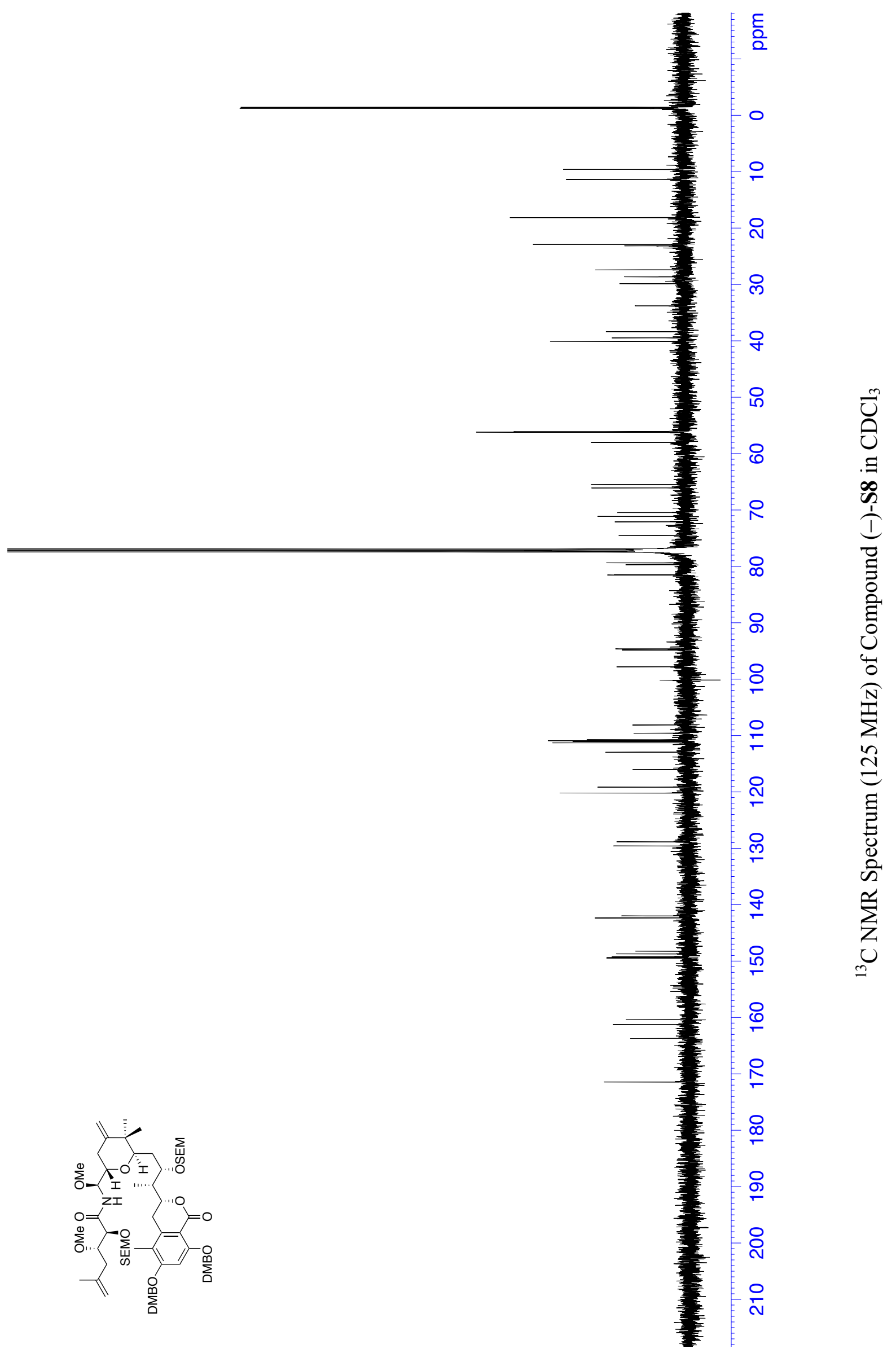




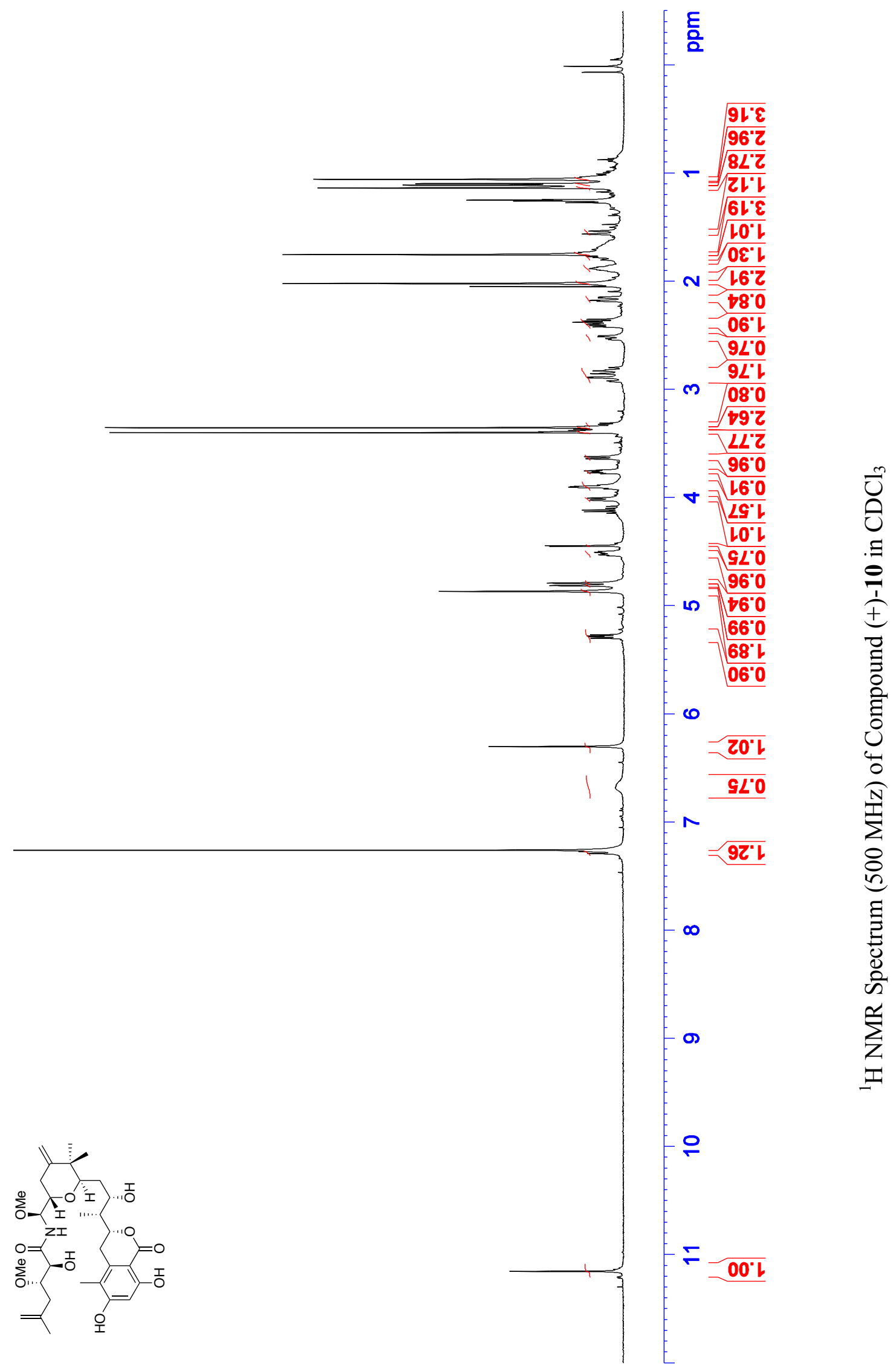




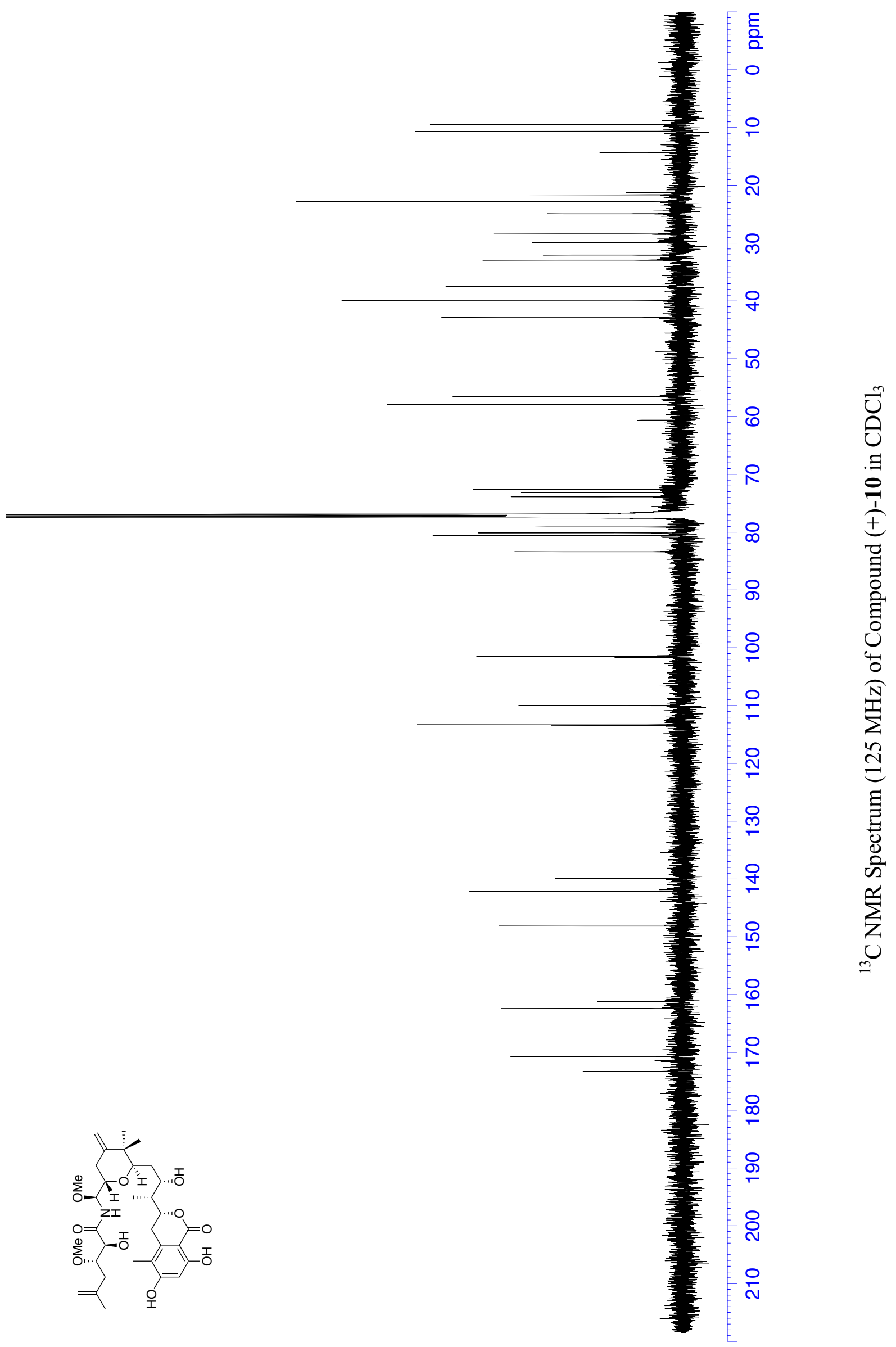




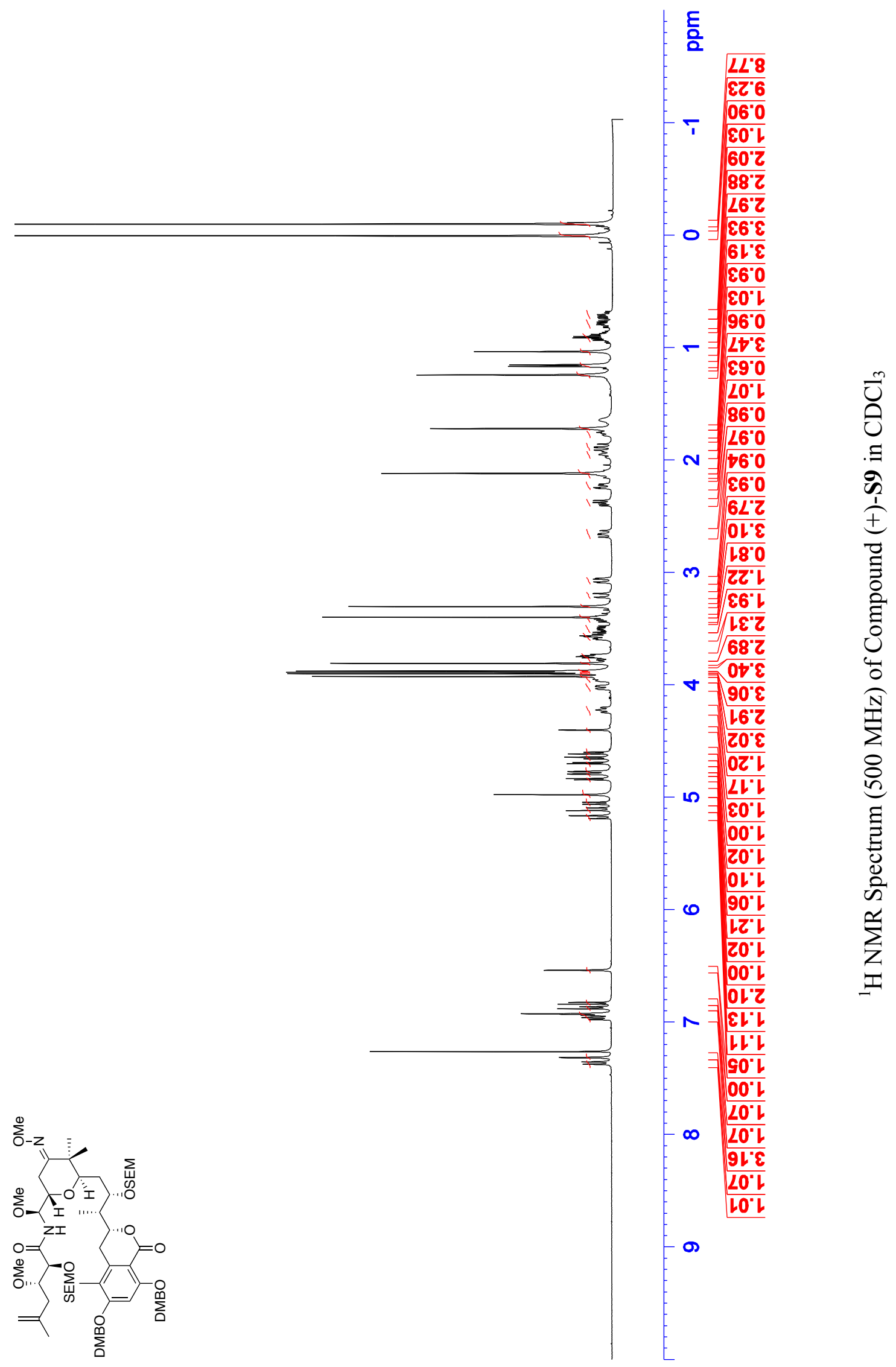




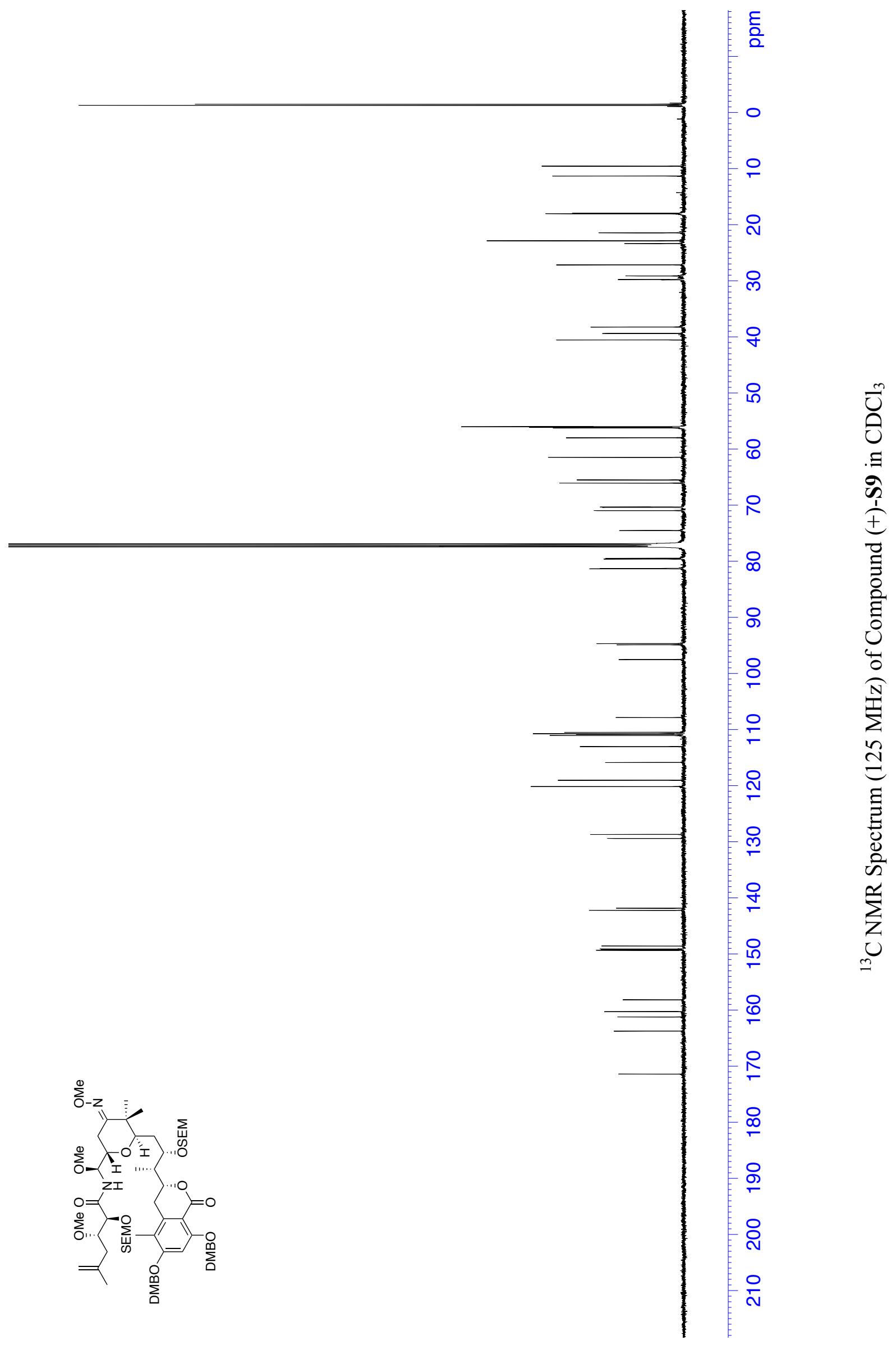




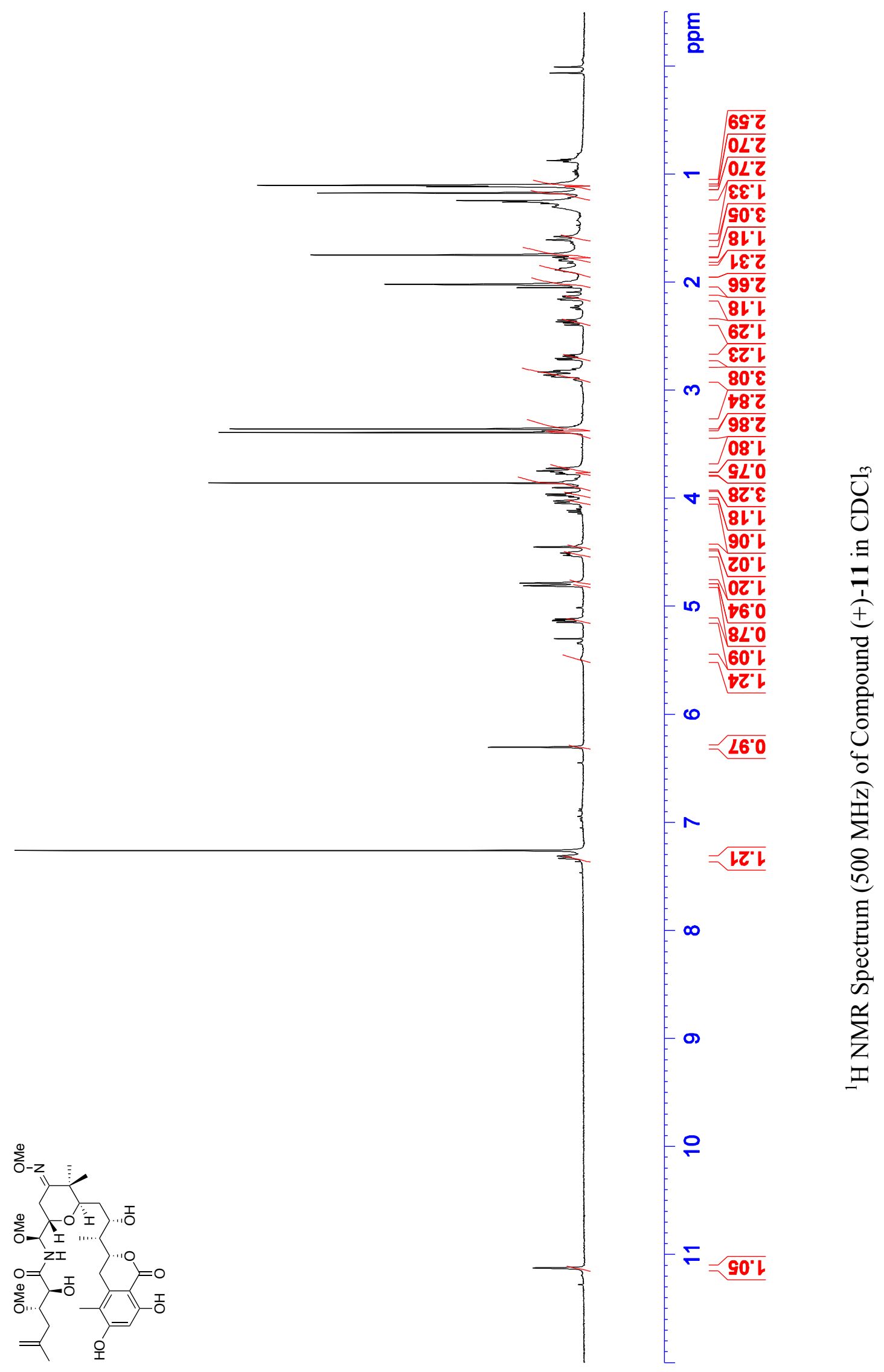




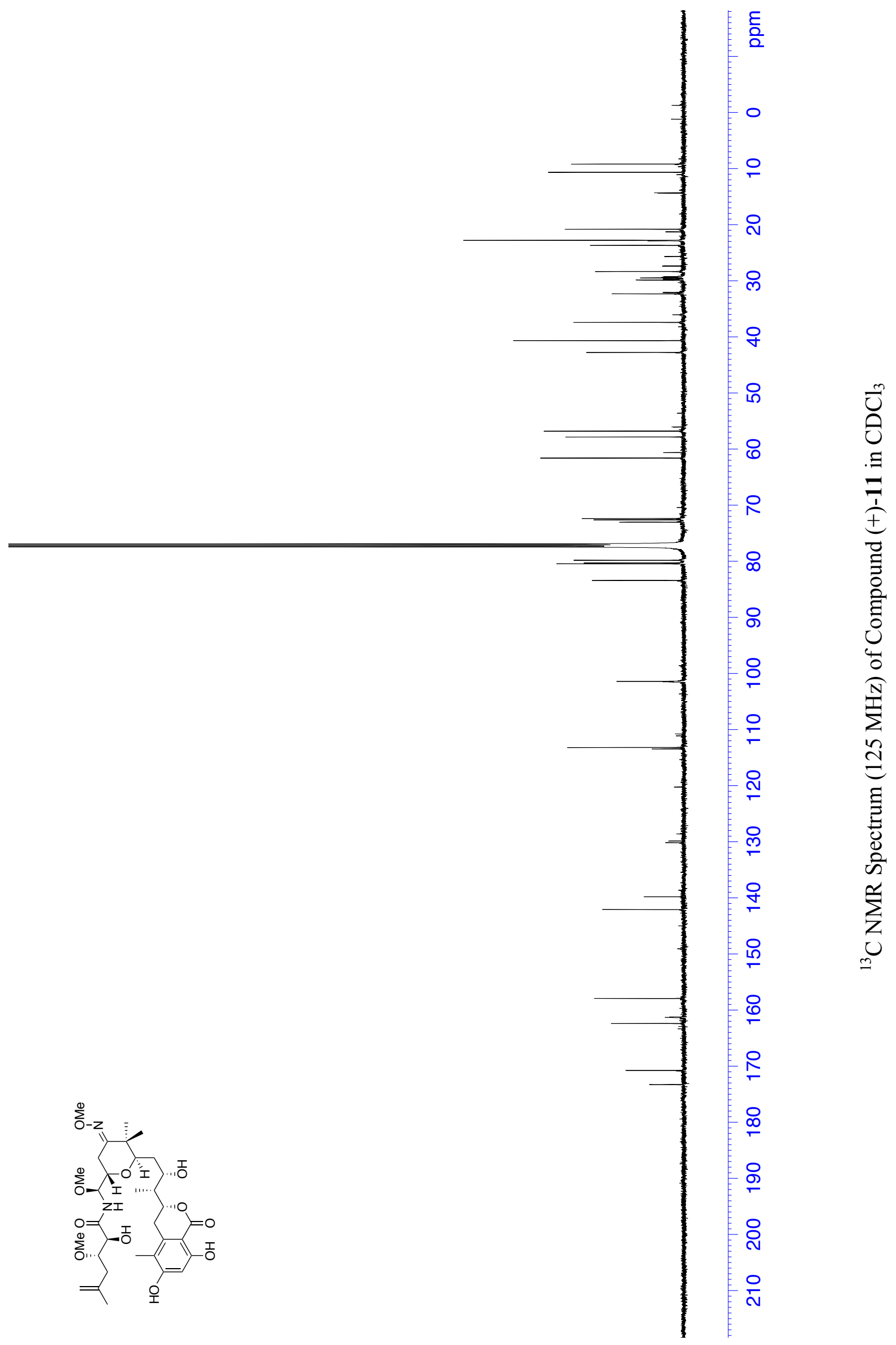

